Portland State University

PDXScholar

\title{
Identifying Factors that Influence Perceptions of Teacher Efficacy as a Means of Building Capacity for Restructuring Schools: a Case Study Approach
}

Deborah Sommer

Portland State University

Follow this and additional works at: https://pdxscholar.library.pdx.edu/open_access_etds

Part of the Educational Administration and Supervision Commons Let us know how access to this document benefits you.

\section{Recommended Citation}

Sommer, Deborah, "Identifying Factors that Influence Perceptions of Teacher Efficacy as a Means of Building Capacity for Restructuring Schools: a Case Study Approach" (1995). Dissertations and Theses. Paper 1140.

https://doi.org/10.15760/etd.1139

This Dissertation is brought to you for free and open access. It has been accepted for inclusion in Dissertations and Theses by an authorized administrator of PDXScholar. Please contact us if we can make this document more accessible: pdxscholar@pdx.edu. 


\section{IDENTIFYING FACTORS THAT INFLUENCE PERCEPTIONS OF TEACHER EFFICACY AS A MEANS OF BUILDING CAPACITY FOR RESTRUCTURING SCHOOLS: \\ A CASE STUDY APPROACH}

by

DEBORAH SOMMER

A dissertation submitted in partial fulfillment of the requirements for the degree of

DOCTOR OF EDUCATION in

EDUCATIONAL LEADERSHIP: ADMINISTRATION AND SUPERVISION

Portland State University 1995 
UMI Number: 9608484

UMI Microform 9608484

Copyright 1995, by UMI Company. All rights reserved.

This microform edition is protected against unauthorized copying under Pitle 17, United States Code.

\section{UMI}

300 North Zeeb Road

Ann Arbor, MI 48103 


\section{DISSERTATION APPROVAL}

The abstract and dissertation of Deborah Sommer for the Doctor of Education in Educational Leadership:

Administration and Supervision were presented June 8, 1995, and accepted by the dissertation committee and the doctoral program.

COMMITTEE APPROVALS:

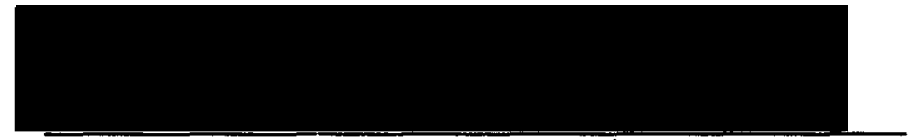

Thomas G. Chenoweth, Chaj.r

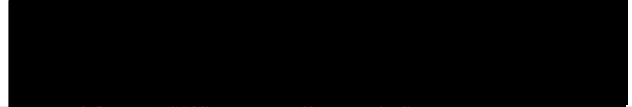

Robert B. Everhart

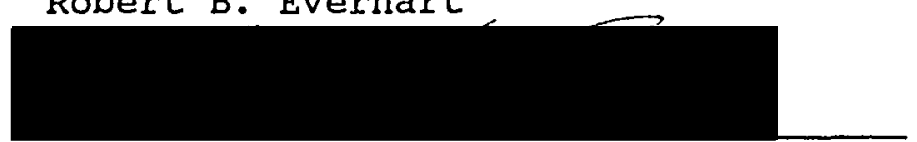

Mary K. Kinnick

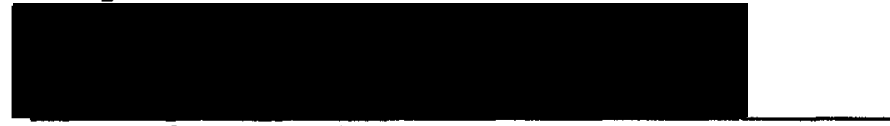

Kenneth D. Peterson

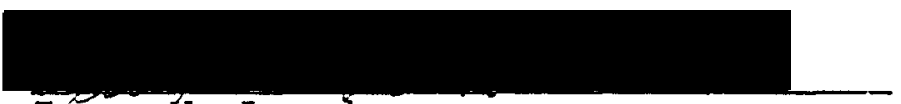

Jéry th. Lansdowne

Representative of the office of Graduate studies

DOCTORAL PROGRAM APPROVAL:

Robert B. Everhart, Dean

School of Education

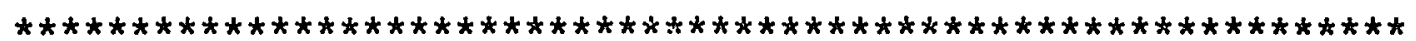

ACCEPTED FOR PORTLAND STATE UNIVERSITY BY THE LIBRARY

by

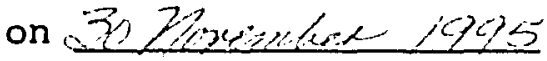




\begin{abstract}
An abstract of the dissertation of Deborah Sommer for the Doctor of Education in Educational Leadership: Administration and Supervision presented June 8, 1995.

Title: Identifying Factors that Influence Perceptions of Teacher Efficacy as a Means of Building Capacity for Restructuring Schools: A Case Study Approach

Recent efforts to restructure schools through increased teacher involvement are likely to fail without a corresponding redesign of the underlying organizational and political structure of schools. Because the current structure of most schools actually prohibits the collaboration necessary to effect change and promotes professional isolation instead, staff members faced with the tasks of restructuring experience frustration more often than success. The changes that do occur are often superficial and cosmetic while the basic hierarchy and mechanisms of control remain intact.

Allowing teachers to redesign their schools, specifically to develop new models that promote interdependence and the sharing of professional expertise, provides an opportunity to explore the reasons teachers
\end{abstract}


might choose to forego the relatively safe world of the self-contained classroom to participate in the often stressful and time-consuming development and implementation of new approaches to teaching and learning. Exploring those factors which motivate teachers to attempt innovation and determining the attributes and beliefs of those teachers about school change is the focus of this study.

The study investigates the concept of teacher efficacy, the teacher's belief that his/her actions affect student achievement or that he/she has the "ability to have a positive effect on student learning" (Ashton, 1984; Ashton \& Webb, 1986). The perceptions of efficacy among selected teachers in an urban elementary school in the Northwest involved in implementing an Accelerated School model are examined in an effort to determine which factors influence those feelings. Identifying the issues which confront teachers engaged in innovation and the conditions they feel contribute to their success or failure is also an outcome. Increased efficacy, the perceived ability to "make a difference," is critical to classroom effectiveness and efforts to restructure schools.

Data were obtained during the 1993-1994 school year by means of an efficacy scale based on the model developed by Gibson and Dembo (1984), structured interviews with selected teachers, an open-ended questionnaire, and 
observations during a sharing session with teachers in a nearby district considering a similar innovation. 
DEDICATION

"Whatever contributes to understanding, also contributes to reconstruction."

$$
\text { (Waller, 1967) }
$$

"Teachers tend to turn inward, relying on their own experience in the classroom. If they persist and become experienced teachers, their reward is to be left even more alone."

$$
\text { (Bird \& Little, 1986) }
$$

"To the teachers, not only those who are the subject of this study, but to all teachers everywhere engaged in such noble work. Without them, where would any of us be?"

(Sommer, 1995) 


\section{ACKNOWLEDGEMENTS}

I am grateful to a number of individuals whose support and encouragement to both pursue and complete the doctorate were immeasurable. Without them, I could not have been successful.

Foremost, I wish to thank my husband, Andy Sommer, and my children, Patrick and Lucas Sommer, for their understanding and patience over almost a decade. The children cannot remember a time in their lives when I was not going to school.

Secondly, I extend my appreciation to various friends and colleagues for their generosity in terms of time, advice and insight. I am particularly grateful to Dr. Tom Chenoweth for chairing my committee and encouraging me and to Dr. Marcia Haack for helping me with the intricacies of research design. 
TABLE OF CONTENTS

PAGE

ACKNOWLEDGEMENTS. . . . . . . . . . . . . . . . ii

IIST OF TABLES. . . . . . . . . . . . . . . . . . ix

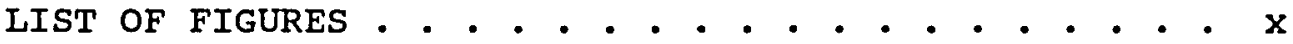

CHAPTER

I RATIONALE FOR THE STUDY. . . . . . . . . 1

Introduction . . . . . . . . . . 1

Purpose of the study . . . . . . . 8

Methodology. . . . . . . . . 11

Definition of Terms. . . . . . . . 14

Summary. . . . . . . . . . 16

II REVIEW OF THE LITERATURE: . . . . . . . . 19

Introduction . . . . . . . . . . 19

The School as Workplace. . . . . . 20

School Restructuring Through Site-Based Decision Making. . . . . . . . . 27

Increased Collaboration: A New School Organization . . . . . . . . . 38

Shared Leadership: Implications for Individuals and organizations. . . . 44

Basic Tenets of the Accelerated School Model........... 50

The Process of Becoming an Accelerated School . . . . . . . . . . 55 
Varying Perspectives on Efficacy as

a Construct. ........... 61

Teacher Efficacy . . . . . . . 66

Teacher Efficacy as an Important

Variable in School Reform. . . . . 75

Summary. . . . . . . . . . . . 86

III METHODOLOGY . . . . . . . . . . . 89

Introduction . . . . . . . . . 89

Research Proposal. . . . . . . 90

Research Questions . . . . . . . 92

Research Design. . . . . . . . 96

Data collection Procedures . . . . . 98

Data Analysis Strategies . . . . . 102

Summary. . . . . . . . . . . 107

IV PRESENTATION AND ANALYSIS OF DATA:

TEACHER PROFILES . . . . . . . . . . 109

Introduction ........... 109

Bridgeport Teachers: A Staff in

Transition . . . . . . . . . 112

Theresa: Bridgeport is a "Goldmine". . . 116

Conditions of Constraint/Support Perceptions of Efficacy

View of the Accelerated school Model

A Characteristic Quote

Maria: Learning to Say "No:. . . . . 120

Conditions of Constraint/Support

Perceptions of Efficacy

View of the Accelerated school Model

A Characteristic Quote 
Sarah: In Touch with Basic Values. . . 124

Conditions of Constraint/support

Perceptions of Efficacy

View of the Accelerated School Model

A Characteristic Quote

Linda: Accelerated School as

Pandora's Box. . . . . . . . . 128

Conditions of constraint/support

Perceptions of Efficacy

View of the Accelerated School Model

A Characteristic Quote

Anne: Still Trying to Get Somewhere. . . 132

Conditions of Constraint/support

Perceptions of Efficacy

View of the Accelerated School Mndel

A Characteristic Quote

Gail: Less is More . . . . . . . 137

Conditions of Constraint/support

Perceptions of Efficacy

View of the Accelerated School Model

A Characteristic Quote

Greer: Together You Can Make a

Difference... . . . . . . . . 141

Conditions of Constraint/support

Perceptions of Efficacy

View of the Accelerated School Model

A Characteristic Quote

Roger: On the Lookout for Change . . . 145

Conditions of Constraint/Support

Perceptions of Efficacy

View of the Accelerated School Model

A Characteristic Quote 
Evelyn: Bridgeport as Sanctuary. . . . 149

Conditions of Constraint/Support

Perceptions of Efficacy

View of the Accelerated School Model

A Characteristic Quote

Summary. . . . . . . . . . . 153

V PRESENTATION AND ANALYSIS OF DATA:

TEACHERS AS AGENTS OF CHANGE. . . . . . 155

Introduction . . . . . . . . . 155

Key Findings Related to Research

Question \#1. . . . . . . . . . . . 156

External Mandates Inhibit Professionalism

Documentation for Failure Promotes Compliance Rather than Growth

Teachers Have No Real Professional Status/Role

Summary

Key Findings Related to Research

Question \#2. . . . . . . . . . . 163

The Accelerated School Model is a Means to an End

Training in Group Process Skills is Critical

Building on Strengths/Unity of Purpose are Effective Strategies

Collaboration is the key to Success

Summary

Key Findings Related to Research

Question \#3............. 168

Teachers are No Longer Focused on Their classroom Alone

The Accelerated School Model Takes

a Great Deal of Time

The Model Itself Can Become Inflexible

Summary 
Key Findings Related to Research

Question \#4. . . . . . . . . . . . 175

General Observations

Gender Awareness High Among Bridgeport Teachers Regardless

of EIficacy Group

Bridgeport Teachers Show

Negative Correlation Between

Years of Experience and

Perceptions of Efficacy

Four Response Patterns Categorize Bridgeport

Teachers

Efficacy is a Highly Individualistic Trait

Little Consensus Exists Among Bridgeport Teachers in Terms of Responses to Questions on Efficacy Scale

Summary

Key Findings Related to Research Question \#5. . . . . . . . . . . 191

Efficacy is Enhanced by Organizational Norms that Support Change by Building community

Efficacy is Enhanced by the Accelerated School Model Itself

Efficacy is Enhanced by a Supportive Principal

Efficacy is Enhanced by Changing the Traditional Role of the Teacher

Efficacy is Enhanced by Various

Factors that are Highly

Individualistic and Situational Summary

Summary. . . . . . . . . . . 204

Introduction ........... . 206

Key Assumptions. . . . . . . . . 207

Key Findings . . . . . . . . . . 208

Limitations of the study . . . . . . . 211 
Recommendations for Bridgeport School. . 216

Recommendations for School

Administrators . . . . . . . . 220

Recommendations for Teachers . . . . 228

Implications for Further Research. . . 234

REFERENCES. . . . . . . . . . . . . . . . . 239

APPENDIX

A INTERVIEW PROTOCOL USED IN BRIDGEPORT INTERVIEWS WINTER 1993 . . . . . . . 257

B EFFICACY SURVEY CONSENT FORM . . . . . 261

C DEMOGRAPHIC SURVEY/EFFICACY SCALE BASED

ON INSTRUMENT DEVELOPED BY GIBSON AND

DEMBO (1984) . . . . . . . . . 263

D FOCUS GROUP INTERVIEW QUESTIONS. . . . 267

E OPEN-ENDED EFFICACY QUESTIONNAIRE. . • . 269

F LETTER TO PRINCIPAL OF BRIDGEPORT

ELEMENTARY SETTING UP PANEL

DISCUSSION ON ACCELERATED SCHOOLS

WITH NEIGHBORING DISTRICT. . . . . 273 


\section{LIST OF TABLES}

TABLE

1. Student Enrollment/Special Programs Data: Bridgeport Elementary School . . . . . 111

2. Teacher Profile: Bridgeport Elementary School............... 115

3. Comparison of Efficacy Group and Total Years of Teaching Experience... . . 180

4. Comparison of Efficacy Group and Number of Years Assigned to Current School. . . 181

5. High/Low Efficacy Teachers Grouped by Response Categories. . . . . . . . 182

6. Group Response to Modified Efficacy Scale. . . . . . . . . . 186

7. Efficacy Rank and Response to Rand Efficacy Questions . . . . . . . . 187

8. "School Rules/Practices Hinder My Ability to Teach". . . . . . . . . . . 189 


\section{LIST OF FIGURES}

1. Relationship of Efficacy to other

Factors. . . . . . . . . . . 176 


\section{CHAPTER I}

RATICNALE FOR THE STUDY

Introduction

Almost any recent professional journal or popular publication raises questions and poses solutions for the many problems confronting America's public schools. Educational reformers are demanding significant changes in the way schools are organized, in the roles of major "stakeholders," and in instructional practices. Above all, critics want increased flexibility and responsiveness from a public school system often viewed as rigid and outof-date. It is obvious that the "one size fits all" approach to education no longer matches the market nor the clientele.

This demand for restructuring education, paralleling similar changes in American business and industry, gathered momentum following the publication by the National Commission on Excellence in Education (1983) of $A$ Nation at Risk. Shortly thereafter, Boyer's (1983) High School, Goodlad's (1984) A Place Called School, and Sizer's (1984) Horace's Compromise each made recommendations for change that emphasized the individual school as the basis for school reform. Because most of 
the "Effective Schools" literature points to the individual school unit as the place where positive change occurs, much of the school improvement effort over the past decade has been based on the premise that principals and teachers must have the authority and capability to structure conditions for learning within their school in order to enhance student success. The work of Brookover and Lezotte (1979), Edmonds (1979), Purkey and Smith (1982, 1983), and Weber (1971) indicated that effective schools share certain common elements: (a) high staff expectations for student achievement, (b) clear leadership from the principal, (c) well-defined goals for the school, (d) high morale and a considerable degree of control by the staff over professional development activities, and (e) a positive school climate.

Although many schools increased their effectiveness through such school improvement efforts, the pace and scope of change in public education has been considered insufficient by many of its critics. Increasing global interdependence and concern over America's ability to compete internationally have recently fueled the ongoing debate over the future of public schooling in this country. Current efforts to reform the public schools call for an even more fundamental restructuring of schools than those that have focused simply on becoming more effective. 
Not only do business and industry want "worker skills" to increase, and curriculum to change as a result, but they decry the too-slow process of adapting to changing economic conditions and the perceived resistance of educators to meeting the demands of the 21 st century. To emphasize the point, both industry and the individual taxpayer in many states have refused to support public education as now defined. The combination of ongoing criticism and the "taxpayer revolt" is forcing another look at school reform. In addition, the persistence of efforts to institute voucher options for private education and to increase opportunities for school choice has forced school leaders to move closer to a market economy and to recognize that their clientele is willing to take its children elsewhere unless significant change occurs. Whatever innovations have occurred up to now, they have clearly been viewed as insuficient. Sarason (1990) analyzed what he called the predictable failure of past school reform efforts and cited two primary factors. First, he noted that the different components of educational reform have neither been conceived nor addressed as a whole or even as interrelated parts of a complex system. For example, significant change in curriculum, assessment or any other domain is unlikely to be successful unless serious attention is also paid to teacher development and the 
principles of professional judgment and discretion inherent to it. Teacher development and enhanced professionalism must also be undertaken in conjunction with new directions in curriculum, assessment, leadership and school organization. The second reason Sarason cited for the failure of school reform is that a major change is unlikely to be successful unless it addresses the issue of school power. "Schools.. . remain intractable to desired reform as long as we avoid confronting their existing power relationships" (p. 5). These include relationships between administrators and teachers, between teachers and parents, and between teachers and students. our new vision of schooling must be based on an understanding of human motivation and commitment and on a sociopolitical understanding of schools as places not only devoted to teaching and learning but also defined through relationships of power and control. Restructuring means redefining the dynamics of schooling in fundamental ways. Schlechty (1990), another advocate of fundamental change in public schools, maintained that the purposes of education in the 21st century should be driven by corporate concerns. The challenge of becoming a global information society must result in children who are construed as "knowledge workers" and schools defined as being in the business of "knowledge work."

It is reasonable to expect that, as the American economy becomes more information-based, and as 
the mode of labor shifts from manual work to knowledge work, concern with the continuous growth and learning of citizens and employees will increase. Moreover, the conditions of work will require one to learn to function well in groups, exercise considerable self discipline, exhibit loyalty while maintaining critical faculties, respect the rights of others and in turn expect to be respected. (p. 39)

Schools should be in the business of creating a culture that promotes "knowledge work," not only for students but for those responsible for teaching them.

It is an examination of the conditions of work, particularly those conditions over which teachers must perceive they have control, that is the subject of this study. It is a case study of teachers involved in an innovation, the implementation of the Accelerated School model developed by Levin (1989a) of Stanford University, and the conditions teachers believe either impede or enhance their ability to bring about instructional change. The school selected for the study is a Northwest-area elementary school in the process of becoming an Accelerated School.

Participants involved in implementation of this particular innovation were selected, as opposed to some other new program or innovation, because the Accelerated school model is predicated on the belief that the key to student change is through the development of teacher knowledge and capacity for inquiry into school problems (Chenoweth, 1992). Teachers are key players in the change 
effort. Also central to the Accelerated School approach is the belief that it is the school itself that is at risk and must change in order to meet the needs of the learner -not the other way around. The school as institution is viewed as deficient, not the child. The model is based on the work of Levin (1988, 1989a, 1989b, 1989c, 1990, 1991) whose perspective as an economist and social activist rather than as an educator was also an important factor in the decision to study teachers involved in Accelerated Schools: his interest in worker participation in decision-making and its effects on organizational productivity and individual self-esteem results in an inclusive model of schooling that places great emphasis on parent participation and community involvement. Above all, the Accelerated School asks teachers, parents and administration to engage in a thoughtful method of inquiry that identifies school problems but ultimately seeks to build on existing strengths. Each of these attributes of the Accelerated School model also characterizes effective school reform.

The study is motivated by the review of the literature on restructuring, on the Accelerated School model (Levin, 1989a) and on the concept of teacher efficacy, much of which supports the contention (Cuban, 1988, 1990; Sarason, 1990) that our prior efforts at reform have been more cosmetic than fundamental. This 
research is also prompted by a sense of personal urgency: as an educator for the past 24 years, I am greatly concerned about the future of public education in this country. This current reform effort must succeed if public education is to remain a viable option for the vast majority of American children. In addition, a number of professional experiences culminated in a focus school reform and the role played by efficacy in successful change efforts. These included: (a) job-related responsibilities for opening magnet schools to provide choice within the public schools, a task that prompted interest in the factors that motivated some teachers to leave the comprehensive high school; (b) the perceived success of schools implementing the Accelerated School model, particularly as evidenced by the many positive comments made by teachers during the interviews conducted by Chenoweth and observed by this author in winter 1993; and (c) the opportunity to receive training at stanford in the Accelerated School process, which convinced the author that something of significance was indeed taking place for those involved in this restructuring model.

Such experiences led me to the belief that as an institution fundamental to the basic tenets of this country, particularly the democratic ideal, the demise of public education can only lead to the decline of what the society purports to value. To avoid such a fate, 
educators must look at truly significant changes in the way they currently operate public schools. They cannot afford to blame others or to waste time criticizing what they perceive as the devaluing of education by a society that seems to advocate little other than wanting more for less. The essential problem faced by America is not a lack of values but rather a discrepancy of values between those inside the educational system and those without. Such dissonance cannot be reconciled without an honest examination of our past efforts at reform and those now proposed. And no effort at reform, no matter how wellintentioned, can succeed unless the structural and cultural conditions to support it are firmly in place.

Purpose of the study

The primary purpose of the study is to examine teacher perceptions of professional and personal efficacy and to profile selected elementary teachers involved in innovative practice, in this instance creating an "Accelerated School." Teachers, whose professional and personal efficacy was measured by a 20-item variation of a 30-item Likert scale developed by Gibson and Dembo (1984), were asked to participate in a structured focus group interview to determine the working conditions and other school-related factors that they believed either enhanced or impeded their perceived ability to "make a difference" 
in the classroom. These same teachers also responded to an open-ended questionnaire and a panel discussion designed to solicit their perspective on the supporting conditions teachers perceive to be necessary to bring about school restructuring and classroom change. A secondary purpose is to gather information related to the implementation of an Accelerated School model to contribute to the literature and research on school reform.

The study provides a full description of the Accelerated School model developed by Levin (1989a) and the characteristics of both participating staff members as well as the elementary school involved in the innovation under review. Descriptive data about the stages of implementation of the Accelerated school model, the staff development/training experience of all participants, and a detailed account of the progress to date of the participating school are included. Within this context, the following research questions have been posed:

1. What are the perceptions of Bridgeport teachers of traditional school organization and the need for school restructuring?

2. What are the components of the Accelerated School model that have contributed to these teachers' perceptions of their ability to make a difference in their classrooms? 
3. What do the teachers involved with the Accelerated School model believe about the scope and pace of change after two years of implementing a major innovation?

4. What differences exist in perceptions of efficacy among teachers involved in implementing an Accelerated School?

5. Which factors influence feelings of teacher efficacy among elementary teachers involved in implementing an Accelerated School?

Essentially these research questions seek to gather information about teachers involved in innovation and about their perceptions of the current conditions of schooling that either enhance or impede their restructuring efforts. Such information could be invaluable to those faced with the need to redefine our public schools. Innovation is hard work, but if teachers successfully involved in such an enterprise can identify the factors that contribute to their perceived ability to "make a difference," then those factors can be emphasized in other schools and classrooms.

Based on the belief that teachers would be more receptive to changes in the current system of schooling if they felt more effective, a second benefit would be to encourage other teachers to abandon more conventional approaches and to demonstrate willingness to make changes 
in current practice despite the increased time and energy required. An understanding of teacher attitudes and feelings about the necessary support for change is critical as well as an awareness of changing relationships with colleagues, principals and with the "central office" that result from restructuring efforts. If school boards and administrators are serious about supporting a reform agenda, then the essential resources and the perceived obstacles to change must be identified.

\section{Methodology}

A case study method was determined to be the research design most appropriate to the primary purpose of this study: to generate teachers' perceptions of professional/ personal efficacy and attitudes about the conditions which either enhance or impede their ability to "make a difference" with children in the classroom. According to Yin (1984), the case study method is preferred "in examining contemporary events . . when the relevant behaviors cannot be manipulated" (p. 19). Furthermore, Yin defined the case study as:

an empirical inquiry that investigates a contemporary phenomenon within its real-life context in which the boundaries between phenomenon and context are not clearly evident and multiple sources of evidence are used. (p. 23)

The research questions as well as the protocols developed for the structured interviews and questionnaire are based 
on the assumptions that teachers, as reflective practitioners, are the primary source of data about the process of school improvement and restructuring. Individual teachers in an Accelerated School are the primary unit of analysis in this case study approach. The case study becomes: particularly useful when one needs to understand some particular problem or situation in great depth, and where one can identify cases rich in information--rich in the sense that a great deal can be learned from a few exemplars of the phenomenon in question. (Patton, 1987, p. 19)

Qualitative methods emphasize depth and detail, and the case study is no exception. An in-depth analysis of the factors that contribute to a sense of professional/ personal efficacy should also contribute to an understanding of the factors that enhance school restructuring efforts. The converse is also assumed to hold true: factors that negatively affect a teacher's belief in his or her abilities to help students succeed are thought to be related to those conditions of schooling that can render this reform effort as ineffective as those that preceded it.

A first step in the research effort was when I observed interviews of teachers involved in the second year of implementation of an Accelerated school conducted in winter 1993 by another researcher in the area of school restructuring, Tom Chenoweth. The data were examined for comments and insights provided by any of the participants 
relative to teacher efficacy and the conditions perceived to foster or impede their efforts at school reform.

Teacher comments seemed to indicate that the construct of efficacy was worthy of exploration, and a second research step was to ask these same teachers, all working in an urban elementary school in the Northwest $(\underline{N}=14)$, to complete a demographic survey and a 20-item variation of a 30-item Likert efficacy scale developed by Gibson and Dembo (1984). Their responses, completed in December 1993 through January 1994, helped the researcher develop teacher profiles and to identify teacher characteristics associated with differing perceptions of efficacy.

Finally, nine $(\underline{\mathbb{N}}=9)$ of these teachers participated in follow-up activities during second semester of the 1993-1994 school year. Because these teachers volunteered to share their insights concerning the Accelerated school model wi.th the author and their perceptions of the factors that either impeded or contributed to their belief in their ability to "make a difference," they were considered "critical cases," teachers likely to have strong opinions about the conditions of schooling that contributed to their sense of success and/or failure. A second assumption was that their perceptions could provide insight to others either considering a major innovation or school reform effort. "While studying one or a few 
critical cases does not technically permit broad generalizations to all possible cases, logical generalizations can often be made" (Patton, 1987, p. 55). These nine teachers participated in focus group interviews and then were asked to individually complete an open-ended questionnaire. Questions for the interview and for the written questionnaire were based on the middle school protocol developed by Ashton and Webb (1986) as well as generated through a review of the literature in the areas of teacher efficacy, school restructuring and site-based decision making. Finally, these "critical case" teachers were asked to share their insights about school restructuring and the Accelerated School model with colleagues in a neighboring district considering whether to join a coalition of Accelerated Schools formed under the direction of Portland state University.

Data collected during the chenoweth interviews, the demographic survey, the Gibson and Dembo (1984) efficacy scale, the focus group interviews and questionnaires, and the observations during the sharing session with other teachers were used to answer each of the five research questions posed by the study.

\section{Definition of Terms}

The following terms appear throughout this study: 
- demographic characteristics--all teachers assigned to an Accelerated School $(\underline{N}=14)$ were asked to provide basic information such as sex, age, number of years teaching, years at current school, number/type of certificates and current level of schooling.

- Accelerated School--a school that has formally undergone the training and made the commitment to adopt the stanford model developed by Levin (1989a) in which school organization, decision making, curriculum and instruction are redefined to build on student strengths, better meet the needs of poor and minority students, and accelerate the learning of underachieving students.

- professional teacher efficacy--a set of expectations related to the impact of teaching on student performance despite variables such as student ability and environment (Ashton \& Webb, 1986). Example: "These kids can't learn!" vs. "All kids can succeed."

- personal teaching efficacy--a teacher's perception of his/her own teaching capabilities and the belief that one can employ these capabilities to bring about student learning. Example: "I can't motivate these kids." vs. "That didn't work. I wonder if $x$ will?"

- efficacy score--a cumulative score reflecting positive/negative feelings about one's job and current working conditions and about one's ability to "make a 
difference" as measured by a variation of a teacher

efficacy scale developed by Gibson and Dembo (1984).

- restructuring--a significant change in the organization of a school including such deliberate practices as redefining the governance structure, arranging time/space in innovative ways, employing alternative methods of assessing student learning, flexibly grouping students, and developing new instructional strategies and classroom routines that break down the barriers to student learning and enhance teacher collaboration.

\section{Summary}

This case study examines the concept of teacher efficacy as it relates to school restructuring efforts in the elementary school. As such, it attempts to identify those factors that contribute either positively or negatively to successful innovation. Recreating those conditions that enhance innovation and de-emphasizing or eliminating those that make change difficult are essential if this current restructuring effort is to avoid the "predictable failure" (Sarason, 1990) of previous reforms. Hargreaves (1991) noted that:

There is nothing inevitably good or inherently bad about restructuring. Much depends on who controls it, who is involved in $i t$, and the purposes to which it is put. At the heart is a fundamental choice between restructuring as bureaucratic control, where teachers are 
controlled and regulated to implement the mandates of others, and restructuring as professional empowerment, where teachers are supported, encouraged and provided with newlystructured opportunities to make improvement of their own, in partnership with parents, principals and students. (p. 7)

How to structure such opportunities, based on information provided by teachers involved in an innovation and well aware of the conditions of schooling that make that innovation more or less attainable, is the knowledge to be gained through this research effort.

This research is presented in the subsequent chapters as follows: First a context for the study is presented in Chapter II by means of a review of the literature on school as workplace, site-based decision making, the Accelerated school model and efficacy. Chapter III outlines the methodology for the study including the research questions, research design, and data collection and analysis procedures. Chapter IV presents the data collected in terms of nine individual teacher profiles and analyzes the results of the survey, the focus group interviews and the questionnaire for each member of the group. Chapter $\mathrm{V}$ analyzes the data collected in terms of the nine Bridgeport teachers as a total group and draws various generalizations about their attitudes and perceptions. Finally, chapter VI recommends areas for further study as well as discusses implications of the research for those in positions of formal leadership who 
are engaged in school reform. Hopefully, the study will benefit those attempting innovation in America's classrooms and contribute to the ever-widening knowledge base related to school change. 
CHAPTER II

REVIEW OF THE LITERATURE

Introduction

A context for the study is presented in Chapter II by reviewing relevant literature in the areas of school as workplace, site-based decision making, the Accelerated School model and efficacy. Central to the literature review is the recurring emphasis on "restructuring," a term that conjures up images of attempting to solve diverse problems by superimposing a new organizational solution to the dilemmas facing today's schools. This insistent demand to restructure schools has resulted in a variety of new approaches and innovations, spawned a debate about national goals and standards, and produced a myriad of state legislative mandates impacting local districts around the country. Before the current model of public schooling in America is totally condemned and abandoned, however, it is worth noting its fundamental organizational values: it was, after all, a model created in response to community expectations, expectations that have changed more significantly in the last decades than the institution itself. 
The School as Workplace

Whether one views public schools as institutions that trace their organizational roots to a bureaucratic division of labor reflecting the beliefs of the industrial age that created them or analyzes the current organization using a structural perspective such as that defined by Bolman and Deal (1984), it is clear that educators have consistently attempted to use rational approaches to meet a complex set of societal expectations. Bolman and Deal maintained that "although the causes of problems are often seen as personal, the solutions are often rational" ( $p$. 7).

Rational systems theorists emphasize organizational goals, roles and technology. They look for ways to develop organizational structures that best fit organizational purpose and the demands of the environment. (p. 2)

Such rational thinking underlies the current organization of the public school, but, most important, shapes the behavior of both the students and teachers who work within it.

Sergiovanni (1990) believed that schools have not changed significantly since the turn of the century and that the focus continues to be on control and uniformity rather than a commitment to learning. Assuming Sergiovanni's assertions are accurate, at least to the extent they characterize many of the nation's schools, the focus on control can be partially explained as a response 
to unwieldy school size, a major dilemma faced by today's schools as well as by their predecessors. As the country's population shifted to cities, public schools grew steadily larger from the turn of the century until the 1950s. Similarly, efforts in the 1950s and 1960s to consolidate smaller schools into larger ones to achieve some economies of scale also created problems. The presence of 2,000 students in a high school, for example, necessitates an organizational system that attempts to effectively control large numbers of students as well as teachers in a cost-effective and efficient manner. Sergiovanni's (1990) charge of "uniformity" is more easily understood if one realizes that in addition to size, the expectation that schools will perform a "sorting function" for society in terms of future employment while simultaneously assimilating large numbers of immigrant children has been a compounding factor in the development of the American public school. Organizational decisions such as class schedules, graduation requirements, and grade levels are all designed to increase control and to promote standardization rather than student learning. credits earned toward graduation may have little apparent connection to learning but are intended to reflect a common experience based on a required length of instructional time. McNeil (1986) documented the control orientation in the contemporary high school and Eisner 
(1988) stated that the general similarity of curriculum and schedule, physical uniformity of classrooms, structured fragmentation of the school day, teacher isolation, and hierarchical organizational pattern have shaped the nature of schooling since the mid-19th century. Tye (1987) referred to these ongoing characteristics of schools as the "deep structure of schooling" and suggested that they present formidable barriers to school reform. In order to overcome these barriers, both policy and practice must change.

All bureaucratic structures, whether in schools or elsewhere, tend to have certain negative effects on employee relationships, asserted Alfonso and Goldsberry (1982). In schools, the effects are compounded by the physical isolation of teachers as they work. The result is a dearth of professional interaction among teachers, which not only deprives them of a valuable tool for selfimprovement, but also denies the school organization a rich pool of human talent for organizational improvement efforts.

While studying teachers in Massachusetts and Florida, Lortie (1975) found that teachers placed a very high value on their relationships with their students and assigned very little value to their relationships with other teachers or with administrators. In their study of instructional leadership in eight secondary schools, Bird 
and Little (1986) found that teachers operated primarily in isolation both from one another and from administrators and tended to be apprehensive of innovations in curriculum or instructional techniques. Sarason (1982) drew on his observations of beginning teachers to conclude that they are unprepared for both the loneliness of the classroom and the lack of relationships in which questions and problems can be openly discussed without fear of evaluation. And from his study of schools, Goodlad (1984) concluded that the classroom "cells" in which teachers spend much of their time are, in fact, symbolic of their relative isolation from one another and from sources of ideas beyond their own. Finally, teachers were found to use little research-based technical knowledge, to receive their rewards from students rather than from the institution, and to view their interactions with administrators, parents and other teachers in a negative light to the extent that most teachers expressed the desire to be left to themselves (Feiman-Nemser \& Floden, 1986).

Not only are teachers isolated, but they are also unable to anticipate a particularly varied career or more than minimal opportunities for professional development. Drucker (1988) made the analogy that teachers are treated as unskilled and semi-skilled production line workers and receive similar treatment as their counterparts in 
business and industry. Teachers have the same career path as automotive assembly line workers--essentially none. Teachers perform much the same job on day one as on the final day of employment, and like assembly line workers, are treated as interchangeable parts.

The traditional model of school improvement also tends to dichotomize experts and practitioners and suggests that knowledge comes from researchers, university faculty, state department officials or consultants and is handed down to practitioners. Educators in the schools are not valued as professionals who can reflect on ways in which they might best do their work, but as workers deficient in one or more skills in need of retraining. Schools are looked at as objects to be changed rather than as centers of change (Sirotnik \& Clark, 1988).

Another characteristic of the teaching profession is that in schools, as in many other organizations, policy decisions are typically made at the upper levels of management, thereby reducing throughout the organizational hierarchy the face-to-face relationships which appear to be necessary to elicit and sustain personal commitment (Guthrie \& Wynne, 1971). Palardy (1988) maintained that two basic assumptions underlie "tall" institutional structures with their long chain of command and small spans of control: The first assumption is that the most capable people in an institution are those who are at or 
near the top of the hierarchy. As a consequence, the institution expects them to provide most of the leadership and make most of the important decisions. The second assumption is that people at or near the bottom of the hierarchy are generally less capable and, in many cases, unreliable. Consequently, the institution expects little from them and, in fact, operates on the premise that they function best only when closely supervised. Applying this metaphor to schools, and certainly teachers would be likely to view a district as a "tall" institutional structure, one finds central office and school administrators making top-down decisions about instruction, curriculum, resources, and personnel. Teachers, not to mention the organization's clients--the students and parents--have little or no input. Teacher socialization, also influenced by the organizational structure of schools, is another phenomenon that makes change difficult. Lortie (1975) maintained that teachers are socialized by their years of experience as students in the classroom rather than through the transmission of expert knowledge by practitioners. Because few faculties share a substantial, cumulative body of knowledge and skill, and because schools are not organized either in terms of physical space or time in such a way as to promote the easy exchange of information among professionals, it falls to the individual teacher to 
"sink or swim." And, given the stress of the classroom, Lortie maintained that many beginning teachers fall back on the instructional strategies they know the best--those of their own classroom teachers observed during the 12-15 years the beginning teacher has spent as a student under the direction of someone else. Such a dynamic clearly supports the assertion that American public schools have changed little since their inception.

Researchers (Bird \& Little, 1986; Lortie, 1975) also pointed out that teachers typically emphasize the significance of their beginning experiences and discount their professional coursework in their own development as professionals. It is this individual learning by the trial and error of the classroom experience that is most formative in the early years of the novice teacher. This notion of the individual teacher struggling alone with a class full of young people can lead to the belief that to ask for help or to admit problems is a sign of failure. Lortie noted,

The individualism of teacher socialization also creates subjective problems for members of the occupation . . All people from time to time doubt their personal efficacy and the value of the services they offer but in fields where people perceive that their knowledge (and their ignorance) is shared, the individual burden is reduced. (p. 81$)$

The working conditions of teachers, their professional motivation and the socializing influences which shape their behavior are all important areas for 
research, for it is clear that teachers play the critical role in the reform of public education. Teachers are the key to school improvement; their efforts are indispensable to student success (Rosenholtz, 1989).

One way to improve the professional life of teachers is ostensibly to shift to site-based management and to assign them to key decision making roles. Such a strategy, designed to reduce staff isolation and to foster new, more collaborative behaviors among teachers, is a course of action now being adopted across the country based on the assumption that without involvement from the primary deliverers of education (i.e., the teaching professionals), no solution to any of the problems now facing the nation's schools will prove effective. Participation by all parties--administrators, teachers, parents, and students--in solving the problems of schools is viewed as both critical and immediate.

\section{School Restructuring Through Site-Based Decision Making}

Many school districts have recently embraced this notion of increased participation by major stakeholders, particularly site-based management or a related concept such as site-based decision making, participatory management, shared leadership, teacher empowerment, or decentralization. Site-based decision making appears to be an essential component of school restructuring efforts 
around the country (Fiske, 1991). Regardless of the term used, the general assumption is that broadening the power base in schools will expedite change--in instruction, in learning, in the image of both teachers and the schools they serve in the eyes of a critical public. The basic concept of site-based management as a governance model for schools arose from similar trends in business and must be viewed as an attempt to make change in the basic organization of schools (Peters \& Austin, 1985). Recent oregon legislation mandating school restructuring calls specifically for site councils in operation in every school in oregon by 1995. Although such a change in governance structure may lead to school improvement, such change may also prove to only be cosmetic and may, in some settings, actually delay improvements. Changing the governance structure of schools in itself does not ensure a change in instruction, in curriculum or assessment, or in the rigidity of a standardized approach to diverse learners that characterizes many of the nation's schools and school districts (Harrison, 1989; Lane \& Wallberg, 1989). Nor does site-based decision making necessarily result in a real shift in power (Duke, Showers, \& Imber, 1980). Often site-based decision making results in symbolic actions in response to political pressures rather than a true structural change. 
Participation in decision making, although sought by many, also requires adàitional commitments of time and energy on the part of teachers. Additional funds to support the necessary staff development and training, as well as release time for teachers to participate, are also necessary. Another caution is that increased participation does not ensure an increase in the quality of decisions, nor guarantee that decisions made focus on substantive issues. Finally, the opportunity to effect change does not address the need for teachers to have or to believe they have the skills necessary to bring about that change at any level--in student learning, in classrooms, or in schools (Fullan, 1982).

It has not been generally the case that a formalized sharing of power between teachers and administrators has occurred in the past, especially relative to such critical issues as allocation of resources, staffing, selection of materials, and development of curriculum (Boyer, 1983; Goodlad, 1984). To effect such a major change in both philosophy and practice, one might seek advice from the business community as often advocated by the public and the media. Drucker (1988) maintained that our society is entering a period of transition during which we will witness a shift from the command-control organization, the hierarchical organization of departments and divisions, to information-based organizations structured around 
"knowledge specialists." If true, and if the school as organization is still viewed as paralleling the industry model on which it is based, then the question becomes how to effectively shift from a "command-control" system to one which relies on the knowledge specialists within the organization itself--in this case, the teachers. Moving to true site-based management is a step in the direction of recognizing the expertise of "knowledge specialists" in our schools.

Typically, however, site-based management is simultaneously offered as a panacea both to ameliorate the lack of control/input teachers now have into the educational system and to solve the myriad number of problems besetting today's schools. The issue of school reform is broader, however, than teacher empowerment and so are the solutions to the problems that confront public education (Cuban, 1988, 1990). Certainly well-informed teachers should be involved in the key decisions regarding the instruction of children. The caution, however, is that site-based decision making is less an "answer" than it is more often a political issue currently being addressed in contract negotiations around the country or an economic necessity: shrinking resources and diminished central services force decentralization. The move to a de facto site-based approach is often driven by lost revenue rather than a commitment to shared leadership. Without a 
commitment to change and the skills necessary to reach decisions that will increase the likelihood of student success, site-based decision making will either fail or fall far short of its stated goals.

In addition, teachers, administrators and parents sharing the decision making authority or accepting mutual responsibility for those decisions is only one manifestation of site-based management. To truly embrace the concept calls for a change in the way the entire district or school operates (Lieberman, 1988b). The notion of site-based management deals not only with how players think and act but how they are organized. It calls for a recasting of the roles of central office and school personnel, the sharing of authority as well as responsibility, and the redefining of relationships among protagonists (Lane \& Wallberg, 1989; Lieberman, 1988a, 1988b). It is a structural issue fraught with political ramifications as well as personal and professional anxiety. Establishing site councils is but the tip of the iceberg.

Finally, it is worth noting that a move toward sitebased decision making may not be greeted with enthusiasm by all players. |Duke, Showers, and Imber's (1980) study of secondary teachers' perceptions of the potential costs and benefits of their participation in school decision making revealed that while teachers rated the benefits of 
involvement in decision making as high, many hesitated to participate--citing skepticism that involvement actually would make a difference. Rarely, the authors maintain, is increased participation accompanied by a real shift in power. Often it only means attending more meetings, expressing opinions on surveys, or giving administrators advice that they ignore. In a later study, Imber and Duke (1984) found that teachers did not find participation satisfying unless it included influence. According to their definitions, involvement means overt or active participation in one or more phases of decision making such as attending a meeting, providing or gathering information or casting a ballot. Influence, on the other hand, refers to the quality of having an effect. An individual is influential in a decision if and only if the decision would have been different had the individual not participated (p. 27). Imber and Duke also noted that while school structure is crucial in determining the amount of teachers' participation, innovative organizational structure alone did not guarantee teachers meaningful roles in decision making. Finally, Imber and Duke asserted that membership on school site committees was not a particularly satisfying form of participation unless the participation was coupled with the transfer of power. 
Given the fact that teachers have generally found their psychic rewards and greatest satisfaction in their ability to reach their students (Kotthamp, Provenzo, \& Cohn, 1986; Lortie, 1975) rather than in other professional areas of focus, it remains to be seen how committed they will be to such broad-based participation, especially given the amount of time it will take and the perceived failure of earlier reform efforts. The underlying goals of site-based decision making are wellintentioned, but how the increased involvement of teachers makes this effort different from previous ones is a meaningful question to be addressed by all of those who advocate school reform and the major restructuring of America's schools through increased site-based decision making.

Certain requirements must be met if teachers are to truly influence decisions and exert power. Smith (1987) and Bird and Little (1986) stressed the importance of involving teachers in forming school goals. This implies that teachers, administrators and parents have the skills to set instructional goals, analyze performance data and monitor progress. Smith further noted the importance of having in place practices and structures that enable teachers and principals to work together. Site committees asked to make collaborative decisions in members" "spare time" or after the rest of the day's work is done will not 
function as effectively as those with time set aside for this purpose.

Even with the time and skills to make good decisions, shared leadership and empowerment does not mean autonomy without training or shared values (Peters \& Austin, 1985). Peters and Waterman's (1982) term "loose-tight" best describes the leadership of successful schools and businesses. Excellent organizations have:

simple, crisp, and clear visions, but the intensity and clarity of the shared values behind those visions allowed lots of room for autonomy, creative expression and love, care and empathy. (Peters \& Austin, 1985, p. 409)

Sergiovanni (1987) suggested "loose-tight" as a necessary characteristic of successful schools. Teachers should not be forced to follow standardized procedures but neither should they operate as "autonomous professionals each applying his/her expertise independently of his or her fellow teachers" (p. 25). Weick (1982) also addressed the notion of schools as "loosely-coupled systems" that require a management approach much different than the traditional "top-down." Weick, in fact, asserted that the primary job of the school administrator is to reinforce and create ties that bind the members of such an organization.

In order to move to a system of site-based management, then, it is important not only to understand the concept but to have a clear idea of what such an 
approach can and cannot do. The literature, for example, generally shows that many educators believe site-based management offers promise toward better educational programs for students. Several researchers (Johnson \& Johnson, 1989; Lightfoot, 1983b; Little, 1982; Sergiovanni, 1987) recommended reforming schools to support the development of cooperative and collaborative structures. Such restructuring, they posited, increases school effectiveness and results in improved learning for students. However, a review of the literature reveals a lack of definitive research that specifically points to site-based management as a primary factor in the improvement of student learning.

The literature does indicate that the general idea of site-based management is acceptable to principals, with less support for the concept from central office staff. Perhaps such differences are related to a greater lack of clarity relative to the central role in a site-based system or to the amount of time elapsed since central office personnel worked directly with students. A report in the November 1989 Executive Educator based on a nationwide survey indicated that:

Where you stand on the administrative ladder in large part determines what you think about school-based management. The closer you are to the building level, the more feasible you consider the idea--and the more authority you think people in individual schools should have over various aspects of school operations. (Heller, 1989, p. 15) 
This same report stated, "One objection to school-based management was noted repeatedly: that parents and community members want uniformity and standardization among schools" (p. 17). This tension between allowing diversity among schools based on local needs versus some degree of state and district consistency relative to instructional standards is constant.

Another organizational dilemma is revealed by Sirotnik and clark (1988) who argued that there is a significant difference between talking about schools as "centers" of renewal and depicting them as "bases" for management, and that we should focus on the school as center of decision making and renewal. In this instance the word "center" has two meanings: first, the school should be the focal point, or target, of efforts to change and improve; second, the school should be the site of professional inquiry and reflective practice--a place for critical thinking, dialogue, decision making, action and evaluation that determine direction and what changes to undertake. The first role recognizes that the individual school operates in an environment--the school district, state educational agencies, professional associations, parents, community groups--all impact the school and make it a target for change. The second role calls for the school to focus on problems and their potential solutions 
rather than implementing solutions determined by those outside the school.

The school, however, cannot serve as a setting in which professional inquiry and reflective practice are modeled unless teachers have the skills and commitment necessary to do so. Teachers are the key components of such change, change that results in increased success for all students--the fundamental mission of schooling. No effort at school reform, regardless of who is involved in the local decisions and how substantive they are, can succeed without teachers who are willing and able to make the instructional changes that result in more effective teaching and increased student achievement.

Given the various conditions that both shape and restrict the professional lives of teachers, and given that the organizational structure of American schools today is not significantly different from that of 50 years ago despite earlier efforts to effect change, perhaps what should be explored first is a "chicken or egg" hypothesis: do teachers who believe in themselves and in their ability to make a difference for students create the conditions of schooling that lead to student success? Do such teachers find ways "around the system" to connect with colleagues, garner resources, and draw attention to the problems at hand? or are there specific characteristics of effective schools that contribute to the development in teachers of 
a sense that "We can do it or I can make it better?" This relationship of professional and personal efficacy to the challenge of instructional change is difficult to define.

It is creating conditions that increase the feelings of professional and personal efficacy on the part of individual teachers that should be a major focus of a site council agenda. It is determining which rules and regulations, which organizational components must be in place or eliminated in order to empower effective teachers, that is at the heart of true reform. Participatory leadership in itself or forming a new committee, even a site council, is not likely to result in significant change. Such changes may alter the political landscape but are unlikely in themselves to create new solutions to the recurring problems of today's schools.

\section{Increased Collaboration: A New} School Organization

A move to site-based decision making, whether in the form of a site council or another variation, does not in itself guarantee change. For school reform to succeed increased professionalism for teachers and new organizational norms are critical. In order to professionalize teaching, Lightfoot (1983b) and others (Boyer, 1983; Goodlad, 1984; Little, 1986; Rosenholtz, 1989; Sizer, 1984) advocated for increased collegiality and mutual support among faculty, a redefinition of roles 
and hierarchy between teachers and administrators, ongoing staff development, increased involvement of teachers in decision making and more decisions made at the school rather than the central level. Rosenholtz posited that teachers' beliefs and actions are formed by the structure, policies and traditions of the workaday world around them:

Principals who involve teachers in generating information about the goals of teaching, in scanning and choosing the best alternatives, grant teachers a part in constructing school reality. (p. 15)

Further she noted, actively engaging teachers in substantive decision making and faculty interaction, setting time aside for joint planning and problem solving, and assigning teachers to task forces with responsibility for making technical decisions begins to build norms of collegiality and erode traditional structures.

Crisci, Giancola, and Miller (1987) believed that collaboration in goal setting and decision making facilitates school reform. In 1982 Little studied schools and found that collaborative practices distinguished the more successful school from the less successful. Lieberman (1988b) noted that learning-enriched schools placed importance on teacher participation in decision making, set collaborative goals at the building level, and provided an environment where teachers observe each other's work. Slavin (1987) maintained "the idea that people working together toward a common goal can 
accomplish more than people working by themselves is a well-established principle of social psychology" (p. 7). Johnson and Johnson (1987) noted that cooperation among adults promotes achievement, positive interpersonal relationships, social support and self esteem. As a result, they advocated organizing teachers and administrators into collegial support groups as a way to increase productivity and school effectiveness.

Hord (1981, 1986) and Rosenholtz (1989) maintained that true collaborative relationships entail the following: mutual goals among individuals as a group, help-related exchange between group members, individuals' caring for others, joint planning and evaluation and commitment to work with others over time. In cooperative efforts individuals or groups encourage one another, reach mutual agreement, and contribute to one another's well being. Such relationships obviously take time, commitment and skill.

Such themes of cooperation and collaboration permeate the research on effective schools and organizations: Brookover and Lezotte (1979), Edmonds (1979), Kanter (1983), Lightfoot (1983a), Peters and Austin (1985), Peters and Waterman (1982), and Purkey and Smith (1983) all have studied effective schools and organizations. Common findings suggest that the effective organization possesses a clarity of vision and purpose, develops an 
organizational structure that involves all members as meaningful participants, and builds a sense of community while preserving worker autonomy.

Brookover and Lezotte (1979) identified key factors in their early studies as being characteristics of effective schools: ideology of the school, instructional practices, and school organization. Other researchers (Lightfoot, 1983a; Purkey \& Smith, 1983) added the characteristics of collaborative planning and collaborative relations. Lightfoot (1983a) noted "good high schools" create a participatory structure, involving faculty and students in school policy decision making and in developing a sense of community. Little (1982) found that in successful schools there were four critical practices: precise and frequent discussions about instruction, peer observations followed by critiques, opportunities for continuous professional development and teachers planning, designing, researching and preparing materials together. In a later study, Little (1986) added that collaborative schools more effectively implement long lasting changes in teaching practices due to coordinators, principals and teachers working together to develop and implement programs.

Peters (1988), Peters and Austin (1985), and Peters and Waterman (1982) described excellent organizations as ones with participatory structures, no rigid chain of 
command, frequent and open communication cutting across all levels, emphasis on sharing information, shared decision making, and importance placed on training and employee development. Johnson (1984), a historian and policy analyst at Harvard, encouraged educators to look at successful U.S. corporations and the way they organize around a set of values that promote worker interdependence and the integration of the individual into the organization. Successful organizations, he argued, nurture cooperation and support among employees, emphasizing the superordinate goals of the organization. Peters and Austin emphasized building "guided autonomy" (establishing shared values, then allowing people to plan, problem solve and make decisions) and a sense of ownership among employees of successful businesses.

Such a people orientation is echoed by the work of Kanter (1983) who pointed out that successful organizations are people-centered: not only are people treated well, but they are recognized as centrally important to the organization. Peters and Austin (1985) echoed Lightfoot (1983a) and others (Bird \& Little, 1986; Goodlad, 1984; Wise, 1988) by stressing the importance of "debureaucratizing (that is consciously policing, nipping in the bud, or rolling back the excessive regulations - . and regulators . . who get in the way of ownership" (p. 295). 
If one goal of school restructuring is to better meet the needs of students, and to avoid simply blaming the student or the home, then it appears that collaboration may be a condition of schooling that fosters increased perceptions of efficacy. In the interviews conducted by Rosenholtz (1989), teachers from collaborative, supportive systems generally expressed the view that problems they encountered with children were learning problems that could be solved if the root causes were identified. In contrast, teachers from isolated settings generally expressed the view that such problems were discipline problems that could best be solved by punishing the child. creating workplace conditions that foster collaboration and support for innovation would appear to be a promising practice.

Rutherford (1986) claimed that the commonly accepted practice of promoting educational reform through changes mandated from above simply has not worked. He believed that one of the major reasons for this failure is the tendency on the part of educational reformers to treat teachers as "passive recipients of change." He suggested solving this problem by involving teachers before such changes are directed and to establish conditions within the organization that encourage teachers to become the initiators and facilitators of change. In other words, 
Rutherford advocated for efforts to increase teacher efficacy.

This research seeks to identify those conditions that schools must create from within to bring about true structural and political change. This restructuring movement can only succeed if it changes the fundamentals of the educational system itself, particularly the people who function within it and the educational services now provided to the nation's children. Without such a systemic shift, this reform effort will fail as did those that preceded it.

\section{Shared Leadership: Implications for Individuals and organizations}

In his analysis of the reasons underlying the erosion of public confidence in public schools in West Germany, Weiler (1983) described three major strategies used by school officials to recapture credibility with the public. These included "legitimation by legalization," evidence for which included an increase in case law, administrative rules and state policy to bring schools into some semblance of standard alignment; "legitimation by expertise" or the use of outside experts and pilot programs to maintain the status quo while giving the appearance of innovation and change; and finally "legitimation through cooptation" or increasing the involvement of clients to create ownership and to silence 
the critics. Notwithstanding the somewhat cynical nature of this approach, the question should be asked as to whether increased involvement of teachers and parents significantly affects the governance of public schools or positively impacts student learning. Certainly one could view the formation of site councils, for example, as efforts to coopt the issue of restructuring. Parents and teachers serving as site council members can be cited as evidence of a district's or school's commitment to change without much adjustment to the status quo.

Another view, a systems approach, might suggest that site councils are policy "outputs" in response to the current political environment affecting schools. In a model espoused by Easton (1965), for example, the various demands on the system, defined as inputs, not only force change in the system itself but produce their own effects on the environment and thus eventually create a new set of both supports and demands that establish the need for additional change. Owens (1987) asserted that there are two key concepts at work in a systems approach to analyzing any phenomenon: the interrelatedness of the various subsystems operating and the idea of multiple causation. In this case, the site council issue is not so much a shift in leadership, and the implicit notion of new direction, as it is being responsive to, or following, the environmental directions set by others. 
Whether one ascribes to a systems view or not, taking a simplistic view of the reasons for the shift to a broader base of school leadership is a mistake. A linear relationship, one that involves cause and effect, misses the point. A system like a school or a school district is what Owens (1987) calls an "open system": one which interacts with its environment. From this perspective, the forces that impact education (i.e., test scores, merit pay, inadequate funding, overcrowding, pressures from the business community to compete on the international market) could be viewed as responsible for the current movement toward shared leadership and collaborative decision making. The various interest groups that compete for control of the educational agenda have created the need to establish a broad base of decision makers or leaders rather than the traditional hierarchical model found in most schools today. Professional educators, voters and taxpayers, school boards, administrators, superintendents, the business community and citizens with children no longer in school are, in essence, being invited to the table to help develop a different model of schooling and new norms of leadership.

Schmuck and Runkel (1985) maintained that:

norms exist when a collection of people approve certain ranges of behavior while others are disapproved, and still others are neither approved or disapproved. Norms sustain the organization's patterns of behavior. Roles, on the other hand, are norms about how a person in 


\begin{abstract}
a particular organizational position should perform . . . or, more exactly, how two or more persons should interact on the job. Structures are norms about roles assigned to several interrelated jobs: about performance on those jobs, responsibilities among jobs, and so on. (p. 19)
\end{abstract}

Clearly teachers, parents and administrators working collaboratively to exert leadership in a school setting need to establish new norms. As they define roles and responsibilities, an understanding of the nature of leadership and their relationship to their various constituencies will emerge.

In an early work by French and Raven (1959) the authors enumerated six sources of leadership power. These include rewards, punishments, information, legitimacy (i.e., the authority or right to make a particular request), expertise and referent power, often recognized as charisma or personal power. Sergiovanni (1990) identified five different types of leadership for effective schools: technical, human, educational, symbolic and cultural. Etzioni (1975) described a compliance model in which the forms of power operating in an organization are correlated with the anticipated response of those working in it. Coercive power, or the application or threat of sanction, results in alienation. A calculative approach in which control over material resources and rewards are paramount produces employees who focus on remuneration and develop a utilitarian approach 
to the tasks they confront. The exertion of moral leadership or power, on the other hand, results in normative controls and an emphasis on the symbolic rewards of participation such as esteem and prestige within the organization. Again, a principal, a leadership team or site council will model behaviors, consciously or unconsciously that will contribute to the developing norms of the school as organization.

As a newly-formed leadership team reaches agreements and begins to develop into a unit, it must define its basic values. Schein (1985) outlined the primary mechanisms available to leaders, whether individuals or groups, to shape and reinforce organizational culture: what leaders attend to, measure and control; how leaders react in crisis; the deliberate role modeling and teaching that must occur; the defining of the criteria by which rewards and status will be allocated within the organization; and the requirements for recruitment, selection, and promotion. Most site-based efforts designate responsibility for curriculum, classroom instruction, allocation of resources and staff development to the leadership team(s). Given involvement in so many of the key functions in a school, those fulfilling the leadership role will indeed help shape the culture of the school. "Leadership is the creation and management of culture" (Schein, 1991, p. 127). Rossman, Corbett, and 
Firestone (1988) noted "culture describes the way things are: it interprets events, behaviors, words, and acts - . gives them meaning" (p. 5). Further, Rossman et al. believed "culture also prescribes how people should act; it normatively regulates acceptable behaviors in given situations" (p. 5). Any leadership team attempting school restructuring will help to "normatively regulate" as well as be shaped itself by the culture of a given school. Rossman et al. (1988) argued, Teachers' responses to an innovation may depend not only on the process by which it is planned and implemented . . . the concern of past research . . but also on the congruence between its normative content and that of the school's culture. (p. 20)

Deal, Meyer, Scott, and Rowan (1985) asserted that every organization has its own culture, that learned pattern of unconscious thought that gives stability and meaning to the lives of people/employees. Change in any organization, even if it is a change to a shared leadership model or one that purports to improve classroom learning, may bring a sense of loss and grief. School leaders must realize that such feelings must be accepted before individuals and organizations can move forward.

School leaders must also understand the dynamics of the school as a "loosely coupled" system (Weick, 1982). Schools are more loosely structured than other organizations, maintained Weick, because their goals are vague and there is little real evaluation or supervision 
of employee performance. The rational, bureaucratic model is not appropriate for schools; rather information (and change) is diffused slowly throughout the organization. The primary task of leadership, then, since there is no tight "chain of command" despite administrative behavior to the contrary, is to resocialize staff members around key values and to reaffirm and consolidate those ties that do exist. Schmuck and Runkel (1985) maintained that if change is to occur, staff members must frequently communicate across all levels.

Collaboration must replace isolation and hierarchical direction so that all concerned can be aware of new action when it occurs, see for themselves who committed it, and give it their own support. (p. 22)

Leadership has to talk change, model change, and reinforce change--sending out official memoranda will not result in any movement at all.

\section{Basic Tenets of the Accelerated} School Model

The first Accelerated School was created in San Francisco in 1986-1987 (NcCarthy, 1991) in response to what Levin (1989a) called the "at risk crisis" in which "about $30 \%$ of America's students in primary and secondary schools are (educationally) disadvantaged" (p. 3). As these students continue in school, they suffer from an ever-widening gap between their actual performance and the school's expectations. Levin called for a new approach, 
not remedial in nature, by which the learning of these children is accelerated through the pre-secondary years to bring them into the mainstream by the end of grade 6 . More recently, the Accelerated school model has been adapted for use in middle level schools applying the same principle of accelerated learning to students in grades 7-8.

Levin's (1989a) Accelerated School model represents an important and growing national effort aimed at increasing the success in school of at risk children. With currently over 700 Accelerated Schools in the country with several states, including Illinois, south Carolina and Texas, considering the Accelerated School as a statewide model for school restructuring, the Accelerated school approach is becoming a major national movement. An important aspect of the Accelerated School model, and perhaps one of the reasons for its rapid expansion across the country, is that the changes that accrue to participating schools result not so much from prescriptive practices as from the process employed by teachers, parents and administrators to examine the nature of schooling itself. The process involves site-based decision making and increased involvement of both parents and staff, important components in any change effort. In the Accelerated School model, teachers create and develop knowledge together rather than simply acquire and 
disseminate it. It is this establishing of new norms of collaboration that makes the Accelerated school model an appropriate context for examining the concept of teacher efficacy as it impacts the scope and pace of instructional change.

Accelerated Schools are transitional elementary schools designed to bring all students up to grade level by the end of sixth grade. These schools are driven by the motto: "Accelerate, Don't Remediate" and a premise borrowed from Dewey (1916), "What we want for our own children we must want for all children" (Levin, 1990). Levin (1990) defined at-risk students as "those who lack home and community resources to benefit from conventional schooling practices" (p. 47). According to the model, conventional schools have failed to meet the needs of atrisk students. The typical response to low achievement has been remedial education with a resulting loss of student self-esteem, lowered expectations, few deadlines, a slower pace and less accountability. "Drill and kill" drudgery and an overall lack of exposure to interesting ideas and concepts to ensure mastery of basics results in schooling that is not stimulating, relevant, interesting or connected to the lives of children (Levin, 1988; 1989a).

The assumptions and basic principles of the Accelerated School model are based on the work of Dewey 
$(1903,1916,1938)$. Dewey built his vision of a humanistic democratic school on the "faith in the potentials of both children and adults to understand and, to some extent, shape the world around them" (cited in Rogers \& Polkinghorn, 1990, p. 7). Dewey also advocated that all decisions about curriculum, instruction, and school organization be made at the school site to create a learning environment that has an "organic connection" with the students' lives and their previous experiences (cited in Rogers \& Polkinghorn, 1990).

Accelerated does not mean simply speeding up learning; it means learning more. Instructional strategies in an Accelerated school range from peer tutoring and cooperative learning to direct instruction. All instruction should be active, "hands on," well-paced, collaborative and designed to meet the needs and interests of students so that they are genuinely motivated to learn. Curriculum should stress an enriched integrated approach rather than a remedial approach and critical thinking rather than the learning of isolated facts and skills. Everyday problems should be incorporated into the curriculum whenever possible. The Accelerated School model follows "an integrated approach to the restructuring of schools. . . instruction, curriculum and organization are all impacted at the same time" (McCarthy, 1991, p. 1). It aims, eventually, to provide a comprehensive education 
for students that meets their academic, social, emotional and self-esteem needs.

Schools embracing the Accelerated School concept are guided by three principles which are brought to bear on all decisions related to school organization, curriculum and instruction. The first principle, Unity of Purpose, forges personal visions into a shared vision of what the school is all about. According to Levin (1988), unity of purpose:

refers to the agreement among parents, teachers, administrators, and students on a common set of goals for the school that will be the focal point of everyone's efforts. (p. 22)

The second principle, Decision Making with Responsibility, involves those who know the school best and who are closest to the classroom in the development of school curriculum, instruction and organization. This principle relates to building the capacity of key participants in the school community to enable them to contribute to the process of making important educational decisions. By contributing to the decision making process, these participants take responsibility for the implementation and outcomes of their decisions rather than wanting "to blame each other as well as other factors 'beyond their control' for the poor educational outcomes of students" (Hopfenberg, Levin, Meister, \& Rogers, 1990, p. 27). A third principle, Building on Strengths, focuses staff on 
student, teacher and community strengths rather than perceived deficiencies or faults (Levin, 1990).

Finally, an Accelerated School is structured around three governing bodies. First, a steering committee, comprised of a principal, faculty representatives from the various cadres, and parents, sets policy and convenes task committees or cadres. Second, cadres of teachers, staff and parents from the various grade levels and special areas work on the accomplishment of identified school goals by following the prescribed stages of the inquiry process. And finally, the site as a whole (SAW) or total faculty meets to endorse policies through consensus that will affect the whole school. Training is provided to enhance group processes, decision making, and interpersonal relations.

The Process of Becoming an Accelerated School

Chenoweth and Kushman (1992) determined that there are four phases of a school restructuring process such as that undertaken by an Accelerated school. During their longitudinal study of several Accelerated Schools in the Portland metropolitan area, they identified these phases as courtship, training and development, changing school structure and culture, and modifying classroom practices. Courtship is the phase during which the initiators of the reforms (i.e., district personnel, building 
administrators, university faculty, other teachers) engage schools and school staffs in a discussion of the need for change and a model for change. In the end, an agreement is made to embark on a major school restructuring effort. The primary goal of the courtship phase is to begin building a shared meaning and commitment around a particular model and to garner staff support for the need to change.

The training and development phase is one in which school staffs receive training in the skills, knowledge and attitudes required for the model to succeed. In Accelerated Schools, this knowledge base includes learning to work in teacher teams, group process and meeting skills, use of an inquiry process to identify and solve school problems, and knowledge of instructional practices that can accelerate learning such as cooperative learning and whole language. Teachers must also develop a sense of collegiality and support.

Several elementary schools involved in the Chenoweth and Kushman $(1992,1993)$ study are involved in the first phase of the restructuring process and focused on staff development and training during 1993-1994. Other schools, including the one selected for this author's study, have recently begun the third phase, the structural and cultural phase of restructuring, in which real changes in school structure and culture are introduced, experimented 
with, and refined for a particular school site. Changes in school organization and climate can include a redesign of the decision making structure and leadership roles of teachers and principal, creation of a collaborative and team-oriented work culture, increased parent involvement, and a continuous focus on school vision and goals jointly developed by all school staff. At this stage the teachers are assumed to be ready to identify the organizational conditions that would enhance or inhibit their own ability to make a difference for children.

The final and most critical phase for student learning is the translation of effort to affect classroom practices. It is only when this last phase is in place that improvements in student learning can be expected to take place.

This four-step process corresponds to what Rosenblum and Louis (1981) have called the rational model of school change, a model that depicts change as a logical, sequential process of readiness, initiation, implementation, and continuation. Such a model recognizes that the foundational aspects of change must be addressed in order for innovation in classroom practice to occur. Without the preliminary work to determine a vision for the school and to establish a culture that allows innovation and promotes risk-taking, true changes in the structure of schooling will not take place. Cuban (1990) observed 
that most so-called school reform involves quick and superficial changes in classroom practices that seldom last, rather than an ongoing process of school reorganization and transformation. Quick and superficial change. however, is not the goal of the Accelerated School model.

The process of becoming an Accelerated School involves certain predetermined steps and activities associated with the Levin (1989a) model, generally estimated to take approximately six years. These foundational changes include the "Launch," "Taking Stock," "Building a Vision," "setting Priorities," "Creating Governance Structures," and "Inquiry." Schools that adopt the model must commit to a comprehensive process and to a long-term restructuring effort that addresses all aspects of schooling: a redesign of the governance structure; modified roles for teacher, parent and administration; and suggested new approaches to curriculum, instruction and assessment.

The Accelerated School model involves a process of school restructuring in which school organization, decision making, curriculum and instruction are redefined to build on student strengths, better address the needs of both poor and minority students, and accelerate the learning of students traditionally labeled "underachieving." The Accelerated School is much more 
than a place that emphasizes academic learning. The emphasis on family involvement turns the school into a community with shared values, a place where children and parents feel safe and secure.

Within that school community, roles and expectations change. Certainly the "Effective Schools" research points to the significance of the school principal and to strong leadership as key variables in school improvement efforts. In an article entitled Emerging National Models of Schooling for At Risk students, however, Chenoweth (1992) pointed out that "while schools restructure, the principal is often left in a vague and uncertain position . . more details and specific recommendations are needed" (p. 266). In the Accelerated school model, there is little information about the anticipated role of the principal. In one of the few articles in which there is a reference to the principal, Levin (1990) believed:

A good Accelerated School principal is an active listener and participant, one who identifies and cultivates talent among staff, who can keep the school focused on its mission, who can work effectively with parents and community, who is dedicated to the students and their success, who can motivate people and who can marshal the necessary resources. Finally, the principal is the keeper of the dream, using keen analytic and planning skills to solve problems and help staff to overcome temporary setbacks. (p. 13)

In contrast, the role of parent is more clearly delineated. Parent involvement constitutes a central feature of the Accelerated School model. As members of 
the school community, parents will be required to first affirm their approval of the goals of the Accelerated school and agree on their responsibilities. These include ensuring that their children go to bed early and maintain regular attendance, setting high expectations for their children, and encouraging them to read on a daily basis (Levin, 1989a). Second, parents are encouraged to participate in governance bodies by becoming active members of one of the cadres or of the steering committee. Finally, parents are expected to be in touch with the everyday school activities of their children inside and outside of school. Accelerated schools adopt an open door policy where parents are encouraged to come to school to interact with school staff. Training is also often provided for parents to help them improve their parenting skills as well as their own academic skills to better understand what their children are doing in school (Levin, 1989a).

Most critical is the changing role of the teacher. Teachers will serve as "facilitators of student activities rather than the sole giver of knowledge" (Hopfenberg, Levin, Meister \& Rogers, 1990). Even more important is the teacher's responsibility for change and response to it. In a qualitative study of two elementary Accelerated Schools, McCarthy (1992) used semi-structured and 
unstructured interviews with teachers to explore the following hypothesis:

if the change (resulting from the implementation of the Accelerated School project) is meaningful, the teachers' personal and professional lives would be impacted as they internalized new beliefs and practices. (p. 8)

The study concluded that the "Accelerated School project seems to have the potential to make lasting and meaningful changes in the culture of the school" (p. 14). These identified and observed changes included the following:

- Teachers' behaviors reflect more cooperation and collaboration while planning for instruction;

- More creative instructional activities are designed by teachers;

- More enriched active learning experiences are taking place in classrooms;

- More teachers had become "empowered learners" ready to take risks and explore new solutions to their problems.

\section{Varying Perspectives on Efficacy as a construct}

The concept of efficacy is closely aligned with theories related to human motivation (Maslow, 1954, 1968), job satisfaction (Herzberg, 1966; Herzberg, Mausner, \& Snyderman, 1959; Vroom, 1964), and adult learning (Knowles, 1978; Levine, 1989). Locus of control theory (Rotter, 1966), another area of related research, attempts to answer similar questions about personal accountability 
and values. Investigating teacher motivation and factors which contribute to job satisfaction are important areas of research in today's educational climate, but to explore teachers' perceptions of efficacy and the conditions which either impede or enhance their efforts to effect change in the classroom is even more critical, at least to this author.

Efficacy is an important concept that has been studied by others in a variety of contexts and found to be correlated with a number of positive results. For example, an individual employee's sense of efficacy has been discovered to be statistically significant in studies of both individual and organizational work performance. It has been related to "job commitment and satisfaction," "performance on work tasks," and "low employee turnover" (Dunnette, Arvey, \& Banas, 1973; Locke, 1976; Mitchell, 1974; Price, 1981; Rabinovwitz \& Hall, 1977). An individual's efforts to preserve or enhance his/her own sense of efficacy influences organizational change (Berman \& McLaughlin, 1979) and that same individual will choose to work in domains where the perceived efficacy is high (Lefcourt, 1976; White, 1959). High perceptions of efficacy have also been related to high performance among students (Brookover, 1977; Coleman, Campbell, Hobson, McPartland, Mood, Wenfeld, \& York, 1966; Stipek \& Weisz, 1981), among adolescent workers (Gurin, 1968); among adult 
workers in general (Hackman \& Oldham, 1975; Herzberg, 1968; Kahn, Wolf, \& Rosenthal, 1964), among teachers (Rutter, Maughan, Mortimore, Ouston, \& Smith, 1979), among middle managers (Price, 1981) and among principals (Sarason, 1971). Clearly it is a concept worth investigating as a potentially key variable in school reform.

Most of these studies view the construct of efficacy as a dependent variable related to performance or effectiveness. In other words, efficacy is enhanced or diminished as a result of success or failure. Efficacy results from personal experience, social interaction and specific situations. It is essentially a learned trait, one that could presumably be taught if situations were structured in such a way that an individual could experience success. Classroom teachers, for example, could learn to be successful, and thereby feel more efficacious, by watching others teach, analyzing their own performance through videotapes, or learning specific strategies that have proven effective with low achieving students.

A second view of efficacy is that it is an intrinsic individual trait, one that is antecedent to productivity or effective action. From this perspective, one either has it (efficacy) or does not. Such a view parallels the "great men make history" point of view versus the belief 
that "history creates great men." Notwithstanding the gender issue implicit in this adage, it is a common view of individuals within a workplace setting. There are "natural" leaders as well as followers. By the same token, there are thought to be some classroom teachers that are more effective than others, more open to change and new ideas.

Sociological research considers efficacy, like power, to be a function of structure or position within an organization (Kanter, 1979). Fuller, Wood, Rapoport, and Dornbusch (1982) argued that "the (school) organization provides achievenent structures within which an individual may develop greater self perceptions of efficacy" (p. 11) and proposed that improved organizational performance would result from "empowering individual actors to improve their own work and feeling of competence" (p. 17). Typically schools reward the "efficacious" by appointing such teachers to positions of authority and by involving them in development work related to curriculum or new projects.

A third view of efficacy is that efficacy is interactive, contingent upon personality, experience and situation. In this sense, efficacy is highly variable, context specific and dependent on a variety of intervening events. Such a view of efficacy parallels recent views of leadership as situational, a function of the interaction 
between events and self. This perspective depicts teacher efficacy as a variable state and assumes that all teachers experience self doubt and frustration, and have views of self and others that fluctuate with the situation.

An interesting parallel between approaches to understanding self concept theory and efficacy was drawn

by Gorrell (1990):

Two basic models of self concept change have been investigated: an enhancement model that emphasizes that changes in self concepts lead to important behavior change and a skills model that states that behavior changes lead to changes in self concept. (p. 74)

Traditional self concept theory generally adopts the enhancement model.

Adherence to the enhancement model rests largely on logical grounds erected by phenomenological theory. If an individual's perception of the world determines their behavior (Kelly, 1955; Snygg and Combs, 1949), and if individuals construct a set of beliefs about themselves out of their experiences, their perceptions of themselves will affect their behavior. (p. 74)

Most importantly for the study of efficacy as it relates to school reform, Gorrell (1990) maintained that:

Individuals tend to resist changes to beliefs that have been distilled from their experiences over long periods of time. The more central these beliefs are in the individual's self concept, the more resistant to change they will be. Individuals also seek to enhance their self beliefs, however, and to replace beliefs that hold negative evaluations with beliefs about themselves that they evaluate positively. The conflicting goals of self-consistency (Lecky, 1945) and self-enhancement may lead individuals to hold on tenaciously to negative self evaluations while struggling to create more favorable ones. (p. 75) 
Regardless of the perspective on efficacy, stipek and Weisz (1981) suggested three theoretical models for understanding its complexity. Efficacy is related to and influenced by:

1. Social learning theory that focuses on the degree to which one believes that outcomes are contingent on his/her behavior, referred to as locus of control (Rotter, 1966);

2. Attribution theory that focuses on the degree to which one believes he/she can control the factors that cause outcomes, referred to as locus of causality (Weiner, 1976); and

3. Intrinsic motivation theory assumes that humans naturally strive for competence or control and that intrinsic motivation is affected by the outcomes of these efforts (Decharms, Carpenter, \& Kuperman, 1965; Deci, 1975; White, 1959).

\section{Teacher Efficacy}

Further study of efficacy as a construct reveals that many researchers have treated teacher efficacy as a unidimensional trait (Barfield \& Burlingame, 1974; HooverDempsey, Bassler, \& Brissie, 1987; Trentham, Silvern, \& Brogdon, 1985) whereas others have distinguished two dimensions of efficacy based on Bandura's (1977) theory of self-efficacy (Ashton \& Webb, 1986; Denham \& Michael, 
1981; Gibson \& Dembo, 1984). Bandura (1986) suggested that motivation is affected both by outcome expectations, that is judgments about the likely consequences of specific behaviors in a particular situation, and efficacy expectations, the individual's belief that he or she is capable of achieving a certain level of performance in that situation. Furthermore, outcomes and efficacy expectations are interrelated. Bandura noted that "the types of outcomes people anticipate depend largely on their judgments of how well they will perform in given situations" (p. 392)

According to woolfolk and Hoy (1990), the earliest use in ERIC of the term "teacher efficacy" occurred in a study by Barfield and Burlingame (1974) in which efficacy was measured by the Political Efficacy Scale (Campbell, Gurin, \& Miller, 1954). Although the measure was not designed for use with teachers, (e.g., "People like me don't have any say about the way government runs things"), it was used unchanged in the Barfield/Burlingame study. The results of their work showed that low efficacy teachers were less humanistic than average or high efficacy teachers in their ideas about student management. In 1973, Brogdon modified the Political Efficacy scale for the specific purpose of measuring teacher efficacy. His findings indicated that teacher efficacy is related to 
feelings of career satisfaction and positive ratings by the superintendent on evaluation instruments.

Later, in 1977, two Rand Corporation studies (Armor et al., 1976; Berman, McLaughlin, Bass, Pauly, \& Zellman, 1977), computed teacher efficacy from responses to two Likert scale items:

1. "When it comes right down to it, a teacher really can't do much because most of a student's motivation and performance depends on his or her home environment," and

2. "If I try really hard, I'can get through to even the most difficult or unmotivated |students."

Both studies demonstrated positive relationships between teacher efficacy and student achievement. In a later study of 48 high school basic skills teachers, Ashton, Webb, and Doda (1983) also found significant positive correlations between teacher efficacy and student performance.

Ashton and Webb (1986) relied on Bandura's (1977) cognitive social learning theory and the earlier Rand research to conceptualize teacher efficacy. Expanding the Rand methodology by using the original two questions plus teacher interviews and classroom observations, Ashton and Webb hypothesized that the teachers' responses to the first Rand item ("When it comes right down to it. . .") indicated beliefs about what Bandura termed outcome expectations or general teaching efficacy. Responses to 
the second Rand item ("If I try really hard . . ") reflected Bandura's efficacy expectations or what Ashton and Webb termed personal teaching efficacy. Applying Bandura's theory to the construct of teacher efficacy, then,

outcome expectancy essentially reflects the degree to which teachers believed the environment could be controlled, that is, the extent to which students can be taught given such factors as family background, IQ and school conditions. Self-efficacy beliefs would indicate teachers' evaluation of their abilities to bring about positive student change. (Gibson \& Dembo, 1984, p. 570)

Ashton, Webb, and Doda (1983) have argued that a teacher with a low personal sense of efficacy, who also believes that other teachers can generally motivate low achieving students, "will experience a loss of professional self esteem, an affective deficit that is likely to be accompanied by high feelings of stress" ( $p$. 5). On the other hand, they believed that "low efficacy teachers with a sense of universal helplessness will experience little stress" (p. 5). Presumably this is a teacher who has given up yet feels no guilt--there is, after all, nothing more that anyone can do, including him or herself.

Two dimensions of efficacy identified by Ashton and Webb (1986), based on Bandura's (1986) theory of efficacy and the earlier Rand research (Armor et al., 1976; Berman et al., 1977), were general teaching efficacy and personal 
teaching efficacy. Sense of general teaching efficacy

refers to "teachers' expectation that teaching can

influence student learning" (p. 4). Sense of personal

teaching efficacy refers to what Ashton and Webb (1986)

defined as "individuals' assessment of their own teaching

competence" (p. 4). In other words, teaching efficacy is

the extent to which one believes that teaching can have an

influence on student learning, regardless of obstacles

such as family background and student ability, while

personal teaching efficacy is a teacher's perception of

his/her own teaching abilities to influence student

learning.

Woolfolk, Rosoff, and Hoy (1990) defined general

teaching efficacy as the "power of teaching to counteract any negative influences in the student's background" ( $p$. 138) and personal teaching efficacy as "the impact of a particular teacher" (p. 138). Results of studies using both the Ashton and Webb (1986) and Gibson and Dembo (1984) procedures have consistently found that these two dimensions are independent. Thus, individual teachers who believe that teaching is a potentially powerful factor in students' learning may believe that they are effective or that they lack the ability to make a difference with their own students. Teachers may also believe that teaching in general can have little impact on students and that their classes are, or are not, exceptions to the rule. (Woolfolk, Rosoff, \& Hoy, 1990, p. 138) 
Emmer (1990) expanded the work of Gibson and Dembo (1984) by adding a third dimension to teacher efficacy related to classroom management and discipline efficacy. Emmer's work portrays teacher efficacy as having three factors: (a) the classroom management/discipline factor related to teachers' self-perceptions of competence in the area of management and discipline, (b) the external influences factor that reflects a belief that influences other than the teacher determine student outcomes, and (c) the personal teaching efficacy factor that reflects teachers' beliefs that they know suitable teaching techniques and are able to help students learn. Emmer maintained that much teacher attention is focused on areas not directly linked to student learning but rather on achieving order and cooperation in the classroom.

Changing the minds of low efficacy teachers about themselves, their colleagues and their students is an important but difficult task. Gorrell (1990) believed that:

the primary process of change involves the incorporation of new information about oneself based upon others' reactions or upon the integration of self perceptions into a new constellation of significant beliefs. This process does not occur easily; protection of existing beliefs may outweigh the individual's efforts to enhance current beliefs. (p. 75)

Teachers at an urban school such as those involved in this case study, when faced with their past performance relative to high-risk learners and with the changes in 
practice resulting from implementation of the Accelerated School model, might be expected to wrestle with old beliefs about children, parents, principals and self. The teachers participating in this study must adjust to new expectations in terms of both the Accelerated school process and changes in their roles and behavior. Low efficacy teachers may feel threatened by exposure and the loss of the protection provided by their isolation or struggle constantly to blame students and families for classroom failure rather than accept responsibility themselves. High efficacy teachers may feel frustrated by the slow pace of change or by the necessity of moving forward by means of group consensus rather than making decisions that affect themselves alone.

This struggle of teachers and others to incorporate new beliefs, regardless of the innovation, is influenced by what Bandura (1977) referred to as four main sources of information upon which self-efficacy beliefs are based. These include:

- Performance accomplishments--Experiences of personal mastery are the most powerful sources of personal information and learning. Success leads to greater expectations of mastery and success. In other words, as teachers share ideas and become more comfortable asking for help, they tend to raise their expectations that they will experience more success as a result; 
- Observing others perform tasks successfully-opportunities to observe peers modeling an innovation influence perceptions of self-efficacy. Having witnessed success, a teacher is more likely to feel capable of duplicating the same successful behaviors.

- Verbal persuasion--Bandura considered verbal persuasion to be a weak method of changing efficacy beliefs and maintained that unless it was accompanied by successful performance accomplishments, it was typically disregarded by an individual. Most change efforts in schools, however, depend on staff development models that rely on outside experts without an opportunity for teachers to practice the new behaviors being advocated or to receive feedback on early attempts at implementation of a new idea or program. As a result, most such staff development efforts fail.

- Emotional arousal--Bandura believed that the emotional reaction to stress, serving as an indicator to an individual that he/she is not coping well with a situation, inhibits future performance attempts because individuals tend to associate emotional arousal such as anxiety as signs of personal incapacity. Certainly many teachers face classroom conditions that they perceive as stressful, conditions that may serve as a "self-fulfilling prophecy" in terms of impeding a teacher's belief that new 
strategies or approaches may prove more effective than the old ones.

Gorrell (1990) maintained that:

as individuals raise or lower their self efficacy beliefs, based upon past performance, observed models' performances, others' encouragement and emotional states, their willingness to attempt behavior or to persist in it increases or decreases. A major goal of self efficacy research has been the specification of the conditions under which self efficacy beliefs alter and of the exact results that occur following such changes. (p. 77)

Also, in "The Organizational context of Individual

Efficacy," Fuller et al. (1982) noted that:

the fundamental question remains largely unanswered: How do organizational interventions serve to enhance or threaten the individual efficacy of participants in the organization? (p. 8)

These same authors suggested that "empirical and ethnographic inquiry into how individual school actors view their own efficacy . . would be very helpful" ( $p$. 25).

Finally, Hargreaves (1991) maintained that "In educational change and educational research the formerly unheard or undervalued teacher's voice has been accorded increasing respect and authority in recent years" (p. 10). The teacher's voice, maintained Goodson (1991), articulated the teacher's life and its purposes. To understand teaching, therefore, either as a researcher, an administrator, or as a colleague, it is not enough merely to witness the behavior, skills and actions of teaching. 
Goodson encouraged those interested in the true dynamics of schooling to listen to the voice of the teacher, to the person the voice expresses and to the purposes it articulates. He clearly believed that failure to understand the teacher's voice was a failure to understand the teacher's teaching.

\section{Teacher Efficacy as an Important Variable in School Reform}

The research undertaken in this study, responding to such admonitions, relies heavily on "the teacher's voice" to identify the workplace conditions that foster efficacy and to determine individual teacher perceptions of self and others involved in school reform. But the very history of past reform efforts has undoubtedly contributed to lack of efficacy and feelings of professional frustration on the part of the same teachers being asked to undergo even more substantive change. The "teacher voice" may be a negative one, especially in cases in which yet one more reform is concerned.

In a synthesis of research on teachers' contributions to school improvement efforts and other reforms of the past, Rutherford (1986) delineated the typical response of teachers to change based on a meta-analysis of empirical studies and thousands of interviews. These responses include the following: 
- "I Don't know" syndrome--a typical response given by teachers when asked about the future use of an innovation or new practice. More specifically, the response was "I don't know; the (principal, supervisor, superintendent) has not yet told us." The message is obvious that teachers believe their future in relation to an innovation is determined not by them but by some superordinate.

- "This Too Shall Pass"--teachers are reluctant to take any change too seriously or to invest in it too much energy for they know from experience that many innovations fade into oblivion after a few years or the importance of the innovation is diminished as other innovations are introduced.

- "Why Change?"--some teachers perceive that by making a change they will suffer loss of a personal or material nature and they resist the loss. A related reaction is "What's wrong with the current practice?" Change for change sake, especially without evaluative data to clearly indicate effective and ineffective methods, makes some teachers suspicious of any attempt at change at all.

- "Let's Fake It"--the teachers in this group try to make it appear that they are doing what the innovation and its facilitators want them to do. These teachers are not necessarily weak or dishonest. Rather the impossible 
demands of multiple innovations may actually prevent them from attempting more. A sub-group within this category actually reshapes the innovation so that as much as possible it fits with what they are already doing. In this way they claim to be using the innovation but in reality they are not.

The sad truth, maintained Rutherford (1986), is that: teachers are far more likely to be recipients rather than initiators of a change that impacts more than their own classroom. When recipients of change had little or no input into the change process, and when change was thrust upon them with little forewarning, some resisted and some reacted positively, but the majority responded with a kind of passive acceptance that this is just the way things are done in schools. (p. 5) In addition to this deplorable state of affairs, Rutherford (1986) also described several other negative effects of poorly-managed change efforts in schools. These include the constant state of anxiety that results in teachers always dealing with the personal concerns and numerous management issues associated with the early stages of use with a new practice or program. Research has also shown that effective use of an innovation requires several years; when a teacher is confronted with one innovation after another, it results in diminished effectiveness on an almost continual basis. Finally, ongoing efforts at innovation give the appearance of innovation without ever allowing time for an examination of either an innovation's depth or significance. "This 
substitution of activity for substance is both deceptive as well as counterproductive for it keeps us from seeking true and lasting solutions to our educational problems" (p. 6). If the goal, then, is true and lasting solutions, educators must examine the conditions of schooling that can truly enhance change and discontinue those that either waste valuable time or actually debilitate teachers and blunt the capacity for real inquiry. Ashton and Webb (1986) maintained that the increasingly negative environment that characterizes teaching today is, of course, related to teacher motivation and ultimately to the success of students in the classroom. The physical isolation of teachers from other professionals has led to a "status panic . . and profound questions by teachers about their worth to society. Panic and isolation influence a teacher's thinking and motivation to teach" (p. $x i$ ). According to Lieberman and Miller (1984) "It is perhaps the greatest irony . . and the greatest tragedy of teaching . . that so much is carried on in self-imposed and professionally sanctioned isolation" (p. 11).

Teachers struggle toward proficiency virtually alone, and accumulate as much skill and wisdom as they can by themselves. Superb teachers leave their marks on all of us. They leave no marks on teaching. (Bird \& Little, 1986, p. 495)

Feelings of loneliness only compound the daily frustrations of the classroom teacher. 
Finally, Ashton and Webb (1986) warned,

Unless something is done to overcome the demoralization of teachers, it is unlikely that any reforms will significantly improve the quality of education in America. There are no teacher-proof reforms. Ultimately, the success of all improvement efforts depends on the quality and the determination of the classroom teacher $(p, 1)$.

If school improvement is dependent on teacher quality and determination, then the construct of efficacy is likely related to the success of any school reform effort.

If teacher efficacy is the teacher's belief that his/her actions affect student achievement or that he/she has the "ability to have a positive effect on student learning" (Ashton, 1984; Ashton \& Webb, 1986), then efficacy is an important variable to study. If, as sparks (1988b) maintained, the development of efficacy makes teachers "believe in themselves as powerful forces in their classrooms, able to help students learn and thrive" (p. 117), then efficacy appears to be an important attribute for teachers to have and for schools to foster, particularly given the national concern over students "at risk." Determining the conditions that contribute to a strong sense of efficacy, then, and attempting to create those conditions in schools, could significantly inpact both student and teacher success, an assertion supported by a number of studies.

For example, research has shown that low-efficacy teachers attribute low-achieving students' problems to 
their lack of ability or poor background rather than to the ability of their teachers. Low-efficacy teachers tend to accept greater responsibility for success than failure. It is assumed that this is necessary to help them maintain their sense of competence by believing that there is little that they, or any other teacher, can do to prevent failure (Webb, 1982).

Ashton, Webb, and Doda (1983) found several differences in the behavior of high and low efficacy teachers: high efficacy teachers maintained high academic standards, had clear expectations for students, concentrated on academic instruction, maintained on-task behavior and demonstrated "with-it-ness." They combined a secure and supportive classroom environment with a strong academic orientation. Gibson and Dembo (1984) found no difference in use of time for academic and nonacademic activities, but low efficacy teachers spent $50 \%$ of their time in small group instruction compared to only $25 \%$ spent by high efficacy teachers in small groups. High efficacy teachers spent more time in whole group instruction, monitoring and checking seat work, and leading students to correct responses through questioning rather than giving answers or calling on other students.

Miller (1991) investigated the relationship between first, second and third grade teachers' sense of efficacy and individual rates of referral of students for special 
education services. Teachers described as high efficacy teachers according to their scores on the Gibson and Dembo (1984) Teacher Efficacy Scale referred fewer students than those who scored as low efficacy teachers. Follow-up interviews were conducted to obtain information about teachers' beliefs and perceptions about teaching. Results included:

- Teachers with high efficacy scale scores believed that good teaching can make a difference with all students regardless of external obstacles.

- Described a greater variety and number of teaching strategies overall and used more specific strategies with low achievers than did teachers with low efficacy scores.

- Used more positive and more academically-oriented language when describing low achievers or difficult learners and saw these students as wanting to learn and capable of learning. Low efficacy score teachers described these students as having "low motivation," "uncaring attitudes," "lazy," and coming from "parents who don't care."

- Articulated a stronger sense of responsibility toward the achievement of difficult learners than did low efficacy teachers. When asked about the cause of a student's not learning a skill, they tended to place the cause within the teaching; they responded by saying they were "not using the right method." 
- Displayed a willingness to persist when faced with difficult students and referred a student for special education services as a last resort.

- Tended to describe their principals and the central administration as supportive and helpful.

- Saw themselves being viewed more as professionals by the principal and by the community than did the low efficacy teachers.

- spent more time in instructional planning outside of school hours than did low efficacy teachers. obviously, teacher beliefs affect teacher behavior, which affects student performance, which affects teacher beliefs. Teacher attitudes about the learning potential of all students and the behaviors they demonstrate in the classroom are critical to both student and teacher success. Factors that contribute to the perceived ability of teachers to positively impact the learning of students help create a cycle of success for both teacher and student rather than one of continued failure. Restructuring efforts must be based on creating those conditions that positively impact teacher beliefs about their own abilities to make a difference with students in the classroom.

Teachers' perceptions of self-efficacy have been tentatively identified as an important variable in accounting for differences in classroom effectiveness 
(Berman et al., 1977). Teacher efficacy is related to such significant variables as student achievement (Armor et al., 1976), student motivation (Midgely, Feldlaufer, \& Eccles, 1990), teachers' adoption of innovation (Berman et al., 1977), classroom management strategies (Ashton \& Webb, 1986), and teacher encouragement of student autonomy, trust and responsibility (Ashton \& Webb, 1986; Barfield \& Burlingame, 1974). Efficacious teachers hold the belief that they can make improvements and consequently are receptive to professional development and willing to try innovations (Ashton, Webb, \& Doda, 1983). This latter concept is particularly important in terms of this research. Teachers who view themselves as efficacious may, in fact, be those most often seeking innovation or are willing to be involved with it. Such teachers may also be ones who are most willing to leave the comfort of the traditional classroom for a riskier or less familiar one.

Like individuals, workplaces manifest developmental traits. Many organizations, and perhaps most schools, require and reward conformity rather than independence. It is not coincidental that adults who demand a great deal of autonomy can find schools confining and may choose to leave. For some, schools can place a ceiling on growth. When that happens, seeking an alternate work environment, may be best... If we expect adults to grow, we must create contexts that support, encourage, and celebrate their development. What this means for individual schools will vary; what this means for all schools is structures and norms that encourage interdependence. (Levine, 1989, p. 270) 
Whether teachers actually leave the traditional setting for an alternative one or attempt innovation from inside, efficacy seems to be a characteristic of effective teachers worth studying. A sense of efficacy makes teachers believe they have the power within to change their world where it encompasses the classroom and students (Gibson \& Dembo, 1984). The more who are so convinced, the more likely educational reform will not only occur but that it will last. Fullan (1982) believed that "one of the most pressing needs in education is for teachers to have the opportunity to restore their sense of confidence, meaning and efficacy" (p. 129). Our ability to restore that sense of efficacy is critical if we are to retain professional educators who know how to make a difference and do so.

As part of their study of teachers' sense of efficacy, Ashton and Webb (1986) examined two schools--a traditional junior high school and a more modern middle school. The two schools had quite similar characteristics: each enrolled between 900 and 1,000 sixth, seventh and eighth graders. Each student body was composed of one-third black students and two-thirds white students. In each school, roughly 458 of the students were entitled to free or reduced-price lunches. The principal difference between the two schools was the way in which they were organized. 
The junior high was organized along traditional lines of grade level and subject area specialization. classrooms were grouped by department such that teachers had little or no contact with their colleagues who taught other subjects to the same students. In contrast, the middle school was organized into teams of four or five teachers who shared students in common. Each multidisciplinary team worked with 120-170 students in neighboring classrooms around common themes.

Ashton and Webb (1986) observed classroom instruction in each educational setting as well as decision making practices and the interaction of teachers. Their observations indicated that in general there was much more collaboration and exchange focused on instruction at the middle school. Teachers were less apt to share information or to be involved in professional dialogue at the junior high. The practices of the middle school reflected the norms of collaboration; the practices of the junior high school reflected the norms of isolation. Ashton and Webb (1986) cautioned that their study of these two schools did not set out to show that the one organization was better than the other; rather it was intended to be a means of developing a tentative hypothesis regarding the relationship between a school's formal organization or ideology and the teachers' sense of efficacy. In all likelihood, many junior high schools are 
highly collaborative organizations just as there are middle schools in which policy decisions are made by administrators working in isolation and classroom decisions are made by teachers working under the same limitations.

Although perception of self-efficacy is recognized as a significant variable in studies of instructional effectiveness (Guskey, 1987), little attention has been given to the nature of the variables that affect teacher efficacy or to the measure of the degree. According to Gibson and Dembo (1984), further investigation is needed to explore the relationship between teacher efficacy and such teacher characteristics as age, gender, experience, and grade level. Given the complexity of the school environment, an understanding of the organizational or situational factors influencing teacher efficacy such as involvement in decision making (particularly in the area of classroom, organization and management), degree of administrative support, availability of resource materials, and perceptions of collegiality is also important.

\section{summary}

Efficacy is a construct that requires further investigation, particularly within the context of school reform and innovation. For example, a four-year study 
conducted by Rand corporation of 293 local innovations funded by federal change agent programs (Berman \& McLaughlin, 1978 revealed that the three teacher attributes that most significantly affected program outcomes were years of teaching, sense of efficacy, and verbal ability. The authors found that:
years of teaching and teacher sense of efficacy had strong and significant, but very different, effects on most of the outcome measures. Specifically, the number of years of teaching had negative effects . . . The teacher's sense of efficacy--a belief that the teacher can help even the most difficult or unmotivated students- -showed strong positive effects on all the outcomes. Teachers' attitudes about their own professional competence, in short, may be a major determinant of what happens to projects in classrooms. (p. 32)

As a result of such findings, and the numerous studies that indicate that efficacy is an important variable in both student and teacher perceptions of success, it is important that school leaders involved with restructuring schools and researchers such as myself understand the role of efficacy in school restructuring and its potential as a factor in successful school reform.

Examining teacher efficacy within the context of a school undergoing major change--in governance, in cultural norms, in workplace conditions--seemed a promising study for purposes of my research. My personal interests and previous professional experiences led naturally to a desire to investigate efficacy "in the field," working with real teachers in a real setting where the outcomes of 
their efforts had the potential to make a difference for children. Bridgeport Elementary, a pseudonym for one of the schools involved in the Chenoweth and Kushman (1993, 1994) studies, provided just such a context--the opportunity to further explore the construct of efficacy within the broader context of a school undergoing organizational change.

Bandura (1977), who believed that efficacy determines how much effort people will expend and how long they will persist in the face of obstacles and aversive experiences, would have been intrigued by the teachers at Bridgeport Elementary school. Faced with a variety of obstacles and adverse experiences related to student success and community support, the teachers at Bridgeport were optimistic about the future since becoming involved in the Accelerated School Project. Their interviews with Chenoweth in winter 1993 were confirming, their responses analytical and wise. The relationship of the Accelerated School Project to their positive outlook presented an intriguing area for study. How could teachers in such a "tough" school seem so energized by the challenges rather than overwhelmed? Additional research on organizational change, the Accelerated School model, and the concept of teacher efficacy seemed warranted to help answer such questions. 
CHAPTER III

METHODOLOGY

Introduction

This study investigates the construct of teacher efficacy as related to changes in workplace conditions and organizational structure. It examines the perceptions of classroom teachers involved in a restructuring effort, specifically their own sense of teaching efficacy and the conditions of schooling they believe either promote or inhibit efforts to increase opportunities for student success. Teachers participating in the study were those involved in the second year of adopting Levin's (1989a) Accelerated School model in an urban elementary school in the Northwest.

This chapter reviews earlier case study research conducted at Bridgeport Elementary, the same site as the current study, and then outlines the basic research questions to be explored. A rationale for the research design and an overview of the data collection and analysis procedures follow. 
Research Proposal

This study examines the perceptions of teachers involved in implementing the Accelerated school model to determine the conditions that contribute to or impede their sense of efficacy. The elementary school selected for the study began its first year of Accelerated school training in April 1992 and was involved in the second year of project implementation during 1993-1994. Data collected during winter 1993/spring 1994 by this author were analyzed for purposes of this research.

The research already conducted in this area by Tom Chenoweth, Portland State University, and Jim Kushman, formerly of the Center for Urban Research in Education and now with Northwest Regional Educational Laboratory, informed as well as expanded this study. The chenoweth and Kushman (1993) study was conducted in three elementary schools involved in ongoing research related to the Accelerated School model and process, including the elementary school selected by this author for an investigation of teacher efficacy and the perceived conditions that foster or impede teacher success. The three schools, all part of the same urban school district, were often described as belonging to one of the city's most disadvantaged areas and long accustomed to student achievement scores in the lowest percentile ranks year after year. 
Chenoweth and Kushman (1993) used a qualitative case study methodology. The participant observation approach was also employed since both researchers were involved in the implementation process as facilitators. Data were gathered from committee meetings, observations of staff training activities and of school and classroom events, as well as from informal conversations with parents, staff and each school's principal. Background history and demographic information on the schools and neighborhood were also collected. The major source of data was obtained through a series of semistructured interviews with teachers from the three schools, each school principal, two school board members, and three key central office administrators. Data analysis was both descriptive and interpretive. Chenoweth conducted additional interviews during winter 1993, a process that helped to inform and shape the case study research related to teacher efficacy conducted by this author in spring 1994 . Results of the Chenoweth and Kushman (1993) study indicated that going through a common "courtship" experience resulted in some shared meanings among participants related to the Accelerated school philosophy. Nevertheless, some differences in perspective were apparent based on different organizational roles. Teachers, for instance, perceived the Accelerated School model as a potential solution to their everyday problems 
that "made their jobs difficult and that served as barriers to student success" (p. 19). On the other hand, principals and central office administrators were more concerned with the governance aspects of the model and how it helped to bring about school change. The study also revealed that:

principals were central in building commitment to school restructuring . . . and must be able to appear as knowledgeable, confident and possessing a "can do" attitude when it came to dealing with instructional issues and dealing with the central office. (p. 44)

Building on the work of others, this research focuses on teachers' attitudes toward school reform and on their perceptions of efficacy and the conditions necessary to create or enhance it. If teachers do not believe they can make a difference in the lives of children, the usefulness of any model, even the increasingly popular Accelerated School model, is questionable. With a "can do" attitude on the part of teachers, however, any model becomes a vehicle for change. Examining the perceptions of teachers involved in the Accelerated School process affords the opportunity to explore that experience with them and, most important, to gather information as to what factors contributed to or detracted from their sense of success.

\section{Research Questions}

The primary purpose of this research was to seek information from teachers involved in school restructuring 
as to their perceptions of efficacy and the workplace conditions they believed fostered a sense of success. A key assumption underlying the study was that because innovation is such hard and time-consuming work, teachers elsewhere might be encouraged to more readily adopt new practices if workplace conditions that were conducive to change could be duplicated and if those involved in change efforts such as those at Bridgeport indicated a greater sense of satisfaction and "making a difference" after restructuring than before.

A key area for investigation included why efforts to achieve substantive changes in school culture, school structure and classroom experiences for students were perceived as more successful in the Accelerated School model than in the traditional model in place prior to 1992. Many of the teachers involved in the study were classroom veterans of $20+$ years who had seen various "reforms" come and go, yet the earlier data collected by Chenoweth and Kushman (1993) indicated that these teachers were enthusiastic about their school, their restructuring efforts, and the Accelerated school model. The first sought to determine:

- What are the perceptions of Bridgeport teachers of traditional school organization and the need for school restructuring? 
Another perception to be explored was how the Accelerated School model contributed to teachers' attitudes about change and to their commitment to the process begun at Bridgeport and Levin's (1989a) Accelerated School notion of "little wheels" (small, dayto-day changes) occurring within "big wheels" (substantive changes that may take 5-6 years). Since the school involved in this study was in its second year of the process, an awareness on the part of both staff and community that change is incremental was also important to ascertain. For any change to be long-lasting and substantive in nature, staff must be committed to a spirit of inquiry and evaluation of effort--both take time. A second and third research question investigated:

- What are the components of the Accelerated school model that contributed to these teachers' perceptions of their ability to make a difference in their classrooms?

- What do the teachers involved in the Accelerated School model believe about the pace and scope of change at their school after two years of implementing a major innovation?

In addition, teacher attitudes and feelings about support for change, particularly their relationships with their principal, their colleagues and with the "central office," are critical if school boards and administrators are serious about sustaining a reform agenda. Those in 
positions of leadership ostensibly seeking to establish conditions that foster innovation can benefit from teachers' beliefs about the necessary support for change at the district, school and classroom level. Given the research on teacher efficacy and student achievement, it is postulated that increased teacher efficacy leads to increased student achievement that, in turn, increases teacher confidence and perceived ability to "make a difference." Identifying and then re-creating in schools the conditions that foster perceptions of high efficacy on the part of teachers are key to the success of current restructuring efforts. The fourth research question explored:

- What differences exist in perceptions of efficacy of teachers involved in implementing the Accelerated School model?

Finally, since efficacy is such a key variable in this study and proposed as one that is significant to the school reform agenda, a fifth research question was also posed:

- What factors influence feelings of teacher efficacy among teachers involved in implementing the Accelerated School model? 
Research Design

The research design was determined by the method of inquiry most appropriate to respond to each of the five research questions. Schatzman and strauss (1970) reported that $a$ :

method of inquiry is adequate when its operations are logically consistent with the questions being asked and when it adapts to the special characteristics of the thing or event being examined. (p. 7)

Given the nature of inquiry utilized in this study, a case study approach seemed most appropriate. An in-depth examination of the perceptions and attitudes of a relatively small group of teachers involved in a specific innovation resulted.

Yin (1984) maintained that:

studies which seek to answer "how" and "why" questions and are more explanatory in nature are likely to lead to the use of case studies, histories and experiments as the preferred research strategies. This is because such questions deal with operational links needing to be traced over time rather than mere frequencies or incidents. (p. 18)

Yin also believed that the case study is preferred in examining contemporary events when the relevant behaviors cannot be manipulated. There are, however, several traditional prejudices operating against the case study approach. These include:

- a lack of rigor in case study research; 
- a lack of generalizability to a broader population or different setting; and

- too much time required to collect and synthesize anecdotal data.

Yin (1984) had a counter-argument to each of these allegations but warned that good case studies are difficult to design and conduct. It is important to do so, however, for there are at least four distinct applications of well-designed case study research: (a) to explain the causal links in real-life interventions that are too complex for the survey or experimental strategies, (b) to describe the real life context in which the intervention occurred, (c) to benefit an evaluation by use of an illustrative case study of the intervention itself, and (d) to explore those situations in which the intervention being evaluated has not clear, single set of outcomes (p. 25).

Using a case study approach to investigate teacher perceptions of the conditions of schooling which either enhance or impede their ability to make a difference in the classroom was appropriate. Subjects were actively j.nvolved in implementing an innovation at the time the efficacy scale was administered as well as when a purposeful sample was interviewed. Further, there were not clear outcomes to be attained by means of the innovation--rather becoming an Accelerated school is more 
of a process than it is a defined set of practices easily recognized in all participating schools.

Miles and Huberman (1984) suggested six steps in developing a case study methodology: (a) formulation of the case study framework to provide boundaries for data collection, (b) selection of site(s), (c) development of methods and measures, (d) field work and field notes, (e) coding of field notes, (f) within case and between case analysis. In a slightly different approach, Yin (1984) maintained that there are five components of a research design for case studies. These include: (a) a study's questions; (b) its propositions, if any; (c) its unit(s) of analysis; (d) the logic linking the data to the propositions; and (e) the criteria to interpret the findings.

Elements from the case study approach advocated by both Miles and Huberman (1984) and Yin (1984) are used by this author to present and analysis data in Chapter IV. A preliminary description of the data collection procedures and a suggested strategy for categorizing teacher responses follow.

Data collection Procedures

As part of the ongoing study of change at Bridgeport School, Chenoweth conducted teacher interviews that were observed by this author during winter 1993. A number of 
questions were included in the structured interviews at the author's request that were intentionally designed to surface issues/values related to the concept of teacher efficacy. The intent was to determine the framework for a subsequent study of these same teachers focusing on perceptions of teacher efficacy and the workplace conditions that either impede or enhance teachers' ability to "make a difference" with children.

As part of the interview protocol (see Appendix A) Bridgeport teachers were asked to comment on their own feelings of effectiveness and whether they felt in control of student learning. The teacher responses to these questions could be classified in three ways: (a) teachers who felt powerful, effective, in control of the teaching/ learning process, and generally optimistic about the future; (b) teachers who felt some measure of control and efficacy, but also felt that external factors limited their control; and (c) teachers who generally did not feel in control of the learning process and felt rather pessimistic about the future. This pessimism centered primarily around possible district budget cuts that threatened both teaching positions and programs (Chenoweth \& Kushman, 1994).

Based on the teachers' responses to the efficacyrelated questions and research conducted in other Accelerated Schools (Finnan, 1994), the author determined 
that the current study would make use of an efficacy scale as well as data generated through focus group interviews and questionnaires to gather more information about individual teachers at Bridgeport, their perceptions of teacher efficacy and the conditions they believed were necessary to bring about school change.

In order to interpret these various data as presented in this chapter, it is important to recall that a reliable measure of the two most common constructs of teacher efficacy, general professional teaching efficacy (PE) and individual teaching efficacy (TE), was used with some modification for this author's research with Bridgeport teachers. Of the 30-item Likert scale developed by Gibson and Dembo (1984) for the purpose of measuring these two dimensions of efficacy, only 16 items were found by those researchers to be reliable. Those 16 items were used in this study, plus the two efficacy-related questions used in the early studies conducted by Rand Corporation (Armor et al., 1976; Berman et al., 1977):

1. "When it comes right down to it, a teacher really can't do much because most of a student's motivation depends on his or her home environment" and

2. "If I try really hard, I can get through to even the most difficult or unmotivated students." Two restatements of the Rand questions were also included as a means of measuring consistency of teacher response. 
This resulted in a 20 -item modified Gibson and Dembo (1984) scale.

The various data collected at Bridgeport included the following:

- All Accelerated School teachers $(\underline{N}=14)$ in the school were asked to complete a brief demographic survey pertaining to certification/years of experience/gender/age so that any differences in background characteristics could be identified.

- These same teachers were asked to complete the modified Gibson and Dembo (1984) scaled instrument to determine their "efficacy score," a source of valuable information about the teachers profiled in this study.

- Nine teachers $(\underline{\mathrm{N}}=9)$ of the fourteen teachers volunteered to participate in focus group interviews based on an adapted version of the protocol developed by Ashton and Webb (1986) to determine efficacy among middle school/ junior high teachers. Questions were designed to elicit teacher attitudes toward organizational and cultural conditions that either enhance or impede their own sense of teaching efficacy in an Accelerated School. Teachers were also asked to identify the factors at work within their schools that promoted or inhibited the following (Ashton, 1984):

1. a sense of personal accomplishment 
2. positive expectations for student behavior and achievement

3. personal responsibility for student learning

4. strategies for achieving objectives

5. positive affect

6. sense of control

7. sense of common student/teacher goals

8. democratic decision making

- These nine teachers were then asked to complete an open-ended questionnaire designed to elicit their beliefs and their reactions to statements about students, their probability of success, and the factors that influence them in the classroom.

- Next, these same teachers were invited to share their experiences and perceptions about Accelerated Schools and the evolutionary process involved in implementing change with other elementary teachers considering become involved with the Accelerated school Project at Portland State University. Teachers, both experienced in the model and those just learning about it, engaged in an open-ended discussion about the process, its positive attributes and its pitfalls.

\section{Data Analysis Strategies}

The predominant framework for this study comes from the four phase conceptual model of restructuring posited 
by Chenoweth and Kushman (1992) and Levin's (1989a) model for the Accelerated School process. It is the third phase of the restructuring effort, described as the changing school culture and structure, that is the focus of the case study involving teachers of varying degrees of efficacy at an urban elementary school involved in the second year of the Accelerated School process during 19931994.

Teachers were asked to complete a demographic survey and the Teacher Efficacy Scale developed by Gibson and Dembo (1984) to identify key characteristics and to measure two dimensions of efficacy: general professional teaching efficacy (PE) and individual teacher efficacy (TE). Because Gibson and Dembo found that acceptable reliability coefficients resulted from only 16 of the original 30 items, only these 16 items were used in the instrument adapted for this study. In addition, the two original questions used in the Rand studies (Armor et al., 1976; Berman et al., 1977) were included as well as a restatement of each to test the teachers' consistency of response.

Response to each item was along a 6-point Likert scale from "strongly agree" to "strongly disagree." The scale is generally scored so that the higher the score on an item, the more efficacious the respondent. In the case of six of the questions, however, the lower the score, the 
more efficacious the respondent. By relying on a composite score, determined by totaling all responses for a given participant, such variations are accounted for and an overall "efficacy score" for any one individual can be established.

In total, 15 of the 20 questions used in the modified scale were related to the concept of personal teaching efficacy (TE); 5 qquestions were designed to measure perceptions of general professional teacher efficacy (PE) . The "optimal" composite efficacy score, based on the lowest response to those questions requiring a "1" as the highest measure of efficacy and the highest response to those questions requiring a "6" as the highest measure of efficacy was 80 . Each participating teacher was thus able to be "ranked" according to his/her composite score relative to the optimal composite score and to be profiled in terms of whether his/her personal teaching efficacy differed from general professional efficacy and to what degree.

In a technique known as "pattern matching," Campbell (1975) sought a way to relate several pieces of information from the same case to a predominant theme or pattern of response. A related approach, one that is particularly useful in analyzing the data collected in this study, was taken by Greenwood, Olejnik, and Parkay (1990) who identified four different possible combinations 
of the two questions first developed as measures of teacher efficacy by the Rand Corporation (Armor et al., 1976; Berman et al., 1977):

- When it comes right down to it, a teacher really can't do much because most of a student's motivation and performance depends on his home environment.

- If I really try hard, I can get through to even the most difficult or unmotivated students. (Berman et al., 1977, pp. 159-160)

Because a teacher might view the world of teaching and learning as operating a certain way but may or may not feel personally capable of operating that way, the following four patterns of teacher attitude might emerge: (a) teachers in general cannot motivate students and I am no exception to the rule, (b) teachers in general can motivate students but I personally cannot, (c) teachers in general can motivate students and I am no exception to this rule, (d) teachers in general cannot motivate students but I personally can if I try hard (Greenwood et al., 1990, p. 102). Teacher responses to the Gibson and Dembo (1984) efficacy scale and to the focus group and survey questions were also interpreted relative to each of these four potential attitudes and presented as part of the teacher profile data described in Chapter IV. Nine participants also volunteered to participate in a focus group interview. The interview questions focused on issues related to perceptions of efficacy and conditions that promoted or restricted innovation. 
Questions concerning leadership issues were included as well. Because Levin (1989a) outlined the areas in which the Accelerated School is to impact existing practices, the researcher was also looking for evidence of ability to make changes in the areas of curriculum, instruction and school organization.

Interviews were semi-structured with an interview guide rather than standardized questions. The guide provided structure while allowing teachers to express their perceptions, attitudes and interpretations of the changes occurring in their school in their own words. Interviews were tape recorded and then transcribed into typed notes.

The data analysis consisted of distilling a large number of notes, issue by issue and case by case. Specific codes or code groups were identified in order to draw generalizations from the data for individual teachers as well as for the group as a whole $(\underline{N}=9)$. As noted earlier, the "four cell" coding process developed by Greenwood, Olejnik, and Parkay (1990) to characterize responses to efficacy-related questions was also useful in attempting to identify patterns of response.

The same approach was taken with the responses given to the open-ended questionnaire and observation data collected during the open-ended sharing session with teachers considering moving toward the Accelerated School 
model. Patterns of responses for individuals and for the sample as a whole were sought so that the generalizations could be made and further research suggested.

\section{Summary}

Kanter (1977) made the distinction between "the stuck and the moving." Thelstuck feel no sense of progress, growth or development so tend to lower their aspirations and appear less motivated to achieve. They tend to stay away from risks in the workplace and proceed in cautious, conservative ways. The moving, by contrast, tend to recognize and use more of their skills and aim for still higher aspirations. Their sense of progress and future gain encourage them to look forward, take risks and grow. The study provides some insight into how these innovators perceive their world and the workplace conditions that contribute to it. It focuses on seeking information from teachers involved in an innovation, information that helps us answer the following research questions:

1. What are the perceptions of Bridgeport teachers of traditional school organization and the need for school restructuring?

2. What are the components of the Accelerated School model that have contributed to these teachers' perceptions of their ability to make a difference in their classrooms? 
3. What do the teachers involved with the Accelerated School model believe about the scope and pace of change after two years of implementing a major innovation?

4. What differences exist in perceptions of efficacy of teachers involved in implementing the Accelerated School model?

5. What factors influence feelings of teacher efficacy among teachers involved in implementing the Accelerated School model? 
CHAPTER IV

\section{PRESENTATION AND ANALYSIS OF \\ DATA: TEACHER PROFILES}

\section{Introduction}

It is important to this research to describe the recent history of Bridgeport School, one of the lowest achieving elementary schools in the Northwest, so that the individual teacher profiles are presented within the appropriate context. A socioeconomic ranking of area elementary schools, based on factors such as student attendance, mobility, and parent education/income, reveals that the school is located in the region's most adversely impacted attendance area (Chenoweth \& Kushman, 1994). Within the school's attendance area lies the largest concentration of public-owned housing in the Pacific Northwest, apartment projects that primarily provide racially segregated housing for families whose children bring numerous social problems to the community and to the schools that serve them.

Despite a number of strong staff members and several instructional improvement efforts that had been undertaken at the school in the past, Bridgeport had remained one of the poorest performing elementary schools in its urban 
district. The school consistently scored, for example, in the lowest $5 \%$ in mathematics and reading at the third grade.

Selected school profile data published annually by the school district is presented in Table 1. The number of Bridgeport students enrolled in special programs is indicative of the special needs the children bring to school and the academic challenges they present to their teachers. ESEA Chapter I (Elementary and Secondary Educational Act, 1965), for example, uses a low-income formula to provide financial assistance to state and local educational agencies to meet the special needs of "educationally deprived children." Similarly, students are eligible for the Federal lunch program based on family income information supplied voluntarily by parents. Talented and Gifted, on the other hand, is a program for students who demonstrate exceptional abilities in the visual and performing arts and/or intellectual and academic areas. Enrollment in this program is conspicuously low. The English as a second Language or Bilingual Program is for students who do not speak English as their first language or for students who need additional cultural or linguistic support to be successful in the regular school program. Those eligible for special classes and services due to deficits in learning ability caused by physical, mental, emotional or other handicaps 
Table 1

Student Enrollment/Special Programs Data: Bridgeport Elementary School

\begin{tabular}{|c|c|c|c|c|c|c|c|c|}
\hline & \multicolumn{2}{|c|}{$1990-1991$} & \multicolumn{2}{|c|}{$\underline{1991-1992}$} & \multicolumn{2}{|c|}{$\underline{1992-1993}$} & \multicolumn{2}{|c|}{ 1993-1994 } \\
\hline & $\# / 8$ & of Total & $\# / 8$ & of Total & $\# / \%$ of & Total & $\# / \frac{8}{8}$ & of Total \\
\hline ESEA Chap 1 Reading & 116 & 43.08 & 130 & 42.98 & 72 & 24.28 & 78 & 25.28 \\
\hline ESEA Chap I Math & 114 & $42.2 \%$ & 136 & $44.9 \%$ & 64 & 21.58 & 61 & 19.78 \\
\hline Federal Lunch Program & 199 & $73.7 \%$ & 187 & $61.7 \frac{8}{8}$ & 244 & 81.98 & 243 & 78.68 \\
\hline Talented/Gifted Program & 16 & $5.9 \frac{9}{5}$ & 21 & 6.98 & 20 & $6.7 \%$ & 14 & $4.5 \%$ \\
\hline ESL/Bilingual Education & \multicolumn{2}{|r|}{0.00} & \multicolumn{2}{|r|}{0.00} & 3 & $1.0 \%$ & \multicolumn{2}{|r|}{0.00} \\
\hline Special Education & 24 & $8.9 \frac{9}{8}$ & 34 & 11.28 & 22 & 7.48 & 25 & 8.18 \\
\hline Total Enrollment & \multicolumn{2}{|r|}{270} & \multicolumn{2}{|r|}{303} & & 298 & & 309 \\
\hline
\end{tabular}


are served by special educators whose training and experiences help them meet the needs of these students. clearly the children at Bridgeport have unique learning needs which present teachers with challenges to be overcome or as overwhelming obstacles. The role that perceptions of efficacy play in determining differences in teacher attitudes about dealing with such learning difficulties is the focus of this study.

\section{Bridgeport Teachers: A Staff} in Transition

Earlier research revealed that five years ago teachers assigned to Bridgeport Elementary School felt powerless and had little hope of making a difference with the at-risk children whose family backgrounds (high poverty), community conditions (gang violence, drugs, crime), and disruptive school climate (no clear discipline policy) created a teaching situation that many teachers viewed as insurmountable. A sense of fatalism pervaded the school kept expectations at a minimum: At best, children could be kept under control and enjoy a safe environment during the day.

The school at this time was described as being in a "crisis mode" (Chenoweth \& Kushman, 1994). There was no real academic focus and little anticipation of student success. In the words of one Bridgeport teacher interviewed by chenoweth in winter 1993, "You hardly ever 
heard any positive talk about things we should be doing to make things better for the kids. It was just the problems, the day-to-day problems, the kids who were in trouble, the kids who were doing outrageous, wild things." It was within this context that Chenoweth and Kushman initiated a long-term research effort to examine the implementation of Levin's (1989a) Accelerated School model as a means of studying the process of organizational learning and its effect on school culture. These researchers developed a four-phase change model to describe the successful implementation of an Accelerated school: courtship, training and development, changing school structure and culture, and changing classroom practices.

In the first year of the longitudinal study, the 1992-1993 school year, Chenoweth and Kushman (1993) examined the "courtship" phase of the implementation process in which the initiators of the Accelerated school Project at Bridgeport engaged the school staff in a discussion of the need for change and worked with teachers to develop a sense of commitment to a major school transformation.

During 1993-1994, the primary focus at Bridgeport and other participating schools was on training and development, specifically helping teachers develop skills in teaming and group dynamics while using an inquiry 
process to identify and solve school problems. A secondary focus was on structural and cultural changes taking place within the school as new norms of collegiality and problem-solving were being established. It was during this second year of training/implementation that this author's research was conducted.

During the 1993-1994 school year the personnel assigned to the Bridgeport school included the following: 1 principal, 13 classroom teachers, 2 special education teachers, 4 educational assistants, 2 other certified (librarian; counselor), 1 secretary, and 3 cooks/ custodians. A staff population overview is presented in Table 2 .

The nine teacher profiles which follow serve as a means to analyze the individual data collected from the Chenoweth interviews in winter 1993; the demographic survey and the modified Gibson and Dembo (1984) efficacy scale administered winter 1993; and the focus group interviews, questionnaires and panel discussion completed in spring 1994. Each of the teachers, all participants in each phases of the research effort, is profiled in terms of his/her observations of the conditions that either constrain or support the classroom, perceptions of efficacy, and view of the Accelerated School model and the resulting changes underway at Bridgeport. The author has identified essential characteristics of each teacher and 
included in the analysis representative quotes and observations to illustrate the distinctions among each of these highly capable individuals, Given that these teachers are assigned to an inner city school with a population viewed as "high risk," their responses to their working conditions and to their students and community are particularly striking.

Table 2

Teacher Profile: Bridgeport Elementary School

\begin{tabular}{lcccc}
\hline Teacher & Gender & $\begin{array}{c}\text { Grade } \\
\text { Level }\end{array}$ & $\begin{array}{c}\text { Total Yrs } \\
\text { Exp/Yrs at } \\
\text { Bridgeport }\end{array}$ & $\begin{array}{c}\text { Highest } \\
\text { Degree } \\
\text { Held }\end{array}$ \\
\hline Sarah & Female & 1 & $21 / 5$ & BA \\
Gail & Female & $\mathrm{K}$ & $26 / 3$ & MS \\
Maria & Female & 3 & $24 / 7$ & MS \\
Anne & Female & $\mathrm{K}$ & $15 / 10$ & $\mathrm{BS}$ \\
Linda & Female & TOSA & $29 / 5$ & MA \\
Theresa & Female & $4 / 5$ & $10 / 2$ & MS \\
Brian & Male & $\mathrm{K}-5$ & $18 / 1$ & MS +45 \\
Marian & Female & Pre-K & $20 / 1$ & BA \\
Greer & Female & Sp Ed & $8 / 3$ & MS \\
Prue & Female & 1 & $5 / 4$ & MS \\
Paula & Female & Couns & $19 / 3$ & MS \\
Roger & Male & 2 & $13 / 8$ & BA +45 \\
Evelyn & Female & 5 & $9 / 3$ & MS \\
Emma & Female & K-5 & $18 / 1$ & MS +45 \\
\hline Note: ToSA is a & Teacher on special assignment.
\end{tabular}

The following profiles are presented using fictitious names in order to protect the identity of each Bridgeport teacher who participated in the study. Theresa, a 10-year veteran of the classroom, is typical of the Bridgeport 
staff. She is verbal, articulate, and more than willing to talk about her classroom and her perspective on recent changes at Bridgeport.

Theresa: Bridgeport is a "Goldmine"

Theresa is currently assigned to grades $4 / 5$ in a team teaching assignment with Evelyn. She is a $101 / 2$ year veteran of the elementary classroom with a number of years teaching in a Southern state, one in which the schools were clearly substandard to what she felt to be the quality program offered at Bridgeport. She has been teaching at Bridgeport for only $21 / 2$ years, but consistently indicated that she believed her school district and Bridgeport, in particular, "cares about all of its children, even in the inner city." She referred to teaching at Bridgeport as being in a "gold mine" as she was particularly impressed with the spaciousness of the classroom, the condition of the facility, and the ready availability of materials and resources. Theresa had recently obtained her Masters degree and viewed herself as "still growing" as a teacher.

\section{Conditions of constraint/}

Support

When asked if she perceived any constraints operating at Bridgeport that inhibited her ability to teach, Theresa could think of none other than money and the insecurity of 
being a relative newcomer in large school district facing budget cuts that might jeopardize her future employment. She also mentioned "lack of funds" as the primary problem facing schools today. She stated that no matter how hard teachers try, they seem to be viewed by the public as "not to be worthy of professional salaries." Other sources of frustration mentioned in both the questionnaire and the focus group were job security and budget cuts. clearly Theresa was worried about her future as a probationary teacher. Her prior experience in a school with few resources also made her anxious, likely fearing a return to a system that she viewed as having insufficient resources to meet students' needs.

Theresa spoke positively about her teammate, her principal and her colleagues. In some instances her statements reflected her belief in teaching as a calling, as a passion. She also indicated that as an AfricanAmerican teacher, she felt particularly supported as a positive role model for many of the children attending Bridgeport.

\section{Perceptions of Efficacy}

Theresa's cumulative efficacy score on the Gibson and Dembo (1984) scale indicates that she is one of the highest ranking teachers at Bridgeport. Her responses to the general teaching efficacy (PE) questions on the Gibson and Dembo scale and to the personal efficacy (TE) 
questions indicated a very small deviation from the optimal responses; in other words, she was high efficacy both in terms of her perceptions of the power of teachers in general to positively affect learning and high efficacy in her belief in her own abilities in the classroom. She would be categorized by Greenwood, olejnik, and Parkay (1990) as one who believes that teachers in general can motivate students and that she/he is no exception to the rule. "I can do it and so can you" is descriptive of Theresa's attitude as reflected by her efficacy score.

Theresa's comments from the focus group were illustrative of her strong belief in the power teachers have in affecting children for the better. She asserted that:

Many times we are it, and so the job we do, it is up to us. We cannot change home. We cannot change Mom and Dad. We can't change the problems they have. But what we can do is to try to teach them to be able to meet those challenges.

She viewed her principal as supportive but the district office as too far removed to be much of a factor in her perceived ability to do her job. She did speak, however, to the relative freedom she has in her current district to function as professional and to feel free to "teach through whatever: medium necessary, from whichever materials I can find, to meet that child's needs" rather than from a prescribed curriculum such as she has experienced in the past. In her previous school she felt 
the curriculum was "bad" and students' individuality was ignored. The focus was on failure rather than success.

View of the Accelerated

School Model

In the focus group interview, Theresa made the participants laugh when she described her early need to see the "notebook," the "recipe" for the Accelerated School model at the Daniel Webster School she visited in San Francisco. She spoke about her gradual realization that an Accelerated School was not predetermined but rather one in which you "literally have to work together to find out." She also asserted that an Accelerated School model would be a difficult assignment for a weak teacher who might survive in a traditional school because of his/her relative isolation. In the Accelerated School, however, "a lot of walls came down for me. It made me feel a lot more comfortable about reaching out and trusting other people." Theresa also spoke to the willingness of teachers at Bridgeport to share, to admit areas of weakness, and to ask for help--all new behaviors for her when compared to her former school and district. Theresa maintained that in that environment she, like most other teachers, was "scared to death for somebody to see what you were doing" and focused on "looking good for the principal and the parents." 


\section{A Characteristic Quote}

"I think it is an honor and a privilege to come to school and be dedicated to helping."

\section{Maria: Learning to Say "No"}

Maria has taught for 24 years, the last 7 years at Bridgeport. Her veteran status has given her an extraordinary wealth of experiences to add to the current restructuring effort underway at the school, but she also demonstrated many of the "typical" responses of teachers resistant to change as descrited by Rutherford (1986): Her attitude of "This Too Shall Pass" and "Why Change?" was apparent in most of the comments made in the focus group and in response to the questionnaire. Maria currently teaches third grade and holds a Masters degree.

\section{Conditions of Constraint/}

\section{Support}

Maria resented the number of curricular areas for which she was responsible and the fact that "people drop things on me without asking, "Are you doing this . . already? What do you think about it? Is it valuable?" When asked to identify the primary problem of schools today, Maria replied, "We're responsible for all things." On several opportunities Maria complained about the total number of students in her classroom, a problem compounded by students with special needs, and she felt strongly that 
she was unable to help her students to the degree she felt necessary given their skill level. Several times Maria pointed out the impossibility of attempting change given the lack of time and money to support teachers engaged in new practices. The most frustrating aspect of her job was:

the amount of time expected for me to put into this school. This is a tough school. I have a tough class. I have no time to teach. I spend most of my time managing rather than teaching.

Maria made no mention of support, even from the principal who was generally perceived by the other teachers as quite effective and very supportive of their efforts. She did indicate that she, as with most teachers, would appreciate more "pats on the back . . real simple ones. They (the rewards) don't have to be money; they have to be a little bit of respect."

\section{Perceptions of Efficacy}

Maria stated that she believed she was viewed negatively by other staff, and that the consensus model required as an Accelerated School was too time-consuming to be worthwhile. She believed that she could be more effective as a self-contained classroom teacher without having her time taken up by the many committee meetings and cadres required by the model. For her it is "easier to just raise my green card and go along," the green card being the way Bridgeport teachers signal they are willing 
to "go ahead" with an idea or proposal. At one point she criticized the District for imposing the Quest program on her despite her opposition. A concern she voiced several times, usually coupled with comments about lack of time to make change, was about not being paid for the planning involved for school-wide efforts. She mentioned that the training she received along with others in team building and decision making was inadequate.

Another theme in terms of efficacy was the genderbased issue of viewing teaching as "day care," a woman's role, and the perceived lack of any real power shift in the move to a more decentralized model of decision making at Bridgeport. She referenced "macho females" who were as offensive if not more so than their paternal, male counterparts and referred to the legislature and school reform in less than positive terms. Essentially, Maria would prefer to be left alone to work with her students in a manner she felt was more effective than the current model operating at Bridgeport.

It is important to note, however, that Maria's total efficacy score on the Gibson and Dembo (1984) modified scale was high, almost as high as Theresa's. Despite her "negative" outlook, Maria is a high efficacy teacher who sees both other teachers (professional teacher efficacy) and herself (personal teaching efficacy) as capable of effecting positive change in the classroom. Her 
negativity is not chronic or unfocused complaining about conditions that appear overwhelming; rather, her consistent message is that she wishes to be left alone in her own classroom to carry on with instruction as she sees fit. After 24 years in the classroom, it is not hard to understand that she might view the Accelerated School model as yet another panacea that will come and go.

View of the Accelerated School Model

Maria characterized herself as the only teacher at Bridgeport who voted against becoming an Accelerated School. She also stated that she believed she was intentionally excluded from attending the panel presentation at a neighboring district because she was too negative. She suggested that the parents on the video tape of Daniel Webster School in San Francisco were not "real" and that the camera crews should come to Bridgeport to take pictures of our "200 kids, most of whom have parents that don't care." Maria was particularly critical of the consensus model, not only because it was so timeconsuming, but because she simply used her green card to move the agenda rather than spend more time in fruitless debate. At Bridgeport, she told the author, "it's not okay to say no" to any idea generated by cadre or schoolas-a-whole committees. She suspected other teachers also just went along with group decisions because it was easier 
and obviously felt her opinions were not valued or respected by others.

\section{A Characteristic Quote}

"I just didn't buy into a five-year miracle deal. That Vera Katz--she's a hit and run lady."

\section{Sarah: In Touch with Basic Values}

Another veteran teacher, Sarah has 21 years in the classroom. She is currently assigned to first grade and has spent 14 years of her teaching career at the preschool level. Sarah was a particularly thoughtful individual, one who carefully responded to questions and who weighed the comments of fellow members of her focus group before offering those of her own. She appeared to be a "reflective practitioner," a teacher who had thought a lot about the changes at Bridgeport and evaluated current practices against those that went before. She was supportive of the present model and the principal and often coupled her observations about changes she had made professionally with observations about parallels in areas of her personal growth as well.

\section{Conditions of Constraint/} Support

Sarah described the previous atmosphere at Bridgeport School before they became an Accelerated school as one in which "you hardly ever heard any positive talk about 
things we should have been doing to make things better for the kids." By contrast, Sarah felt that current conditions had improved greatly. Whereas before she felt isolated and often withdrew to her own classroom because she thought she could not connect with her colleagues, Sarah shared how the climate of Bridgeport had changed to one of support and mutual inquiry. She mentioned, as did most of the teachers, the lack of time to adequately address the change agenda. Teachers who "do not deeply respect kids and their families" were another source of constraint in that they took time away from those who did want to focus on improvement and "find more ways to connect to individual students and families." Sarah spoke quite positively about the support she received from her principal, realizing that the principal "had an apparent lack of power, but that in reality she had tremendous power" in her ability to help others grow.

\section{Perceptions of Efficacy}

Sarah's cumulative efficacy score on the Gibson and Dembo (1984) scale indicated another high efficacy teacher. The difference between her professional teacher efficacy score (PE) and individual teaching efficacy score (TE) was so slight that she was the most "balanced" of all staff. In other words, she is closest to the ideal response in both efficacy dimensions, more so than any other Bridgeport teacher. She, like Theresa and Maria, 
falls into the Greenwood, Olejnik, and Parkay (1990) category of the teacher who believes in the power of teaching and in his/her own abilities as well. Based on her efficacy score, her attitude might be summarized as "I can do it, and so can you."

Sarah was realistic in her assessment that teachers must expect some failures, but she clearly believed in goal setting and collaboration as tools for effecting change. The newly-found sense of community she perceived as operating at Bridgeport was also responsible for "harnessing so much human power" and for "connecting with the really important underlying values of why we are here." Too many decisions were made at the district level that failed to consider the differences among schools. Learning to work collaboratively was hard, but overall Sarah felt that she was "seeing more of an impact now" because of the process she supported and wanted to be a part of rather than remain isolated in her own classroom with the door closed. She felt that she had little control over issues of budget or staffing, and she worried for colleagues possibly facing lay-offs, but within her own school, Sarah clearly felt in control of the instructional program and the progress of her students. 
View of the Accelerated

School Model

Like several other teachers, Sarah supported the emphasis in an Accelerated School on parent involvement and building on strengths rather than correcting deficits. She clearly believed that the model had "broken down barriers that had kept us spinning our own wheels." When asked to name the primary benefit of the Accelerated School model, sarah cited the creation of "a community of shared values that empowers everyone to work together for change." The Accelerated school model made a difference, she believed, because it "changes the way decisions are made. People learn how to work together." Sarah clearly supported the collaborative model of decision making and her colleagues involved in the day-to-day business of teaching school.

The model, because of its adaptability, was viewed as a vehicle for change rather than being perceived as a prescribed set of procedures and practices. It was about "coming together and the practice of helping everyone. By coming from within, it can really unify diverse people." Particularly striking in Sarah's comments were observations about her previously self-imposed isolation, a strategy she employed to avoid the frustration associated with teachers whose primary goal was not meeting the needs of students. She accomplished the one goal of reducing frustration, but her statements about her 
loneliness and isolation were poignant indeed. The Accelerated School model had "connected" Sarah and helped to make her whole.

\section{A Characteristic ouote}

"Learning to work collaboratively can be difficult, but it is very renewing."

\section{Linda: Accelerated School as Pandora's Box}

Linda is a teacher on special assignment, in this case a consulting teacher who was responsible for staff development, student discipline, and curriculum design. She has spent 29 years in the classroom, the last 5 at Bridgeport. Because Linda assisted with the staff development plan for the building, she had been involved in the actual training activities for the Accelerated School model and had worked closely with faculty at Portland State University to monitor changes taking place at Bridgeport as a result. She served as both a confidante and counselor to staff undergoing change as well as a supporter and advocate in disciplining students and providing the consistent response she felt was necessary for teachers to be effective in the classroom. Like Sarah, she was very thoughtful, very reflective and often quiet--listening first, speaking only after others had shared their points of view. 
Conditions of Constraint/

Support

Perhaps more than any other staff member, Linda

addressed the benefit of so many parents involved in the

school. There was no hesitation, she maintained, in

"calling home and getting them to come in and work as a

team." She spoke many times of the sense of community

that had developed at Bridgeport, a community based on

common interests and the Accelerated school slogan that

"Our parents send us the best children that they have."

Linda also identified collaboration as both a time

constraint and a time saver. She acknowledged that when

one worked with another person the work load in some ways

decreased and in some ways one became less efficient.

Most important, however, she noted that when working with

another individual, one's stress level decreased.

"Sharing the load" as she expressed it can help reduce

stress and make the business of teaching more enjoyable.

Linda differentiated between two kinds of support she felt

were necessary for teachers: one, the recognition that

what one was doing was being valued by colleagues and the

principal; and two, that there were procedures such as a

discipline policy that supported teachers as they

performed their work.

Constraints identified by Linda were unrealistic

expectations of teachers in terms of the amount of

material they were expected to teach and a central office 
too far removed from the classroom to be effective. Staff's inability to give criticism or negative feedback regarding a cadre proposal was another problem she identified. This references an incident earlier in the year when a cadre had developed an idea, put a great deal of time and energy into a proposal, and then felt humiliated and hurt by their colleagues who were less than enthusiastic when the proposal was brought forward.

\section{Perceptions of Efficacy}

Linda clearly felt that Bridgeport was having more of an influence over students and that teachers were helping more families outside the school program than before. She spoke quite sensitively about the students teachers believe they have failed to reach. She believed that students were influenced by all those they met in some way and that

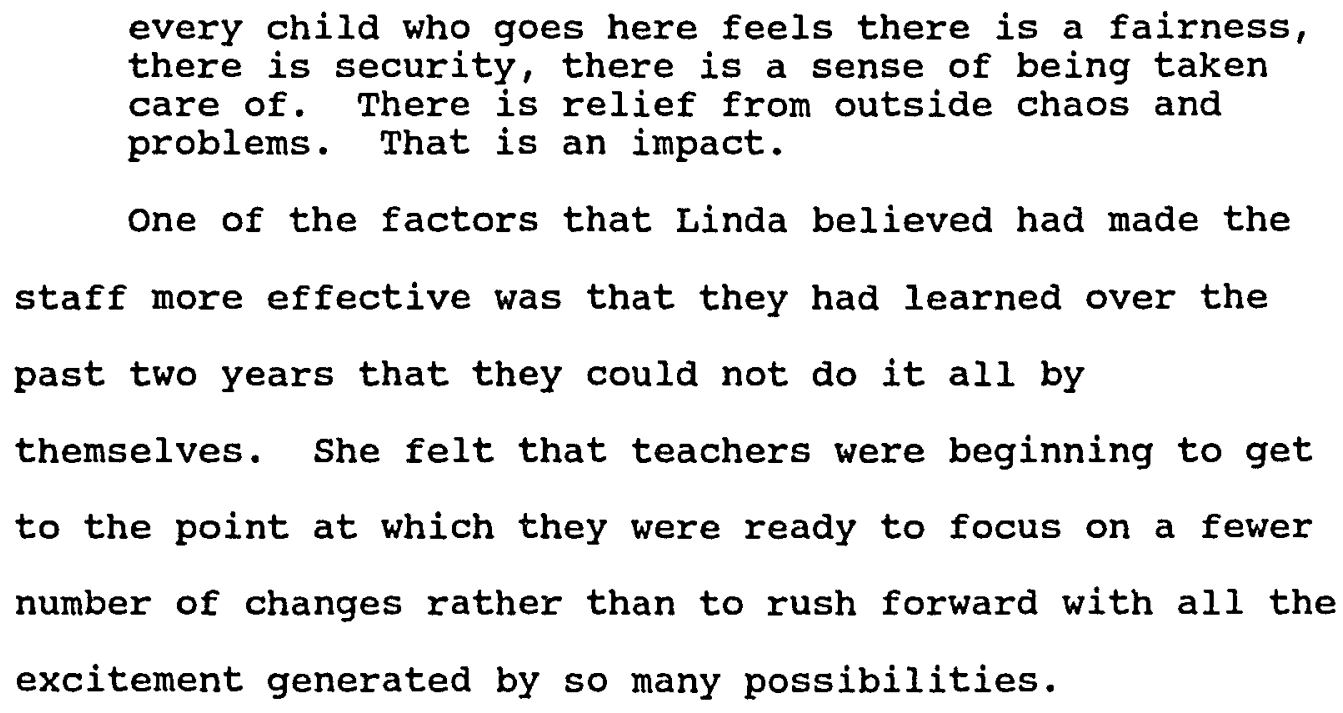


We've taken ourselves on as a community, and we've been thrown together in an incredible amount of meetings and the whole thing takes a lot of time. But the outcome is teachers talking to teachers.

Linda perceived the principal as another factor that helped staff be more effective. This individual was supportive, sympathetic, encouraging. Above all, Iinda realized, the principal had the hardest job of all: "She had to accept responsibility for making decisions but let go of making them." An astute observation, perhaps not surprising from one given to reflection and analysis. Based on her total points on the Gibson and Dembo (1984) efficacy scale, Linda joins Theresa, Maria and Sarah as one of the high efficacy teachers at Bridgeport who believes in herself and in the power of teaching to positively influence the lives of children.

View of the Accelerated School Model

Linda was supportive of the model for various reasons, not the least of which was "it is like a little seed. It makes a flower, whatever it grows--that's what your school will look like." She believed strongly that the Accelerated School model worked because it fostered collaboration, inquiry and dialogue. In the model, it was no longer acceptable to let others decide. She recognized that for years she had sat in faculty meetings and let other people make the decisions as long as she was left alone in her classroom to make her own. Linda 
articulated what several others mentioned as well: Everyone had to have an opinion at Bridgeport. Everyone was part of the process since there was no longer any place to hide.

The training conducted by Portland state staff had also helped teachers listen more and to be more observant of others' behavior, important attributes contributing to a successful consensus model. "We have to pay attention to individual differences" on the part of teachers who may feel uncomfortable or "exposed" now that the model has changed. Above all, Linda maintained that the school had become a community with teachers working together for the benefit of children. That did not happen in her previous school.

\section{A Characteristic Quote}

"Accelerated School is like opening up Pandora's box, good and bad. Everything starts surfacing and initially everyone feels they have to make all these mammoth changes. You surface all the problems . . . gradually you have to back off and give it time."

\section{Anne: Still Trying to} Get Somewhere

Anne is another experienced teacher with 15 years in the classroom, the last 10 at Bridgeport. She currently teaches kindergarten, and many of her comments in the 
focus group and in response to the questionnaire reflected her concern and anxiety about a pending decision to reduce from full-day to half-day kindergarten to save money. She had been at Bridgeport long enough to remember conditions before the implementation of the Accelerated School model, and she believed the recent changes had been positive. She was worried about budget cuts and increases in class size to the exclusion of almost all other issues at the time of the interview, however.

\section{Conditions of Constraint/}

Support

The anticipated loss of funds to support full-day kindergarten as well as the Accelerated school model was a major theme in Anne's comments. She spoke critically of the public and the District's failure to set its priorities appropriately. There were what she termed "overlapping questions" that created more ambiguity than she appeared to be comfortable with. The lack of time for meetings associated with cadre activities and class loads that were already too large were mentioned as well. The recent addition of a kindergarten student with Down's Syndrome generated a number of observations about special needs students and their proper placement.

\section{Perceptions of Efficacy}

The result of those constraints was "an overwhelming feeling, hopeless feeling" that led Anne to anticipate the 
following year as one in which staff would have to "try and do as much as they can, and work with the parents, and still try to get somewhere." She mentioned that there was a "feeling of just kind of waiting, or time-out, to see what is actually going to happen." The lack of certainty about the future was creating stress for all of them, she believed, particularly in that staff were aware that the current PE/music teacher was likely to be "riffed" and that the support for Accelerated schools was likely to be affected as well. "It's kind of frustrating," she noted, "when you put in all this time and effort."

Anne felt that she would be more effective in the classroom with more parental support. She maintained that it was not the teacher's fault if he/she failed to make progress with a student in that so many of the students came to school with low skills or as "drug babies." Having been at Bridgeport for 10 years, Anne had seen a marked increase in the number of serious problems students brought to school and mentioned several times the high number of children from dysfunctional families attending Bridgeport. She stated several times that the home environment was a major factor for the students at Bridgeport, one that limited the students' and teachers' ability to be successful.

Anne's perception of the principal was that she was supportive, and Anne felt free to express her own 
opinions, including disagreeing with a decision without fear of censure. A principal was necessary, she felt, and worked best when he/she was able to "give up authority and let others have a say."

She felt that the decisions made by the staff since the implementation of the Accelerated school model were good ones, but like the other Bridgeport teachers, she thought that the time required for meetings detracted from her effectiveness|in her own classroom as an individual teacher.

Anne was the only teacher to bring up the issue that a smaller faculty /were more impacted in that there were too few staff members to serve on multiple committees and projects. In a larger school, she noted, there would be more people to accomplish the work required.

Her efficacy score revealed great variation in her professional teaching efficacy score (PE) and her individual teaching efficacy score (TE) when compared to the optimal responses on the 20 questions of the Gibson and Dembo (1984) scale. Anne deviated from the optimal efficacy response in both efficacy dimensions, and as a result, she fit's none of the categories proposed by Greenwood, Olejnik, and Parkay (1990). Her attitude might be summarized more' as "I can do it if the problems can be solved, but you'don't stand much of a chance at all." Her varying scores on the efficacy sub-scales, when coupled 
with her low-efficacy comments in the focus group, reveal a teacher who is focused on the externals that she believes limit her effectiveness in the classroom, externals that may be exacerbated given the pending decision about kindergarten staffing.

View of the Accelerated School Model

Anne supported the model and the resulting changes in the decision making structure of the school. She did not think that the curriculum had changed significantly but that there was more recognition of both students and staff as a result of the model. She maintained that "we are committed to Accelerated Schools, and we like what has happened. But we need to cut back, to sit back and have a breather." She believed that she asked for help more often than she did before being involved with the Accelerated School philosophy and that there was "companionship before, but now we are more of a working group." She felt that any teacher could work in an Accelerated School, but that if he/she were not willing to put the time and commitment into making it work, it was a waste of time.

\section{A characteristic Quote}

"There is a great discrepancy between what happens for many of these students here at Bridgeport and what they experience when they return home after school." 


\section{Gail: Less is More}

As a kindergarten teacher, it was interesting to note that Gail mentioned none of the concerns voiced by Anne over pending decisions about a full versus half day program. She has taught for 26 years, the last 3 at Bridgeport, and her lack of tenure weighed on her mind more than program-related issues. Involved in the Masters program at Portland State University, Gail had focused on the Accelerated School model in a number of assignments, and she mentioned several times that she was seeing a gradual awareness on the part of faculty as to the benefits of the model.

\section{Conditions of Constraint/} Support

Gail cited the voting public and the state Department of Education as imposing constraints with which she struggled as a classroom teacher as well as lack of family involvement, funding and low staff morale. Bureaucracy at the District level was another source of frustration, and she expressed her dissatisfaction with her physical classroom several times--lack of color, poor lighting, etc. She felt unable to arrange her classroom environment so that it would better support learning. She believed the staff, however, was a major source of support in that Bridgeport teachers understood the need for building on one another's strengths in order to effect change. She 
mentioned the need for a discipline policy that was less negative in its approach to solving behavior problems, and the overall lack of time to both implement the Accelerated school model or to adequately address the needs of the students in her classroom. She wished for students who came to school "loved, fed and clean."

\section{Perceptions of Efficacy}

Gail felt strongly that her opinions were valued and her input important to the making of school decisions. Working with colleagues, including the principal, who had "no hidden agenda" was important to her ability to succeed as well as "open, two-way, respectful" communication. Several times Gail commented on the staff's growing acceptance of the idea that it was permissible to try a new idea and then discard it at a later date. "You can explore this idea, and it's not like forever. You don't have the sense that there is only one solution." She also noted the high sense of ownership that she and others had for decisions they had made, and she believed that "every single person is vested."

Gail mentioned, as did Maria, the gender-related issue of teaching as "women's work." The collegial atmosphere at Bridgeport had allowed Gail as a female to feel that she had strengths and that it was acceptable to have disagreements with others rather than experience a typical female need to "make everything okay." Her 
professional growth had created a parallel awareness in her personal relationships that were empowering to her as both a teacher and a woman.

As with Anne, Gail's efficacy scores from the Gibson and Dembo (1984) sub-scales dealing with perceptions of general teaching efficacy (PE) and personal teaching efficacy (TE) indicate +14 and -10 variations from the optimal response. She too defies categorization using the Greenwood, Olejnik, and Parkay (1990) model.

one might interpret Gail's score similarly to Anne's ("I can do it if the problems can be solved, but you don't stand much of a chance at all."), but her comments in the focus group and responses to the questionnaire send a more positive message than Anne. Gail appears to be more supportive of the Accelerated School model than Anne and less focused on the "negatives." It should also be noted that her efficacy score(s) indicate a lower perception of efficacy than her comments in the interview would support. The dynamics of a focus group interview versus an individual written response to the efficacy scale may be a factor. In an effort not to appear negative in front of her colleagues, or to "fit in" with the positive tenor of the focus group itself, Gail may have made comments that were more supportive than she really felt. During the focus group discussion of new group norms, Gail expressed sensitivity as to how difficult it was for a person to 
stand alone against the group when decisions were being made. In reality, she may have be experiencing that difficulty herself, one interpretation of the difference between her efficacy scores and her verbal comments while a member of the focus group.

\section{View of the Accelerated} School Model

Gail, like several others, noted the need to reduce teacher expectations as to what was possible within the first few years of the new decision making model.

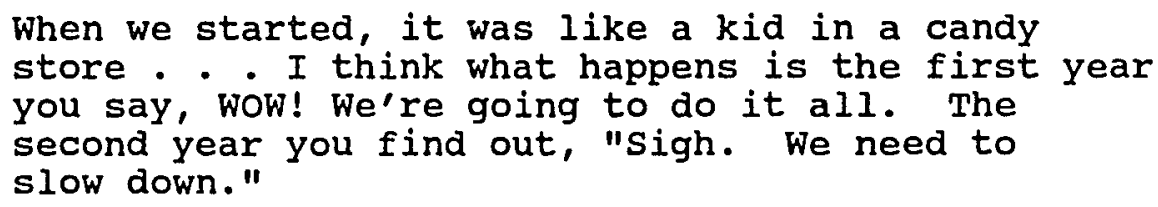

Gail, like Anne, mentioned giving oneself the "gift of time," allowing the gradual realization that "less is more" in terms of accomplishments with individual students and within the context of the school as a whole. She realized that the Accelerated school model was only a framework, a vehicle for change, and that the commitment to making collaborative decisions was time-consuming and sometimes difficult. "A person really has to stand on his own, in front of the group. It is very difficult," she maintained. She saw a great deal of progress at Bridgeport but also believed that the staff needed to work more on teaming skills and building a safe place for teachers and students to take risks. Above all she 
cautioned that an Accelerated School would make one rethink and change, processes often difficult and lengthy.

\section{A Characteristic Quote}

"From what I've seen in other places, when a decision comes from the top down, unless you really buy into what is being said, you buy out."

\section{Greer: Together You Can Make a Difference}

Greer's teaching assignment was to provide special education services to students through a combination of "pull-out" and inclusive interventions. Greer was relatively new to the profession, especially compared to other Bridgeport staff: $81 / 2$ years as a teacher with the last $31 / 2$ years at Bridgeport. Her Masters in Special Education, plus her classroom experience, had made her an advocate for the inclusion model for special education students, and she resorted to "pull-out" only with younger children under limited situations. Since teachers at Bridgeport were so willing to share students and to group them flexibly across classrooms, Greer appreciated being able to meet her students' needs in the regular classroom, a fact she mentioned several times throughout the interview. 


\section{Conditions of Constraint/}

Support

Greer felt that teachers, in general, were dictated to by the District and "non-educational type" principals who saw teachers as pursuing a vocation rather than a legitimate career path complete with professional stature and respect. Being a successful teacher was the combined result of dedication, flexibility, creativity and high expectations--conditions Greer believed were operating at Bridgeport. She felt that there was too much emphasis at Bridgeport on not "rocking the boat," giving the examples of needing to deal with weak teachers or inconsistencies in the school-wide discipline procedures. Not addressing such problems, she felt, made her job more difficult. This fear of confrontation was mentioned also in the context of some teachers being afraid of parents and of students themselves, two conditions she found difficult to deal with in a school committed to change. She had come to see parents as important resources, seeing them now more as "allies and peers rather than victims or villains."

\section{Perceptions of Efficacy}

Greer felt that she had little influence over the socio-economic status of her students which she viewed as so limiting of their life choices or the dysfunction she believed characterized many of their families. She 
indicated a need for a supportive principal, one with whom she had a relationship based on professionalism and the sharing of power. She viewed her current principal as supportive but indicated that more time to work collaboratively, to address the abuse issues she felt were prevalent at Bridgeport, and to reflect on current strengths would improve her ability to do her job successfully. Like the other teachers at Bridgeport, having more time was viewed as critical. Recognizing that teachers were "separate units in a traditional system," Greer identified a need to confront one another as teachers rather than saying "That's not my responsibility. That's the principal's job." The changing workplace conditions at Bridgeport were positive, but the need to advance to the point of dealing directly with one another around professional behavior was a necessary next step in terms of truly empowering staff to make changes. Greer viewed teachers who did not "buy in" not necessarily as subversive but rather she believed they felt more comfortable, safer in their own classroom than in dealing with peers.

Greer's overall efficacy score as measured by the variation of the Gibson and Dembo (1984) scale indicated a medium ranking. She had only slight variance when compared to the ideal general teaching efficacy score (PE) but viewed her own skills as less than adequate (TE) . 
Based on her efficacy scores, she would be categorized by the Greenwood, Olejnik, and Parkay (1990) model as Low TE/High PE, a category characterized by an attitude such as "I can't do it (be that effective), but you can." Her verbal responses in the focus group interviews and her written answers to the questionnaire reveal her to be more attuned to the power issues implicit in the traditional school organization, a factor that may explain a lower personal efficacy score. It may not be that she views herself as lacking the necessary skills to be effective but rather that she perceives herself as politically ineffectual within the larger hierarchy.

View of the Accelerated School Model

Greer mentioned several times the importance of the current principal to the success of the Accelerated School model at Bridgeport. "She doesn't take things as a personal affront to her authority or power. She just sees them as problems to be worked out." The principal was able to let go of decisions and accept that "It's like the structure has the authority here," a reference to the decision making model and the role of cadres in setting goals and direction for the school. Greer is committed to the collaborative model and spoke about the limitations of time less than any other staff member. Her focus was much more on the power of working together to set high 
expectations for students, for parents and for teachers themselves.

Her advice to teachers in a neighboring district considering a move to the Accelerated School model was also reflective of her view of the changes at Bridgeport: "It's worth the investment, even if you are nervous about having no blueprint."

\section{A Characteristic Quote}

"Obviously you have to assume you are making an impact or else why are you getting up and going to work every morning. You have to have that faith."

$$
\begin{gathered}
\text { Roger: On the Lookout } \\
\text { for Change }
\end{gathered}
$$

Roger was the only male out of two on staff who volunteered to participate in the focus group interviews and to complete the questionnaire. With 13 years of experience, the last 8 at Bridgeport, Roger was the one teacher profiled who was looking for a change. He had not expressed a desire for a possible reassignment to his principal, and had some trepidation about doing so in that he did not want to appear dissatisfied, but he had been at Bridgeport long enough to realize he did not want to finish his career there. He enjoyed the Accelerated School process and being on the cadre, in particular, but Roger was a teacher always looking for change. He felt he 
needed "to experience another school, a different type of child to work with, a different economic climate."

\section{Conditions of Constraint/}

\section{Support}

Roger spoke several times about the time-consuming nature of the Accelerated school model and how difficult the time constraints made his job in the classroom. He believed that the enormous amount of effort the consensus model required was creating some degree of teacher "burnout" and causing some teachers to raise their green card "just to get it done." Holding up the green card was how Bridgeport teachers signaled their willingness to support a staff decision. Like Maria, he was skeptical of the benefits of so much time required to support such a slow pace of change. He also expressed frustration that the training schedule moved too slowly and held back some teachers, such as himself, who had had extensive experience in team building and consensus models of decision making.

\section{Perceptions of Efficacy}

Roger's efficacy score based on his responses to the efficacy scale was at considerable variance from the ideal score. He was, in fact, the teacher with the lowest efficacy score at Bridgeport. His responses to the questions associated with general teaching efficacy (PE) were solely responsible for his low ranking; his personal 
teaching score (TE) was optimal with no variation from the ideal. Roger is a teacher whose efficacy score indicates he is quite confident of his own abilities in the classroom but who has little or no confidence in his colleagues to make the appropriate interventions to effect learning. His attitude might be expressed as "I can do it, but you certainly cannot." He scores as a low PE/High TE teacher, but like Gail, his verbal remarks indicate much more of a collaborative bent than his efficacy scores support.

Perhaps his sensitivity to his standing in the group influenced his responses during the interview. Another interpretation might be that Roger, who came across as more of a loner, believed in the Accelerated School process more for political reasons than he did for personal benefit. He was the only teacher who did not specifically mention the need for or appreciation of support from colleagues, a fact which is consistent with his efficacy scale results. He viewed himself as in control of the instructional decisions made in his classroom, and he emphasized the dynamic nature of everassessing and modifying his approach to teaching and learning. His focus was his individual classroom and the empowerment that resulted for the school from the Accelerated School model, but he did not offer examples of 
how any of the changes at the school had benefitted him or his students directly.

\section{View of the Accelerated} School Model

Roger, like Maria, voiced the opinion the Accelerated School structure had taken on a life of its own, and that it was "not an option not to participate or form a new committee whether we feel the need to move forward with the new idea or not." He felt that some of the earlier committees might have been more vital in that they were based on common needs and the most pressing concerns of the school as opposed to the current committees now searching for problems to solve. He was, however, very positive about the Accelerated School model, particularly the cadre which he felt had become the focus of the school where real decisions were being made. Roger, like almost every teacher, expressed support for the current principal and recognized the balance she brought to the issue of who controls the decision making process. He felt that the person in that role must be someone who "is able to delegate and let go." He voiced the opinion that ultimately a staff could run an Accelerated school without a principal at all, but that the relationships necessary to support that model at Bridgeport were not yet fully developed. 


\section{A Characteristic Quote}

"A teacher should always be willing to look at another program, another answer, another approach --always looking for something new."

\section{Evelyn: Bridgeport as Sanctuary}

Evelyn was in her ninth year of teaching at the time of this research effort, teaching 5 th grade at Bridgeport for the third year in a row. Evelyn's responses to the Gibson and Dembo (1984) survey were of interest in that she made comments indicating frustration after almost every question and edited the language of the questions themselves. She ultimately chose not to answer 4 of the 20 questions. She apparently thought there were clear "right and wrong" answers which she could not provide or the questions lacked enough clarity for her to be able to appropriately respond. Evelyn also was the only teacher who pointed out that she had asked to come to Bridgeport because she wanted to work in a low-income school. Evelyn was involved with Theresa in a team-taught $4 / 5$ combination classroom.

\section{Conditions of constraint/} Support

Evelyn addressed the issues of pending budget cuts as well as the time required to make the consensus decision making model work. Overall, however, she was the most 
positive personally about Bridgeport, citing many examples of support she felt as a teacher and for students in general. She felt energized by the realization that she no longer had "to do it all" because the collaborative structure meant that someone else would take responsibility for projects and activities that formerly she felt she had to forego. She perceived that she could go to others for help with a problem or a difficult child and not be the odd person out. "There is a sense of everybody taking care of each other." This was a common theme expressed by Evelyn, and her teaming with Theresa was another major factor in her positive outlook on the students and the school.

\section{Perceptions of Efficacy}

Evelyn offered comments, as did Gail and others, of the effect the Accelerated school model had had on her as a woman. "We don't always take responsibility, and especially being women, we don't always speak our minds. We're used to letting other people decide for us." She believed that teachers at Bridgeport were experiencing much more power, the power to use what they knew, to share that information, and to model effective teaching for the community at large. Feeling that power allowed Evelyn to "be assertive without being aggressive."

The collaborative conditions at Bridgeport had allowed Evelyn and others to "take a risk in saying what 
you feel and how." Evelyn recognized that change was easier for some than others, but she spoke about helping teachers who might feel that they needed more time on an issue or did not quite understand the implications of a decision. In the traditional hierarchy that Evelyn described as operating in most schools, "We turn our backs on people who are struggling a bit harder. Here we keep on offering support."

Evelyn's efficacy score on the Gibson and Dembo (1984) scale was much lower than the score associated with the ideal response. The four questions she chose not to answer were not included in the computation. Her general teaching efficacy score (PE) varied only +2 from the ideal response, but her personal teaching efficacy score (TE) varied by -18 points from the optimal score. Evelyn's efficacy score indicates that she is a high PE/low TE teacher, almost the opposite of Roger. She views others as more powerful than herself when it comes to classroom effectiveness. "You can do it, but I can't" is one way of expressing the view of a teacher who fits in this category (Greenwood, Olejnik, \& Parkay, 1990).

Such a pattern is consistent with her verbal responses to the focus group interview questions and the questionnaire: She feels the need for a great deal of support from her colleagues in order to feel successful. The Accelerated School model had perhaps provided her the 
opportunity to reach out to colleagues, and her positive statements about the model sounded almost like slogans. She was a convert and a believer because the model had allowed her to no longer face her own inadequacies as a teacher in isolation and fear.

\section{View of the Accelerated} school Model

The model had brought many positive changes to the school, but the process was still evolving. Evelyn thought they were getting better at "looking at people who hold up the red card," but that without building a safe environment before starting the Accelerated School process, the staff would go back behind their closed doors. She also spoke to the requirements for a principal working within the model--the principal could not be one is treated staff and children as if "the school was theirs, that it did not belong to the community." A major strength of the model was its focus on collaborative decision making but also its emphasis on involving parents and bringing the community into the school. Evelyn viewed the Accelerated School model as effecting positive change for herself as a professional and as a female. The training had equipped her with new skills that extended into her personal realm. As a result, she was among the most avid supporters of the model and the changes that had occurred at Bridgeport School. 


\section{A Characteristic Quote}

"We have so many good things here that we have something to fight for. We also have some things that can't be taken away."

\section{Summary}

Each of the Bridgeport teachers profiled in Chapter IV has a unique perspective on the conditions of schooling he/she feels are necessary to support both professional and personal growth. of interest also is the highly individualistic nature of perceptions of efficacy and that perceptions about other teachers (general teaching efficacy) and self (personal teaching efficacy) in terms of their effectiveness in the classroom are independent rather than interdependent variables. In other words, a teacher can feel confident about his/her own skill but not confident in the abilities of others as representative of the profession as a whole or vice versa.

There are, however, commonalities across the nine teachers that deserve discussion, as well as implications for school leaders involved with school reform that should be identified. Chapter $\mathrm{V}$ focuses on trends and generalizations about efficacy, the Accelerated School model, and the conditions that support change that result from looking at respondents and the data generated across the group as a whole. Chapter VI includes recommendations 
for school leaders striving to effect change within the school setting based on what Bridgeport teachers and related research reveal and make suggestions for further research. 


\section{CHAPTER V \\ PRESENTATION AND ANALYSIS OF DATA: \\ TEACHERS AS AGENTS OF CHANGE \\ Introduction}

The nine Bridgeport teachers who participated in all phases of the research effort speak clearly as distinct individuals with different perspectives on the Accelerated school model, the process of school restructuring, and the personal and professional changes that they perceive have occurred as a result of undertaking a major school improvement effort at their'school. Their perceptions of teacher efficacy and the factors that either impede or promote their individual sense of success are particularly important in terms of the focus of this study. After one analyzes the data, however, it is apparent that there are both individual differences and commonalities in teachers' perceptions which are worthy of note.

Information from the modified Gibson and Dembo (1984) efficacy scale, the demographic survey, the focus group interviews, the questionnaire, and the panel presentation involving teachers from another|district considering the Accelerated School model is abstracted in this chapter to 
form a total group portrait of Bridgeport teachers. By summarizing the responses to the various data collection efforts, inferences can be made that can inform the work of those at Bridgeport presently involved in implementing an Accelerated School model as well as others who may be contemplating a future restructuring effort.

A key assumption underlying this study is that because innovation is such hard and time-consuming work, teachers elsewhere might be encouraged to more readily adopt new practices if workplace conditions that were conducive to change could be duplicated and if those involved in change efforts indicated a greater sense of satisfaction and "making a difference" after restructuring than before. The lessons learned at Bridgeport can inform the efforts, therefore, of those who hope to create a climate that fosters positive change.

The data from which those lessons can be drawn are organized around the research questions and presented in terms of key findings and a summary relative to each of the five questions.

\section{Key Findings Related to Research Question \#1}

What are the perceptions of Bridgeport teachers of traditional school organization and the need for school restructuring? 
External Mandates Inhibit

Professionalism

None of the nine Bridgeport teachers participating in the study spoke in support of traditional school

organization. Whether prior experiences occurred in Oregon or elsewhere, each had stories to share that illustrated the inflexibility of a system they felt failed to meet the needs of children. Particularly in the area of prescribed curriculum and assessment, Bridgeport teachers stated that they had been the victims of the central office and state mandates that resulted in programs and practices that were not only inappropriate but that violated their professional judgement as well. A typical story inevitably used such terms as "top down" or "bureaucratic." Forced use of basal readers, the Quest Program, and legislative mandates concerning a prescribed "scope and sequence" were cited as examples. Whenever a practice was required by those outside the school, teachers seemed to feel that it was almost always misdirected or misapplied.

All Bridgeport teachers, regardless of efficacy ranking, cited examples of both personal and professional frustration at decisions made by others too far removed from the realities of the classroom. What was lacking, according to these teachers, was professional respect and trust that would allow teachers at the school level to make their own classroom decisions about the materials and 
skills most appropriate for their students. Bridgeport teachers are experienced teachers, and none was naive enough to believe that each school could function independently of the politics they believed were often involved in decisions ostensibly made for educational reasons. All, however, believed that a better balance could be achieved by the district role being limited to setting broad requirements and guidelines within which individual schools and teachers would work. That was not the current situation as they perceived it.

Documentation for Failure Promotes Compliance Rather

than Growth

Extensive documentation of student deficiencies, particularly in the area of reading, resulted in one teacher's complaint that she was so busy documenting failure that she had no time to teach the skills her students lacked. Theresa maintained that:

The curriculum was bad. The kids' individuality was ignored. Teaching reading with crazy things like basals and phonics workbooks and the principal was the big father deciding everything, mainly the curriculum. They way the kids had to learn seemed rotten to me.

The focus on documentation led several teachers to observe that much of their past teaching was spent in trying to "look good" for the principal, the parents, and in front of colleagues. Teachers were not following the goals to serve students better or because the goals were 
instructionally sound; rather, several Bridgeport teachers referenced "trying to protect oneself" from the principal who was likely to call the teacher on the carpet or from parents who needed to feel comfortable that the prescribed learning was taking place in the classroom.

Teachers Have No Real Professional status/Role

Frequent criticism of the traditional hierarchy in which a central offices dictate to building principals who, in turn, direct teachers to implement programs, materials and new directions in "their" school was also voiced. Bridgeport teachers felt that their input in the past had had little impact or that decisions were made that they could not support. If they wanted to "move up the ladder," presumably into the few positions of leadership available to classroom teachers such as a grade level leader or curriculum facilitator, they had to "play the game." They learned to fake compliance, to act, for example, as if they had been "doing" whole language for years. They went through the motions of appearing innovative and forward thinking, at least in terms of the latest fad. The other course of action, one that several teachers mentioned as a viable alternative, was to withdraw into their own classrooms to affect learning as best they could. Recognizing that teachers operated as "separate units" in the traditional structure, Bridgeport 
teachers were well aware that the price for independence

was isolation. Sarah shared the following:

When I first came into teaching I felt I was an outsider in a system that was crazy, you know? And I just wanted to keep as much independence as I could so I could do my little thing. And maybe gradually the system would change.

Having few, if any, collegial interactions that were professionally or personally sustaining, especially given the competition implicit in the need to "look good" and make parents want their children in a teacher's classroom, Bridgeport teachers referred to their relationship with previous principals as important yet detrimental since they were more often treated as a subordinate rather than as a colleague. Again, descriptors such as "top down" and "paternal" were frequent.

Several teachers raised the issue of teaching being perceived as a female occupation, one closely akin to day care. They spoke of what they perceived teachers to be: products of a socialization process that made them reticent about making waves and prone to keeping the peace, even at the cost of effective teaching. Their role within the traditional system, of being ignored as if they had no professional expertise, was reinforced by the school organization itself. Theresa, for example, came from a system is which she was told "This is your curriculum. This is what you will do, and there was no deviation from that." 


\section{Summary}

The need for restructuring was expressed by Bridgeport teachers as implicit in the educational system. Their past experiences were negative in that they had come up against a powerful organizational structure that disenfranchised them as professionals. Their criticism of local constraints was not as frequent nor as emotional as when they talked about the politics of education in general or the personal experiences they had had in the past.

surprisingly, only a few comments were made about recent Oregon legislation to create "Schools for the 21 st Century," including one by a teacher who referred to vera Katz as a "hit and run lady." The Bridgeport teachers did not raise the issue of local reform other than in reference to the multi-age classroom, one way to address the need for developmentally appropriate practices promoted in the oregon legislation. This organizational change was being considered at Bridgeport, but the teachers had determined the previous spring that they were not ready for implementation without additional study and extensive discussion of the impact on teaching and learning. One explanation might be that the teachers were so involved with the changes underway at Bridgeport as a result of implementing an Accelerated school model that they had little time or interest in contemplating other 
innovations being directed from "outside" their own environment. The teachers who had "lived and breathed" the Accelerated School model for over two years were immersed in the model and totally involved in the changes underway at their own school.

There was more criticism at Bridgeport of the textbook adoption practices at the local level than there was of state mandates, at least at the point in time that the interviews and questionnaires were completed, and even that was not widespread. Lack of funding, however, and the budget cuts resulting from the shift in school funding from local property taxes to the state legislature was a topic that engendered a great deal of frustration, a topic examined later in discussion of factors associated with teacher efficacy.

Perhaps the lack of local criticism was due to the school district's support of the Accelerated School model at Bridgeport by means of increased financial assistance and public recognition of the academic progress being demonstrated by students at the school. This positive relationship may have muted the criticism of the central office as part of the overall "system" that the teachers felt inhibited them as professionals and which they criticized more soundly as it existed elsewhere. 
Key Findings Related to Research Question \#2

What are the components of the Accelerated school model that have contributed to these teachers' perceptions of their ability to make a difference in their classrooms?

The Accelerated School Model

is a Means to an End

There was a great deal of discussion among teachers within each focus group and with teachers from the neighboring school district considering the Accelerated School model concerning the various components of the model, the training required in order to become an Accelerated School, and the various highs and lows experienced by Bridgeport teachers over the past two years. There was universal agreement among Bridgeport teachers that the model was not a "recipe" nor was there a blueprint for change. The model was only a means to an end, a vehicle for discussion and direction set by an individual school staff.

Teachers from the neighboring district asked many concrete questions, obviously used to new programs and models that prescribed steps along with flow-charts and timelines to be followed. They were warned that the Accelerated School model can be frustrating to those that want "answers" before they start. Theresa described her experience as follows: 
There's no model for saying you do this, this and this and you'll have an Accelerated School. You literally have to work together as a team to find out what should your school looks like as an Accelerated School. I had the opportunity to go to the Daniel Webster School and I kept saying, "When are they going to fix up a notebook with all the directions?" "I don't understand what you have to do. Where's the little paper?"

It was clear that Bridgeport teachers understood that becoming an Accelerated school was a process rather than a program, a process that took a great deal of commitment and time because as Linda believed, "It's about teachers talking to teachers, teachers talking to kids, and teachers talking to parents." Maria, often critical of the decision making process and the staff in her focus group comments, also appreciated that the strength of the model lay in its flexibility:

I think an Accelerated school is just a method really to enable teachers to come up with ways that enhance learning and self-confidence of children. It's not a program. It's a process really, a philosophy. It is not a product.

\section{Training in Group Process} Skills is Critical

Another benefit of the model voiced by almost all participants was the training required for all staff prior to making decisions about the future direction of the school. Training in team building and consensus decision making was viewed as critical to success, and the preliminary steps required prior to goal setting were also important. Participation in the "Launch," "Taking stock," 
"Building a Vision," "Setting Priorities," "Creating Governance structures," and "Inquiry" was important to help teachers understand the complexity of the issues they would confront as well as the diversity of staff. The fact that these teachers are, as a group, given to reflection and analysis of both their behaviors and that of their students, means that their praise for the training is important to note.

Teachers recognized that without training in team dynamics, the model would fail. Several expressed the need for further inservice, particularly more refinement of skills in ways to deal constructively with conflict and with "weak teachers" now that they were two years into the process. Two teachers, Roger and Maria, expressed frustration that all staff had to participate in the same inservice activities regardless of experience or prior training in teaming skills. Roger maintained that the training schedule itself was too slow.

Building on strengths/Unity of Purpose are Effective Strategies

Another positive characteristic of the model mentioned often was its insistence on learning to "build on strengths" rather than focus on student deficiencies as in a traditional school. High efficacy teachers, of course, generally see the possibilities or the strengths rather than the obstacles already, but at Bridgeport 
almost all teachers use the phrase "Building on strengths" when they speak of students or the community as a whole. It is one of the slogans those trained in the model learn to use often. Building on strengths entails identifying the skills and interests of every individual child; it means finding ways to entice parents, many of whom have been disenfranchised themselves by a traditional model of schooling, to come into the school to work in partnership with teachers to better meet the needs of their children. The teachers visit homes, go into the community themselves, and begin the school year by conferencing with parents as to each child's positive attributes. The payoff was universally viewed as well worth the extra time and effort. Even Maria believed that the parents were "happier with the school than in the past."

A number of teachers also commented positively on the Accelerated school model's focus on what the trainers term "Unity of Purpose." This is a key organizational value of the model and one of the training themes which is often repeated. In the context of an Accelerated School, it refers interchangeably to goal-directed activity, a focus on important issues, and collaboration as a means of making decisions and providing daily support to colleagues. Sarah believed that "the Accelerated School model has really helped us share who we are and what's 
important . . and connect with the really important underlying values of why we are here."

\section{Collaboration is the Key}

\section{to success}

Both "Building on Strengths" and "Unity of Purpose" pervade the teachers' attitudes about supporting one another and sharing materials and ideas. Implicit in a collaborative approach is that each member of a team has something to share that can enhance the effort of the group as a whole. The spirit of cooperation at Bridgeport, however, extends beyond the daily problem solving focused on the planning of lessons and activities. It has led to an increased sensitivity to one another as adult learners coping with the stress of the classroom, learners who are sometimes uncomfortable with the dynamics of change at Bridgeport.

\section{Summary}

The Bridgeport teachers were uniformly positive about the Accelerated School model and the changes they had witnessed since its implementation at their school. Comments revealed their commitment to the training process, to long-term change, and to continuing with their efforts. The teachers were focused on Bridgeport and their identity as an Accelerated school rather than as a member of a large, urban school district undergoing substantial changes due to downsizing and program 
reduction. Their enthusiastic responses to questions about the model or comments about their "new" school had the tone and fervor of converts, especially in the dialogue with teachers in a neighboring district. Bridgeport teachers had long been viewed as one of the low-achieving schools in the district, and the Accelerated School model had given them back their sense of respect and purpose. It was clear that "success bred success," and the Accelerated school model, in their estimation, had made that success possible.

Key Findings Related to Research Question \#3

What do the teachers involved with the Accelerated School model believe about the scope and pace of change after two years of implementing a major innovation?

Teachers are No Longer Focused on Their Classroom Alone

Several teachers expressed their belief that they had become better listeners and more aware of their individual differences related to values and style than they were before their involvement in the Accelerated school effort. This heightened sensitivity to colleagues appeared to emerge naturally from teachers spending a great deal of time together as a staff in faculty meetings, on steering committees, and on the various cadres that collectively 
form the decision making structure of the Accelerated School. The traditional model of the teacher working independently behind the classroom door is not possible in an Accelerated School, at least not to the same degree.

Linda recalled that:

A faculty meeting never used to be a place to bring up differences of opinion . . . It was nuts and bolts. Ours isn't that way at all. We may not all agree with the outcome, but we always have time to discuss it before we make a decision. I think that makes a difference. People realize you don't always have to say "yes." So questions are coming out. People are asking questions. I don't think we're aware of how we have done things. Now you're going to be asked an opinion. You're going to be asked to respond to issues . . . I sat there for years and basically let other people decide.

Increased decision making power and the reinforcement value of seeing the positive impact of decisions by consensus tended to pull Bridgeport teachers away from the traditional focus on their own classroom. Research indicates that teachers receive most of their rewards in teaching from their students and are concerned about their well being much more than they value their relationships with administrators or peers (Kotthamp, Provenzo, \& Cohn, 1986; Lortie, 1975). As new norms of collaboration in a school are formed, however, new relationships and new motivational factors emerge for teachers. The commitment to the Accelerated School process and to the changes underway at Bridgeport was not questioned, but the impact 
of their restructuring effort was beginning to be evaluated by participants.

The Accelerated School Model

Takes a Great Deal of Time

Teachers were positive about the cadres and the various goals that had emerged from the decision making structure that characterizes an Accelerated school, but they complained that the consensus model took a great deal of time. Several teachers expressed the dilemma that their participation created: on the one hand, they were involved in real decisions and were accountable for the first time in their careers for the choices they made to support more effective teaching and learning. on the other hand, the cost of involvement was high. Several expressed the fear that they were not meeting the needs of the children in their individual classrooms to the same degree as before becoming involved with the Accelerated School model.

The teachers at Bridgeport clearly saw progress and were proud of their many accomplishments, but they also expressed fatigue and felt a need for limiting an overambitious agenda. They were clearly worried about the impact of their involvement with the model on themselves and their students. Balancing the time it took to implement a change with the other demands of the job was causing teachers to think in terms of "more quality, less 
quantity" of ideas and innovations. Linda voiced the concern of many:

Accelerated School is like opening up Pandora's box, good and bad. Everything starts surfacing and initially everyone feels they have to make all these mammoth changes. You surface all the problems . . gradually you have to back off and give it time.

Only Roger expressed the view that the original committees were involved in more vital activity than those that were currently "looking for problems to solve." Anne expressed the more prevalent view:

There are only so many of us and so many people on so many committees. The issue is how to maintain what you're doing plus the new ideas the cadre and the steering committee are generating. We're feeling the stress this year of so many meetings. We can't do any more. We're committed to Accelerated Schools and we like what has happened but we need to cut back. we need to sit back and have a breather.

The consequences of too much change or perhaps too many meetings, coupled with the fact that the interviews took place in May at the end of the school year, were what Roger perceived as the beginning of "burnout." He suspected that some teachers were approaching this danger point:

I'm skeptical sometimes as to how much more we're going to be able to do as a staff. I think there are some people who, looking at the enormous amount of time it takes to make decisions and to move anything forward, that we may be experiencing some burnout and some folks voting a green card, for example, just to get it done. So some days $I^{\prime} m$ skeptical, even for myself. The time commitment is the major issue. 
As a high personal efficacy teacher with a low opinion of the skills of others, Roger is concerned often with the scope and pace of change as it affects him and his classroom. Roger advised teachers considering adopting the Accelerated school model to "Be concerned about the time commitment. It's a long-term commitment."

Maria was also quite clear in her belief that the model took too much time, that the pace of change was too slow, and that many teachers just raised their green card in order to "get on with it." She voiced her frustration with the process and her conviction that she would be more effective in her own classroom if left alone. She did admit, however, that the Accelerated school model was an improvement over what had gone on before because it offered teachers the opportunity to participate. Maria shared that she:

used to doodle in faculty meetings. I can't do that now because $I$ 'm expected to be part of the group. Sometimes I'd still rather doodle but not always. Just on the bad days when the discussion is really boring.

Maria's perception that she was expected to participate indicates that new norms were being established at Bridgeport Elementary School as teachers wrestled with both the Accelerated School model and the learning needs of the high risk children they teach. 
The Model Itself Can Become

Inflexible

In general, the new norms of collaboration, sharing and increased risk taking were viewed positively by staff, but two teachers, Anne and Maria, had a less optimistic view. A strong component in the comments of both of these teachers was that there was pressure to conform to the group and that it was no longer acceptable to stand alone or work independently of others. The new system seemed to have created its own inflexibility.

Both Anne and Maria exhibited high personal teaching efficacy scores and demonstrated confidence in their own skills and abilities, skills that may or may not be enhanced by a new model of operation. The "green card" referenced in the following comments referred to the consensus model being used at Bridgeport. A "green card" signaled acceptance, a "go ahead" with an idea or decision. A "red card," on the other hand, indicated a lack of support for an idea or decision and sent the proposal back to the cadre for additional discussion. Anne asserted that:

There are some teachers who may hold up a green card just to go along and get consensus even if they are not truly bought in. And some put in more time than others.

This view was echoed by Maria who felt as if she were not part of the collaborative culture at the school because she had not supported becoming an Accelerated 
School and was often critical in meetings of the time required to make even what she perceived as relatively simple decisions.

Right now, it's not okay to say no to anything that's associated with the Accelerated school or any idea that comes from the faculty. One thing that has changed this year is that I notice that I don't want to spend much time discussing something if the majority wants to do it. I don't want to take the time to argue or to present my point of view. I mean if most of the teachers are going to do it, I just put up my green card and I just want to be done with it. I don't want to spend the time on going through this consensus crap.

\section{Summary}

Such comments, although "negative" in nature, indicated that the scope and pace of change at Bridgeport may be taking an unforeseen direction. The model may be creating new divisions among staff as they struggle with the time required for change and the new relationships being formed as a result. The staff has matured in that they are more realistic about the amount of change that can be successfully undertaken at one time. It remains to be seen how they will grow in terms of their ability to deal with their fatigue and the small number of teachers who voice concerns about the value of the consensus model and the time it takes away from the classroom. A certain amount of the success at Bridgeport must be attributed to a "Hawthorne Effect," and whether the long-term commitment 
required for lasting change can be sustained remains to be seen.

$$
\begin{gathered}
\text { Key Findings Related to Research } \\
\text { Question \#4 }
\end{gathered}
$$

What differences exist in perceptions of efficacy of teachers involved in implementing the Accelerated school model?

\section{General Observations}

There are numerous differences in perceptions of efficacy among the 14 Bridgeport teachers based on their responses to the demographic survey and the Gibson and Dembo (1984) efficacy scale as well as among the 9 teachers who also participated in the focus group, questionnaire and panel presentation. Because efficacy is a complex construct, one that appears to be related to a number of other variables, interpreting those differences, especially in a study relying on such a small sample, is difficult. Figure 1 depicts efficacy as connected to numerous other factors which variously influence one's perception of the ability to make a difference or to produce the desired outcome.

Teachers with high efficacy have been found to exhibit less evidence of stress and greater internal locus of control than low efficacy teachers in a variety of studies. Based on the composite efficacy scores tabulated 
from each teacher's responses to the modified Gibson and Dembo (1984) efficacy scale, the "high efficacy" teachers at Bridgeport mirror these same tendencies. Thus, Theresa, Linda, Sarah, Maria, Anne and Gail each exhibit a strong sense of internal locus of control, and their responses in the focus group, questionnaire and panel presentation, indicate a strong sense of efficacy or belief that they can effect the changes necessary in their school and classroom.

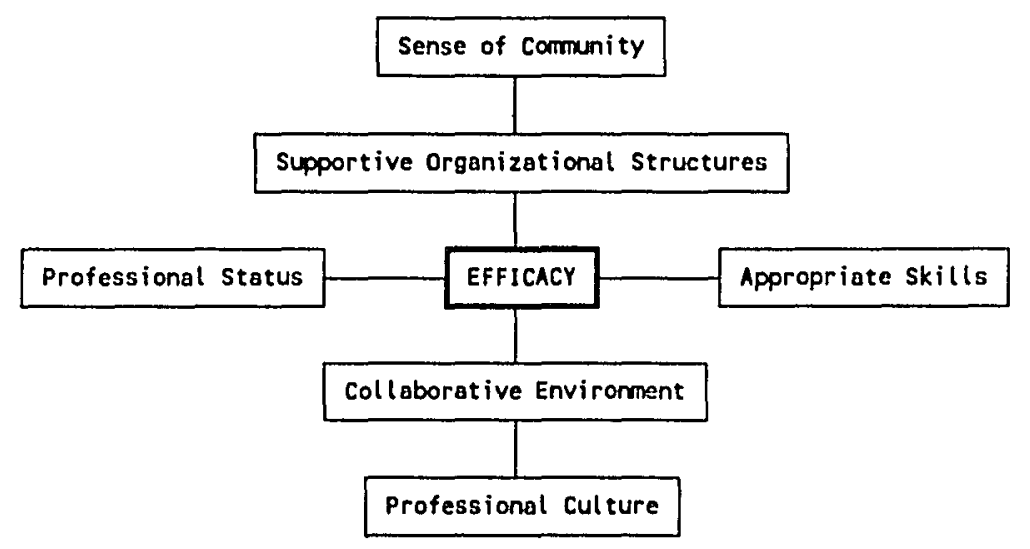

Figure 1. Relationship of efficacy to other factors.

The low and medium efficacy teachers at Bridgeport were more likely to express feelings of fatigue, anxiety over the future, and a sense of frustration at the externals that were impacting their classroom. None of the teachers at Bridgeport, however, even those who had "negative" comments or who received a low efficacy score on the Gibson and Dembo (1984) scale, exhibited the 
excessive blaming or fault finding behaviors often associated with those suffering from lack of efficacy or from an external locus of control. Evelyn, for example, spoke glowingly of the school and her colleagues despite her obvious lack of confidence in her own abilities to move forward without their support.

It should also be noted that any negative comments made as part of the data collection efforts, whether from high or low efficacy teachers, might well have been a function of the time of year the research was conducted. For example, when asked identify her most outstanding accomplishment for the 1993-1994 school, one teacher commented, "Getting to May 24," the day of the focus group interview.

Gender Awareness High Among Bridgeport Teachers Regardless of Efficacy Group

In a number of studies comparing perceptions of efficacy of women and men, women demonstrated less confidence than men about their ability to perform assigned tasks, scored lower than males on measures of internal control, and were more likely than males to attribute their failure to lack of ability. Since the Bridgeport staff was predominantly female, however, one cannot examine the male versus female perspective on various questions or topics. 
Data obtained from female Bridgeport teachers through the focus group, questionnaire and panel presentation would indicate that "gender awareness" is a characteristic of at least some members of the staff regardless of efficacy rating on the Gibson and Dembo (1984) scale. Teachers in each focus group, all women except for Roger, raised the issue of gender and shared frustration at the pervasive belief that teaching is more a custodial/day care function than it is a professional enterprise. The single male participant in the study did not initiate any comments about gender.

Perhaps the Accelerated School model, with its emphasis on analysis and reflection, has also increased awareness on the part of Bridgeport teachers that they are professionals with a great deal of specialized knowledge about teaching and learning. Greer's comment was representative:

I also think as women that it has helped for each of us to find out that we do have strengths - . I think that there are more parents that have respect and understanding of the teacher role.

The perceptions of increased efficacy that appear to result from implementation of the Accelerated School model may also be increasing these teachers' beliefs in their abilities as females to effect change in their personal lives. Decreasing their sense of powerlessness in their 
professional setting may be impacting them in terms of other adult relationships outside the classroom.

Bridgeport Teachers Show Negative Correlation Between

Years of Experience and

Perceptions of Efficacy

Differences in perceptions of efficacy among Bridgeport staff can also be examined in terms of the variation in the number of years of their experience. The first Rand study of innovative programs (Berman \& Mclaughlin, 1979), which made use of two efficacy-related questions widely used in subsequent research on teacher efficacy, determined that:

years of teaching and teacher sense of efficacy had strong and significant, but very different, effects on most of the outcome measures. Specifically, the number of years of teaching had negative effects . . . The teacher's sense of efficacy--a belief that the teacher can help even the most difficult or unmotivated students--showed strong positive effects on all the outcomes. Teachers' attitudes about their own professional competence, in short, may be a major determinant of what happens to projects in classrooms. (p. 32)

Consistent with the Berman and Mclaughlin findings, the research of Huberman and Miles (1984) indicated that the school itself was the most critical unit for renewal rather than the background characteristics of individual teachers with the one exception of the extent of teaching experience. The higher the average number of years of teaching experience, the less renewing the school and presumably the less efficacious the teacher. 
In the case of Bridgeport teachers, however, the data displayed in Table 3 indicate that the more experienced teachers had higher perceptions of efficacy than did those with less total experience. The same findings held true with a comparison of efficacy group/rank and total years at Bridgeport Elementary (Table 4). Bridgeport teachers did not seem to fit the popular perception that the older the teacher and/or the longer he/she stayed at a certain school, the more likely the teacher was to lose enthusiasm and patience for students. The Bridgeport teachers who had been dealing with at risk children and the many obstacles to their academic success the longest were more efficacious than their colleagues who have been there less time. Because of their seniority, the Bridgeport teachers could have requested a transfer at any time. The fact that they did not, nor did they exhibit the classic signs of "teacher burnout" does not fit the stereotype.

Table 3

Comparison of Efficacy Group and Total Years of Teaching Experience

\begin{tabular}{lc}
\hline Efficacy Group & $\begin{array}{c}\text { Average \# Years } \\
\text { Teaching Experience }\end{array}$ \\
\hline HIGH & 20.9 \\
MEDIUM & 15.5 \\
LOW & 12.8 \\
\hline
\end{tabular}


Table 4

Comparison of Efficacy Group and Number of Years Assigned to Current School

Efficacy Group
Average \# Years at Bridgeport
HIGH

MEDIUM

LOW
5.4

1.8

3.8

\section{Four Response Patterns}

Categorize Bridgeport

Teachers

One method of displaying and then analyzing the differences in perception of efficacy using the data involving the $\mathrm{PE}$ (general teaching efficacy) and $\mathrm{TE}$ (personal teaching efficacy) scores is presented in Table 5. Greenwood, Olejnik, and Parkay (1990) identified four different possible combinations of the two questions first used as measures of teacher efficacy by the Rand Corporation (Armor et al., 1976; Berman et al., 1977):

- When it comes right down to it, a teacher really cannot do much because most of a student's motivation and performance depends on his home environment.

- If I really try hard, I can get through to even the most difficult or unmotivated students (Berman et al., 1977, pp. 159-160) . 
Table 5

\section{High/Low Efficacy Teachers Grouped \\ by Response Categories}

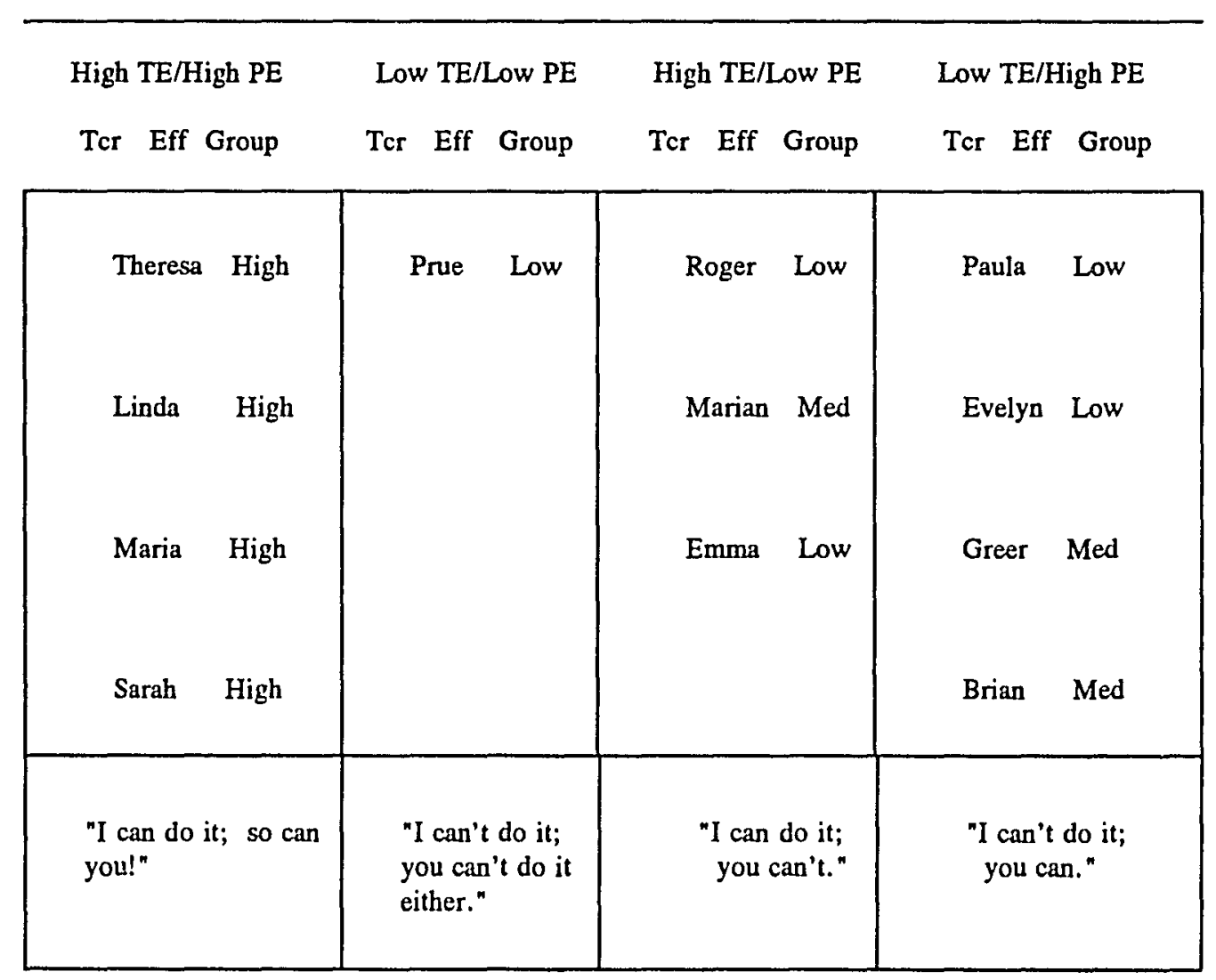

NOTE: Gail and Anne not included because responses do not correspond to categories proposed by Greenwood et al. (1990).

Because a teacher might view the world of teaching and learning as operating a certain way but may or may not feel personally capable of operating that way, the following attitudes might emerge: (a) teachers in general cannot motivate students and I am no exception to the rule, (b) teachers in general can motivate students but I personally cannot, (c) teachers in general can motivate 
students and I am no exception to this rule, (d) teachers in general cannot motivate students but I personally can if I try hard (p. 102).

Using this approach, one might group the Bridgeport teachers' responses to the modified Gibson and Dembo (1984) efficacy scale as indicated in Table 5. It should be noted that two relatively high efficacy teachers, Gail and Anne, were classified as "other" because they did not clearly demonstrate any one of the four patterns or the pattern of other teachers within their efficacy group. Although the composite efficacy score of these two teachers placed them in the "High" category, their individual PE/TE scores did not fit the High PE/High TE pattern exemplified by the other high efficacy teachers' attitude of "I can do it; so can you!" Their sense of their personal skill was high enough, but their opinions of the teaching profession generally were too negative to qualify them for a high TE status. Their TE scores were borderline "low efficacy," and they come closer to the High PE/Low TE category than any other.

One caution in interpreting this data, however, is that it reflects responses to the Gibson and Dembo (1984) scale and may or may not prove consistent with the verbal comments shared by the nine teachers participating in the focus group, questionnaire and panel presentation. In the case of Gail, for example, the discrepancy between her 
efficacy score and her high efficacy comments should be noted. Maria also voiced very low opinions of her colleagues and their abilities to make the right decisions for students, yet her efficacy score indicates a High PE (general teaching efficacy) as well as a High TE (personal teaching efficacy).

Efficacy is a Highly Individualistic Trait

The Bridgeport teachers would appear to be highly individualistic. This data also reflects the consistent findings that the two dimensions of efficacy, general teaching efficacy and personal teaching efficacy, are independent:

Individual teachers who believe that teaching is a potentially powerful factor in students' learning may believe that they are effective or that they lack the ability to make a difference with their own students. Teachers may also believe that teaching in general can have little impact on students and that their classes are, or are not, exceptions to the rule. (Woolfolk, Rosoff, \& Hoy, 1990, p. 138)

As with the case of two high efficacy teachers, Gail and Anne, who did not fit any of the four response patterns posited by Greenwood, Olejnik, and Parkay (1990) outlined in Table 5, when one examines differences in efficacy as reflected in the individual responses to questions included in the Gibson and Dembo (1984) scale, this highly individualistic response pattern prevailed. The same question received a full range of responses both across 
high, medium and low efficacy teacher groups and within each efficacy group itself. The highest variation occurred when asked whether "My teacher training/ experience has given me the right skills" (Question \#6) and "School rules/practices hinder my ability to teach" (Question 19).

Each question included in the efficacy scale and the variation in teacher responses is displayed in Table 6 . Given the broad range of responses within each efficacy group, it would appear more useful to look at teacher responses, and at efficacy in general, on an individual basis. Table 7 displays individual teacher responses to each of the original Rand study questions (Armor et al., 1976; Berman et al., 1977).

\section{Little Consensus Exists Among}

Bridgeport Teachers in Terms

of Responses to Questions on

Efficacy Scale

Recalling that an efficacious response may be either a high response ("6"--strongly agree) or a low response ("1"--strongly disagree) depending on the nature of the question, it is interesting to note the wide variation in teacher answers on the efficacy scale. If a minimal range of response was indicative of "agreement" across high/medium/low efficacy teachers, then there were only a few questions that evoked any form of consensus. Responses to questions 8,10 , and 18 varied by only 
Table 6

Group Response to Modified Efficacy Scale

\begin{tabular}{lllll}
\hline Qst \# & Mean & Mode & Range & Paraphrase of Question \\
\hline 1 & 4.63 & 5 & $2-5$ & When a student does better, its because I exerted extra effort. \\
2 & 3.63 & 5 & $2-6$ & The hours in my class have little influence compared to home. \\
3 & 3.21 & $5 / 2$ & $1-5$ & A teacher is limited in what he/she can do because of home influence. \\
4 & 3.42 & 2 & $1-6$ & If students aren't disciplined at home, they won't accept any here. \\
5 & 4.69 & 5 & $3-6$ & I have enough training to deal with almost any learning situation. \\
6 & 4.78 & $5 / 6$ & $1-6$ & My teacher training/experience has given me the right set of skills. \\
7 & 4.35 & 5 & $2-6$ & If I try hard, I can get reach even difficult/unmotivated students. \\
8 & 5.35 & 2 & $4-6$ & When a student is having trouble, I can adjust assignments to his level. \\
9 & 4.44 & 1 & $2-6$ & If parents would do more with their children, I could do more in class. \\
10 & 5.28 & 4 & $4-6$ & If a student is disruptive, I know how to redirect him/her. \\
11 & 2.38 & 4 & $1-6$ & The amount a student can learn is primarily related to background. \\
12 & 2.21 & 2 & $1-5$ & Teachers aren't powerful influences when all factors considered. \\
13 & 4.46 & 5 & $3-6$ & If student grades improve, it's because I found better strategies. \\
14 & 4.38 & 4 & $1-4$ & If a student masters new skill, it's because I knew how to teach \\
15 & 2.30 & 5 & $1-4$ & Teachers can't do much because motivation depends on home. \\
16 & 4.46 & 1 & $2-6$ & If student grade improves, I found a better way to teach. \\
17 & 4.25 & 6 & $2-5$ & If a student forgets info, I can increase retention in next lesson. \\
18 & 4.64 & 5 & $4-6$ & When I really try, I can get through to the most difficult kids. \\
19 & 2.85 & 1 & $1-6$ & School rules/practices hinder my ability to teach. \\
20 & 5.07 & 6 & $2-6$ & If student can't do an assignment, I can assess level of difficulty. \\
\hline Note: "1" response & $=$ strongly disagree; "6" response = strongly agree
\end{tabular}

Source: Gibson and Dembo (1984). 
Table 7

Efficacy Rank and Response to Rand* Efficacy Questions

\begin{tabular}{|c|c|c|c|c|c|}
\hline $\begin{array}{l}\text { Tchr } \\
\text { Name }\end{array}$ & $\begin{array}{l}\text { Efficacy } \\
\text { Score/Group }\end{array}$ & $\begin{array}{l}\text { Qstn 15: A Teacher Can't Do } \\
\text { Very Much Because of Home }\end{array}$ & $\begin{array}{l}\text { Qstn 7: If I Try Hard, } \\
\text { I Can Get Through }\end{array}$ & $\begin{array}{l}\text { Qstn 3: A Teacher } \\
\text { is Very Limited }\end{array}$ & $\begin{array}{l}\text { Qstn 18: When I Try Really } \\
\text { Herd, I Can Reach All Students }\end{array}$ \\
\hline Sarah & 85/High & 1 & 4 & 1 & 6 \\
\hline Gail & 84/High & 2 & 3 & 5 & 4 \\
\hline Maria & 82/High & 2 & 4 & 2 & 4 \\
\hline Anne & $81 / \mathrm{High}$ & 3 & 2 & 4 & 4 \\
\hline Linda & 79/High & 2 & 5 & 2 & 5 \\
\hline Theresa & 77/High & 2 & 5 & 2 & 5 \\
\hline Brian & 74/Medium & 2 & 5 & 5 & 5 \\
\hline Marian & 86/Medium & 2 & 4 & 4 & 5 \\
\hline Greer & 73/Medium & 2 & 5 & 2 & 5 \\
\hline Prue & 64/Low & 3 & 4 & 5 & 5 \\
\hline Paule & 68/Low & 1 & 5 & 1 & 6 \\
\hline Roger & 101/Low & 4 & 6 & 5 & 5 \\
\hline Evelyn & 64/Low & NA & 5 & 3 & 5 \\
\hline Emma & 92/Low & 4 & 4 & 4 & 5 \\
\hline
\end{tabular}


three points, the lowest variation across all 20 questions. These questions dealt with an individual's technical skills of adjusting level of assignment, dealing with classroom discipline and the ability to motivate students. A related question, "My teacher training/experience has given me the right skills" (Question produced one of the highest variation in response, a fact that puts it at variance with the other questions dealing with technical skills on which there appeared to be some pattern of increased agreement. All other questions other questions have a 4-5 point variation and indicated very little agreement as to interpretation or response regardless of efficacy group.

Individual teacher responses to Question \#19, "School Rules/Practices Hinder My Ability to Teach," were of interest for two reasons: (a) there was wide variation in the response among the high and low efficacy group but the identical range of response (1-6) from both high and low efficacy teachers; and (b) given the focus at Bridgeport on the Accelerated School model and an approach to school governance in which teachers make the decisions about school focus and direction, it would seem that there would be greater agreement that at Bridgeport at least there would be little perceived hindrance at the school level imposed by anyone other than the teachers themselves. 
Table 8 indicates response by teacher/efficacy group. Three of the high efficacy teachers have a relatively low efficacy response to this question: Maria, Gail, and Theresa. Since Bridgeport teachers make many of their own "rules," at least in terms of organizational agreements that foster school improvement, one wonders if the lowerthan-expected efficacy response was due to feelings associated with federal, state and district mandates rather than site-based restrictions.

Table 8

"School Rules/Practices Hinder MY Ability to Teach"

\begin{tabular}{llc}
\hline Teacher Name & Efficacy Group & $\begin{array}{c}\text { Response to } \\
\text { Question 19 }\end{array}$ \\
\hline Sarah & High & 1 \\
Gail & High & 4 \\
Maria & High & 6 \\
Line & High & 2 \\
Theresa & High & 1 \\
Brian & High & 4 \\
Marian & Medium & 2 \\
Greer & Medium & 1 \\
Prue & Medium & 2 \\
Paula & Low & 2 \\
Roger & Low & 3 \\
Evelyn & Low & 3 \\
Emma & Low & 6 \\
"1" & Low & \\
response (high efficacy) & & \\
Another possibility is that these teachers were \\
expressing their frustration over the Accelerated school
\end{tabular}


emphasis on consensus-based decision making and group process since several teachers mentioned when interviewed how much time it took to work collaboratively rather than alone. Perhaps these teachers also felt that the Accelerated School structure was inhibiting in that sense--it would take less time and effort to make decisions for oneself and one's own classroom. strong classroom teachers may feel handicapped by their less efficacious colleagues.

\section{Summary}

There were some differences among the perceptions of efficacy among teachers when responses to the modified Gibson and Dembo (1984) scale were examined by efficacy group. There were, however, more variations within group than might be expected and the results of the efficacy scale did not always match the verbal comments shared by means of the focus group, the questionnaire or the panel presentation. As a result, the efficacy scale scores, particularly with such a small sample of teachers, should be viewed as only one source of limited data that must be considered in combination with other sources of information to avoid drawing conclusions that may be inaccurate.

Bridgeport teachers appear to be a highly independent group of thinkers, perhaps more used to a spirit of inquiry because of their involvement in the Accelerated 
School training. Such a tendency towards analysis and reflection may lead these same teachers to respond to general questions in a context-specific way. Simple questions, like supposedly simple school issues, may prompt an analytical and complex response consistent with the Accelerated School inquiry process itself.

Key Findings Related to Research Question 5

What factors influence feelings of teacher efficacy among teachers involved in implementing the Accelerated School model?

The key factors that influenced the varying perceptions of efficacy exhibited by Bridgeport teachers are summarized based on extensive teacher comments and written responses to the questionnaire. Implicit in each generalization, stated in terms of how efficacy is enhanced, is the converse: efficacy is impeded by the lack of the same factor. For example, if efficacy is enhanced by granting teachers true decision making power, then efficacy is impeded by denying teachers any real role in decisions that impact their classroom. 
Efficacy is Enhanced by

Organizational Norms that

support Change by Building

community

New norms are being established at Bridgeport Elementary School as teachers wrestle with both the Accelerated School model and the learning needs of the high risk children they teach. A predominant theme is that of building a new "community," one that supports children as well as the adults at Bridgeport.

Comments reveal an extensive network of support for children, and a collaborative effort to find appropriate placement for each and every child, but also a network of support for staff. Bridgeport is becoming a true community of learners for both the adults and children who "live" there. The sense of support felt by staff is also highlighted in specific comments related to risk-taking and experimentation, not activities encouraged prior to the Accelerated School training. Specific changes have taken place in terms of establishing a safe environment for risk taking. Theresa maintained that:

I feel now that if there's something I'm weak in or I don't have materials or need help in something, I can walk into any number of classrooms and say, I need help with this. And I can go to the principal.

A related change in organizational norms is an increase in the amount of sharing that occurs. Teachers feel comfortable not only in sharing their successes and 
failures because of an atmosphere that encourages risktaking, but they also share ideas, materials and time. Bridgeport Elementary has become a school in which the traditional barriers that separate staff are being eliminated as teachers learn the power of working together rather than in isolation.

Such perceptions were expressed by high efficacy teachers as well as low efficacy teachers at Bridgeport. Both sets also perceived a growing sense of community and support for both themselves and for the children. It may be that the low efficacy teachers, whose opinions of their own skills and of teachers in general lacked confidence, found the support from colleagues even more important than their more efficacious colleagues. They may have had more direct experience with being the "odd man out" or not feeling confident to take a risk or let others know if a new idea was unsuccessful. If so, their comments concerning the new organizational norms evolving at Bridgeport must be viewed as even more poignant. Evelyn, a low efficacy teacher, believed that:

There's a sense of everybody taking care of each other. And nobody is the odd person out, you know. It made a lot more things possible because you begin to think of more ideas, you begin to try them.

She also described the support she felt was extended to all teachers at Bridgeport that encouraged all to attempt change: 
Accelerated Schools lay out a format where differences of opinion can come up in a safe environment. You feel you can say I need a little more time on this, I'm not quite understanding this, or help me see this more, or I'm really frustrated here. But there's a feeling that it's okay to say those things because we're all working towards the same goal here.

Efficacy is Enhanced by the Accelerated School Model Itself

The second research question, which seeks to identiffy the components of the Accelerated School model that have contributed to perceptions of efficacy, is explored earlier in this chapter. The various comments and perceptions as to the model itself will not be repeated here, but it is important to recognize that the model itself, because of its reliance on open-ended process, forces the dialogue among staff that is critical to the spirit of inquiry necessary to effect instructional change. In other words, the model forces teachers to model the behaviors they must ultimately adopt. The process itself is instructive.

Another positive feature reported by teachers is that the model i.s based on mutually reinforcing behaviors and focuses on support mechanisms for teachers undergoing stress regardless of whether they are involved in implementing the Accelerated school model. Any model that focuses on "Building on strengths," for example, canrot help but attract converts. So much of what takes place in 
school can be negative: upset parents, hostile children, insensitive administrators and impersonal mandates. The recurring issue of too little time and too many expectations creates additional stress. The Accelerated School model, however, encourages teachers to simplify, to focus on strengths, to pursue "Unity of Purpose," all slogans that appeal to individuals feeling pressured. The major strength of the model reported by teachers in the study is its focus on participatory decision making and its organizational structure that relies on committees and cadres to identify goals to move the school forward. The ownership that results from such total involvement both contributes to the quality of the decisions made as well as to the sense of "buy in" that fosters such loyalty and commitment on the part of the Bridgeport staff. One can hear almost a proselytizing tone as teachers talk about the changes that have taken place both professionally and personally due to their involvement with Accelerated Schools. Because the model is "empowering," gender issues, for example, emerge naturally from the many discussions held by staff. Because real power has been bestowed, teachers feel powerful--and that is a reinforcing message that helps to make the model a success.

Theresa expressed it best:

If there is one thing that Accelerated school does is build up your strength . . all of us 
just sat down and came up with a plan and built off that child's strengths first. We do a lot of that and it's real different. Before it was like, that's your problem--you deal with the parents. You were doing these things, but you were doing them individually which wasn't as powerful.

Greer, a medium efficacy teacher also expressed the power implicit in learning to solve what appear to be overwhelming problems by working together rather than apart.

(Working alone) you end up spinning your wheels, and now with the Accelerated school model we have we to really work together to surround these children and lift them up.

The Accelerated School model contributes to feelings of increased efficacy because it is not only the children who are being "lifted up."

Efficacy is Enhanced by a Supportive Principal

Another major theme discussed in each focus group was the role of the principal in the Accelerated school model and the characteristics of a principal necessary for their success in an Accelerated school. Teachers in all efficacy groups spoke to the many positive attributes of their current principal. Not a single negative comment surfaced from any of the nine teachers participating in the interviews. Also of interest was that fact that all teachers, whether high, medium or low efficacy, recognized that the traditional hierarchy, with its emphasis on power and control, was antithetical to the Accelerated School 
model. To be successful in the model, a principal had to have the ability to "let go," to honor the decisions made by staff, and to provide support for change in a nonjudgmental way. Such attributes were not viewed as universally held by administrators, particularly many of those who had provided "leadership" to these teachers in the past.

Not all administrators were viewed as being able to be an Accelerated School principal. They lacked "inner security," had problems with control, or could not adjust to the changing expectations or a new role. Sarah summarized the comments of several teachers:

Some of them (principals) have inner insecurity and they have to be firm or too hard and this is the way it's going to be folks because I'm the boss. But I think it takes the kind of strength that our principal has to deal with all of this. She has an apparent lack of power even though we all know she has a lot of power.

Linda was also insightful as to the difficult role that had to played by a principal engaged in a collaborative effort with staff, especially one of the magnitude of the Accelerated School model:

It is hard for the principal. Their job, and the school itself, how well or how poorly the school ultimately does is the principal's responsibility . . . so it's the hardest thing for them to do to step back and say, I'm going to open up these decisions to the staff and once I do I have to live with their decision whether I agree with it or not. She has to accept responsibility for decisions but let go of making them. 
Specific skills of the principal were also mentioned as having a positive effect on teachers' ability to feel more or less effective. Exhibiting strong human relations skills in the face of conflict or controversy, finding ways to protect the school from the mandates of the central office, and acknowledging the "burn out factor" were mentioned specifically. The principal was also credited with being sensitive to the scope and pace of change being attempted at Bridgeport and recognizing individual staff differences. Each teacher clearly understood that there was support for risk taking to help them meet the expectations that each of them advance in terms of their own personal and professional skills. Another comment made several times was that the current principal did not take conflict or disagreement personally. She approached such an incident as a "problem to be solved" rather than as an affront to her authority or position. Bridgeport teachers appreciated this quality in their current principal as well as her ability to "let go" of decisions as well as past difficulties to continually a positive message to staff.

Efficacy is Enhanced by Changing the Traditional Role of the Teacher

In addition to a common understanding across efficacy groups of the necessary attributes for a successful Accelerated school principal, a second consistent theme 
was the changing role of the classroom teacher. Teachers in each focus group viewed the governance model for an Accelerated school and their own role in decision making as being significantly different than other schools where they had taught before coming to Bridgeport. The simplistic view is that making the decisions about school direction is reinforcing as a goal in itself. Many site-based efforts that set up councils or leadership teams reflect the belief that the process itself is fulfilling. What Bridgeport teachers reported, however, is that making decisions was exciting and energizing, but that the process was tremendously time-consuming and difficult. Each teacher expressed some frustration at the amount of time required.

Another astute observation was made by Theresa:

The Accelerated School model would be very difficult for weak teachers. Your weaknesses will definitely come up. Weak teachers have survived in the schools because we get so isolated. In the old system it was unsafe for a teacher to stay weak in an area rather than say I'm still learning how to do something.

She realized, as did several other teachers, that with the decision making power came the responsibility of dealing with one another's strengths as well as weaknesses. Efficacy can be enhanced by having real influence on the decisions that are made, but the changes may be broader in scope than initially realized. 
Bridgeport teachers also reported learning that their new role as decision maker gave them control over the pace and scope of change. Several teachers cited examples in which decisions had been postponed or goals discarded because a situation had changed or the enough time was not available to assess the impact of a decision. Rather than rush from one activity to the next, teachers were learning that the pace of change can be a factor in their success. Linda believed that:

In the broad sense I think we have learned that things take time. We keep saying we need to give children enough time--we need to give staff enough time for change. And I think we first started--we're going to do all these things - . and now we've found that yes we're going to do these things so you can take a deep breath and work them through and slow them down and allow everything to happen that needs to happen.

The teachers were learning to be "in charge," of themselves, of their process and of their ultimate success. They were beginning to understand that as professionals, they had responsibility for the full range of consequences resulting from the choices that they made. No longer do they have a principal or a central office to blame. As a result, they were both enthusiastic and tired. 
Efficacy is Enhanced by

Various Factors that are

Highly Individualistic

and situational

When Bridgeport teachers were asked specifically to identify the factors that contributed to their own sense of efficacy, they offered a variety of responses. Most of the Bridgeport teachers viewed themselves and their profession as strong and capable of making a difference for those who struggle in America's schools, but each teacher surfaced different influencing factors that contributed to their sense of efficacy.

one influencing factor was having had prior experience with apparently unsuccessful students who ultimately were impacted by the actions of a teacher. Several teachers articulated their belief in their power to positively impact the lives of children even if it was not readily apparent or took years to develop. Knowledge of human learning, and the complex factors that affect student behavior in a given class at a given time, enabled Theresa to say:

I think when you are working with children who sometimes come from very difficult home lives, you have to have more than adequate basic skills. You have to have the desire to want to help and you have to have a real strong motivation to do that. We cannot change home - . We cannot change mom and dad. We can't change the problems they have. But what we can do is to try to teach him to be able to meet those challenges, to be able to make it through that difficult time and give him an opportunity for a future. 
Theresa felt efficacious because she had had experiences in the past that reinforced her belief that positive change may not be apparent yet may be occurring nonetheless. Linda also expressed this optimism in a future she could not see:

There's a few where you don't see an impact, you feel like you're barely surviving with them and the family is very dysfunctional and you assume there are some very serious things there . . But I've learned over the years that those kids, those few kids, where you don't really see a lot of change, they are probably transitory. You don't have a prolonged amount of time. As they move through a fairly chaotic piece of their life, each person that they meet--and the teacher being a very powerful person who's in their life for an extended period of time every day--that they do gain something, they internally gain something--whether it's in the sense of being valued or what.

Several teachers also spoke to their ability to do their jobs more effectively at Bridgeport as a result of the increased parent involvement in the school. The traditional barriers between home and school seemed to have been lowered, and each teacher expressed a belief in the power of working in conjunction with the family. One teacher observed that the Accelerated School slogan on the faculty room wall, "our parents send us the best that they have" was truly reflective of the new attitude at the school. Rather than work in a traditional mode in which parents are viewed as part of the problem, Bridgeport teachers clearly saw them as key to the solutions that affected their child. 
Working with colleagues was also cited as a factor contributing to feelings of efficacy, especially apparent in the Accelerated School model with its emphasis on "Building on Strengths" and collaborative effort. Only one teacher, Maria, expressed a desire to return to the days of the past in that she wanted to be left alone in her own classroom. The other teachers spoke often of examples in which they had found a solution to a problem with a student by working as a team. They all felt more effective as a result.

\section{Summary}

Synthesizing the many comments of these highlyindividualistic teachers was subject to the researcher's bias, but these generalizations do reflect consistent patterns exhibited at differing times and in different contexts. As such, the generalizations can instruct any in a position of school leadership or involved in school reform. It is clear that in order to enhance teacher efficacy, and to enable teachers to "take charge" of this reform effort, changes must occur in the way schools function as organizations. New norms must be established, and the Accelerated school model appears to have the potential to provide schools with a means to that end. 
Summary

In summary, there are some general differences among the perceptions of efficacy among Bridgeport teachers when responses to the modified Gibson and Dembo (1984) scale are examined by efficacy group. There are, however, more variations within group than might be expected. Bridgeport teachers appear to be a highly independent group of thinkers, perhaps more used to a spirit of inquiry because of their involvement in the Accelerated School training. Such a tendency towards analysis and reflection may lead these same teachers to respond to general questions in a very context-specific way. Apparently simple questions, like supposedly simple school issues, may prompt an analytical response consistent with the Accelerated school inquiry process itself. Most important, however, is that as a group none of the Bridgeport teachers reflected the sense of hopelessness that often pervades the comments of teachers who work in inner city schools with high concentrations of at-risk students and families. Individuals may have made comments about a class that was too large, or insufficient resources, or in one instance a Down's syndrome kindergarten student the teacher felt was misplaced. The lack of time was a universal constraint, but the lack of criticism of students or parents is what is striking about Bridgeport. They have tough kids and a tough community, 
yet they feel positive and energized by what they are doing. clearly the factors that influence their perceptions of efficacy are related to the decision making model, the collaborative spirit of the school, and to the positive reinforcement resulting from a changing role that is changing the results of their efforts. 
CHAPTER VI

\title{
SUMMARY AND CONCLUSIONS
}

\author{
Introduction
}

This study was undertaken in the belief that current efforts to restructure the nation's schools will be as unsuccessful as previous reforms if considerable attention is not paid to the essential role of the teacher in implementing change. Not only is the teacher's role critical, but the perceptions of teachers as to the necessary organizational and structural conditions of the workplace that either facilitate or impede change are also important--to school administrators, school Boards and teacher training institutions ostensibly serious about supporting innovation on behalf of children.

It is to the advantage of all concerned with the valued outcomes of school reform to create the conditions necessary to maximize teacher efforts to change their environment. Miller (1991) believed that teacher efficacy is central to school restructuring in that:

Fundamental beliefs held by society and the educational community concerning the achievement potential of at risk students are an important cause of our current drop out problem; 
the only way to reduce drop outs is to radically alter both the beliefs and the behaviors that follow from those beliefs; and

if school restructuring efforts are to succeed, they must focus on creating conditions that will foster such changes in educational thought and practice. (p. 30)

It is imperative that this reform effort succeed. In order to increase that possibility, it is hoped that this study may offer some insights that will help others who are attempting to create conditions in schools that will foster conditions that support change. In order to understand the lessons of Bridgeport, however, it is important to understand the assumptions on which the study is based: assumptions about the relationship between increased perceptions of efficacy, the Accelerated School model, and the future of school reform.

\section{Key Assumptions}

1. Promoting both teachers' abilities and teachers' confidence in their abilities are important variables in school reform. Without the belief that they can "make a difference," teachers will not attempt the major overhaul of the current educational system required in order for the institution of public education to survive;

2. Those committed to changing America's schools must encourage the development of efficacious teachers, for without their efforts, public schooling will remain the same. No mandated changes can succeed without them, 
nor will increased accountability for results occur despite the legislative and public demands for an increase in the quality of schooling in this country.

3. The author believes that the reason why instructional, curricular and political reforms recur is not due to a lack of rational proposals or a failure of implementation. Rather, such reforms are targeted at superficial change rather than at addressing the political and institutional forces which render change impossible. Superficial change such as establishing site councils will not, in themselves, make a difference. New models that grant teachers the time and the power to effect change and which foster their sense of efficacy must be developed and encouraged.

4. The Accelerated School model has potential for increasing feelings of efficacy on the part of participants and thus bears further study and implementation in other settings. Regardless of the specifics of time or place, the lessons of Bridgeport have implications for change efforts underway in various stages of implementation.

\section{Key Findings}

1. Teachers at Bridgeport Elementary School reveal that efficacy is a complex, interactive construct rather than a fixed personal trait. Analysis of questionnaire 
data, the demographic survey and the focus group interviews reveals that efficacy beliefs are highly individualistic.

2. The efficacy scale used to categorize teachers as high/medium/low efficacy was of limited use. The responses were often inconsistent with comments made in the focus group, on the questionnaire or during the panel discussion with other teachers investigating the Accelerated School model. There was as much variation within efficacy category as there was across the group as a whole.

3. There were more similarities than differences among Bridgeport teachers regardless of "efficacy score." All teachers raised the issue of too little time and the need for a long-term commitment to change. All teachers recognized that the Accelerated school model was not a program or a recipe but rather a means to an end.

4. Almost all Bridgeport teachers supported the Accelerated school model and believed that they were having a positive impact on children.

5. Two teachers criticized the Accelerated School consensus process and indicated an inflexibility in the model that discouraged independent thought or action. A third teacher tended to be less effusive about the model and more focused on the time requirements before 
indicating qualified support. Two of these teachers were in the high efficacy group.

6. The most often identified barriers to teacher effectiveness were external to the school. Specific concerns included the amount of time required for the model and for change itself; a set of district/state mandates that were insensitive to the realities of schooling; and uncertainty as to the future (i.e., funding, reduction in force).

7. All teachers indicated awareness of the special qualities of their current principal and the potential conflict between a "traditional" (i.e., power/control focus) principal and the Accelerated school model.

8. Questionnaire and focus group data were similar in the themes identified. These included a sense of collegiality and support at Bridgeport since the implementation of the Accelerated school model; the establishment of an atmosphere at the school that encouraged risk taking; and a realization that the staff had taken on an agenda that was time-consuming and perhaps overly ambitious.

9. Bridgeport teachers exhibited a clear understanding that the culture of most schools inhibited risk-taking and viewed the admission of any failure or need for help as a sign of weakness. Instead, these 
schools seemed to foster deceit and continual pressure to "look good."

10. Bridgeport teachers did not fit the researchbased profile that portrays older, more experienced teachers as less efficacious, less effective than younger ones. There was a negative correlation between years of experience and low efficacy at Bridgeport.

11. Support from the principal, from the district office, from the university and from parents was viewed as critical for success by all teachers at the school. Even more important, however, was the support of colleagues-sharing ideas and materials, agreeing to take a student into their classroom in order to find success, creating a sense of inquiry and continuous school improvement.

12. Outside forces such as public loss of confidence in education, the undervaluing of children as a national priority and an unrealistic expectations of teachers were also clearly viewed as detrimental to their effectiveness by Bridgeport teachers. Conditions within the school, on the other hand, were conducive to their success with students and to their sense of powerfulness or efficacy.

\section{Limitations of the Study}

A major limitation of the Bridgeport study was the small size of the population $(\underline{N}=14)$ and that the data collected represent teacher perceptions at one point in 
time. The questionnaire responses, the focus group interviews, and the demographic survey were all completed over a short period--three-months in winter/spring 1994. Prior interview data collected by chenoweth and Kushman (1992, 1993) at Bridgeport related to teachers' perceptions regarding the Accelerated school model, the role of the principal, and the changing climate of Bridgeport were consistent with this author's research, however, and supported its conclusions.

A second limitation was the context in which the data were collected. During the winter and spring, 1994, the school district was engaged in budget cuts resulting from the passage of Oregon Ballot Measure \#5 (1990), and there were many comments from teachers regarding the uncertainty of future funding, job security and possible program cuts. The strong sense of "safety" they perceived at Bridgeport may have seemed even more apparent when contrasted with the hostile and uncertain world outside the school.

Another potential flaw in the research design was the fact that interviews were conducted at different times in different settings. Two of the focus group interviews took place in a nearby school district considering the Accelerated school model for two of its lowest-achieving elementary schools. The first two focus groups, invited as guests and honored with lunch and a "day out" may have reflected these special circumstances. Comments about the 
Accelerated School model may have been more positive as a result. Data could have been distorted by wanting to say "the right thing" or to conform to unspoken norms of being a guest. The third interview took place at Bridgeport itself with at least one teacher making reference to the fact that she "was not invited to District $x . "$ The only difference noted in the first two focus groups as compared to the third group was length of responses. The six teachers invited as guests were much more verbal and explicit in their answers. The members of the third focus group at Bridgeport tended to be more "matter of fact" and to provide less detail.

Those interviewed $(\underline{\mathrm{N}}=9)$ in the focus groups were neither randomly selected nor randomly assigned. They were representative of high, medium and low efficacy teachers based on their responses to the Gibson and Dembo (1984) scale, but they were volunteers who indicated willingness to participate. The fact that only one male was included from the total of two males teaching at Bridgeport also made it impossible to draw any generalizations concerning gender differences.

Also because subjects were neither randomly assigned (internal validity) nor randomly selected (external validity), questions as to the generalizability of results in a single case study must arise. Yin (1984), however, defended against this criticism of case study design by 
maintaining that the same question could be asked of a single experimental study.

In fact, scientific facts are rarely based on single experiments; they are usually based on a multiple set of experiments, which have replicated the phenomenon under different conditions. The same approach can be used with multiple case studies. The short answer is that case studies, like experiments, are generalizable to theoretical propositions and not to populations or universes. (p. 21)

Another concern relative to the study is that the teachers in the Accelerated school cannot be viewed as truly representative of teachers in general because they had voted to implement a new model for change. Thus, one might question if these teachers are indeed "average," or whether they are perhaps more efficacious than what would be found in a random sample taken from the population at large since they have made a conscious decision to restructure their school. These teachers also were unusual in that the schools to which they were assigned had such a great need of improvement that one might speculate that they were ready to accept almost any innovation that might result in improvement. Since the study is not experimental in nature and there is no control group matched for gender, age, certification and experience, it is not possible to know how representative the teachers in the Accelerated school model might be. Low school achievement or socioeconomic attributes are primary reasons for being asked to consider participation 
in the Accelerated School Project as a pilot site.

Whether the teachers who work in such schools are more or less efficacious than their colleagues in more affluent or "successful" schools is beyond the scope of this study. Such questions, however, lend themselves to additional research in this area.

Finally, the data concerning efficacy scores included in the teacher profiles may be problematic and limited in terms of its usefulness. The issue of what is a meaningful difference in scores among only 14 teachers involved in implementing the Accelerated school model must also be determined. In addition, the efficacy scale responses were often at variance with responses given by the same teachers in the focus group, the panel presentation or on the written questionnaire. The primary focus of the study, however, was identifying the factors that promote or impede perceptions of efficacy rather than validating the construct of efficacy itself.

To further refine the scaled instrument used in the study as a means of providing additional data on teacher participants, Gibson and Dembo (1984) called for:

further research on the validation and refinement of the Teacher Efficacy Scale is needed . - also construct validation should continue to be investigated across different populations and settings. (p. 579)

Since school restructuring is an enterprise that can only take place effectively at the school level, there are 
a number of recommendations for educators that have emerged from the Bridgeport study despite its limitations. Although there are implications of this research for those in teacher training institutions and for policy makers at the state and local level, it is primarily those who work in schools who can benefit the most from the lessons of Bridgeport school. Therefore, recommendations have been made for those at Bridgeport School, for school administrators in other school settings, and for classroom teachers everywhere.

\section{Recommendations for Bridgeport School}

The teachers of Bridgeport should feel positively about the changes they have made in their school as well as the level of awareness they have achieved concerning school restructuring and change. They have, in fact, realized the most important lesson of all: change must be addressed in increments rather than wholesale. The notion of "big wheels and little wheels" is a key component of the Accelerated School model:

Big wheels are the formal school philosophy and change process that are collaboratively shared by all members of the school community. Little wheels are informal innovations resulting from individual or small groups participating in the school's philosophy and change process. These little wheels result from individuals or small groups internalizing the school philosophy and change process in their belief system, thereby bringing it into their daily lives and practices. 
Little wheel innovations are crucial because big wheel processes take time and produce institutionalized changes. Little wheel innovations give participants an outlet for making some immediate changes, thereby satisfying their natural inclination for wanting to see change happen quickly. They can revitalize and energize participants as they struggle to implement a whole school restructuring process. (Center for Educational Research at Stanford, 1992, p. 4)

The teachers at Bridgeport, almost all of whom felt positively about the changes they have enacted, seem to have gained wisdom in the process. They must, however, be able to consider scaling back without feeling they have somehow failed, a lesson that all of those who undergo change in a school setting must learn. Several teachers referred to the need to limit the scope of their activities, to accept their own limitations, and to model that "less is more" in terms of effecting change. Another lesson for Bridgeport teachers is that there are at least some among them, including two teachers who score as high efficacy on the Gibson and Dembo (1984) scale, who are beginning to feel that the Accelerated School model in itself has become inflexible. Maria, Anne and Roger all mentioned their perception that it was not acceptable to not "go along with the group" or to not "buy in" to the process or the decisions made by staff. There is some element of discontent with the consensus process and the use of the red and green cards to signal concerns or support for a new goal or direction. It would be 
worthwhile to take time to examine the decision making process itself and to encourage a careful examination of new norms. Stifling disagreement or concerns is certainly not the intent of the Accelerated School process, yet there are teachers who hinted that this may, in fact, be the case.

A number of teachers also voiced concern that the time required for consensus decision making was detracting from their time in the classroom. They felt that in some cases they were not meeting the needs of their students as well as in the past. They were supportive of the Accelerated school model, but they were anxious about their primary responsibility: the classroom. A careful balance between the time required for group process for the faculty as whole, for the work of cadres and other committees, and for focusing on individual teacher planning must be achieved if teachers are to continue to support the model and not feel they are cheating their students. Perhaps limiting the number of proposals that can be advanced each year or rotating the committee assignments so that teachers have a quarter off during which they have no other duties are strategies to be tried.

Finally, the current principal's continued support for change and her ability to step back from decisions and let others help shape the direction of the school is 
critical. The trust and respect this highly-skilled individual has won from the staff during implementation of the Accelerated School model is important to the future success of the school. Every effort should be made to not reassign this principal and to attend to her professional and personal needs so that the amount of change she has helped to foster does not become exhausting and selfdefeating such that she requests reassignment in order to step back from the all-consuming nature of school reform. In summary, Bridgeport teachers should:

- Allow themselves to scale back and attempt fewer projects; Examine the Accelerated School model in terms of its own inflexibility;

- Make efforts to gain the trust/perspective of any staff member who feels disenfranchised or shut out because of unpopular views;

- Balance the time required for consensus and the time teachers feel they need to devote to their own classroom; and

- Discourage turnover by taking steps to reduce the stress resulting from change that might result in a decrease in involvement and commitment or a desire to transfer elsewhere. 


\section{Recommendations for School \\ Administrators}

Principals who think they are allowing others to make decisions or staff who feel they are not meaningfully involved in the decisions being made at their school can both profit from the experience at Bridgeport. Each teacher at Bridgeport sent the message that all principals cannot be successful in a truly site-based school. The Bridgleport principal was viewed as able to give up control and to allow teachers to make decisions. She was a resource, a facilitator for change, rather than a traditional top-down administrator. When asked if they could be successful without a principal, almost all Bridgeport teachers said, "No." They qualified their responses, however, by citing stories about former administrators and their predictable failure if assigned to an Accelerated school. It was clear that if a hierarchical principal was assigned to Bridgeport, he/she would be detrimental to the model and to their success. School administrators who are committed to fulfilling their supervisory role in a supportive and effective manner must not only avoid the "top down" behaviors that disenfranchise teachers from the business of schooling, but they must also develop effective strategies that create conditions that enhance perceptions of efficacy. For example, McDaniel and Dibella-McCarthy (1989) 
suggested that administrators learn to "recognize the factors that contribute to a diminished sense of efficacy and take positive steps to counteract them" (p. 36). They advocated helping teachers learn to identify and adapt skills to meet student needs and working to establish a collegial approach to problem solving.

Ashton (1984) identified five major conditions that contribute to teachers' sense of inefficacy:

1. lack of economic rewards;

2. role overload;

3. a pervasive sense of uncertainty;

4. isolation;

5. sense of powerlessness.

Clearly the role of the school administrator is to reduce or eliminate these conditions so that teachers can feel successful in their work. Although administrators have little, if any, real control of school funding or the public perception that many teachers exploit their tenure and their 9-month contract while complaining about low wages, they can certainly impact the other four conditions that Ashton (1984) described.

For example, role overload results from too many expectations of teachers (i.e., solving the social problems in addition to the educational ones) as well as teachers feeling they are losing the educational battle because the public will not support their efforts or fund 
social programs to address the family problems that make learning impossible. Sample strategies a principal might employ to reduce the stress associated with role overload include the following:

- interagency cooperation;

- social services offered within the school setting;

- counselor/staff awareness of professional agencies and personnel trained to handle families and students in crisis;

- focus on individual teacher and school success rather than failure;

- frequent communication to parents highlighting staff accomplishments;

- developing alternative programs to work with at risk and other youth who do not respond to the traditional model of schooling;

- development of policies that establish grounds for suspension/expulsion and clear expectations for students/ staff;

- strong parent/business volunteer program;

- career exploration/applied academics for students who anticipate entry into the job market upon graduation; - expand "free and reduced" breakfast/lunch program fund raisers and parent club donations so that children can eat decent meals at school; 
- set up a clothes closet staffed by volunteers to accept donations of clothing for needy families;

- clean the school--make it a bright, safe place.

Bridgeport teachers express frustration at a public that seems unwilling to care for its children, but they do not exhibit "role overload" in the sense of feeling overwhelmed by the social agenda not being met. Instead, they focus on "Building on Strengths" and creating "Unity of Purpose." They invited the parents into the school or went out and got them. They put the children first, then found the help they needed. They held parent meetings in apartment complexes when necessary. Gail wished for students who came to school "loved, fed and clean," but the fact that some did not did not appear to be overwhelming. During the focus group interviews, several teachers shared their stories about the community-wide raffle and garage sale that they had just conducted. Proceeds went to help with field trips and to provide warm clothing for those who had none.

Strategies to combat other factors that diminish efficacy could be generated as well. Certainly teachers' sense of isolation and powerlessness could be addressed by any model, not just the Accelerated school model, that allows teachers real decision making power and promotes interdependence. Site councils with no real decision making power are not the answer. 
Administrators must also learn to apply sound instructional theory to what passes for staff development. Sense of efficacy is clearly related to the belief that one can produce the behaviors necessary to achieve the desired outcome. Miller (1991) drew parallels between the research on increasing feelings of efficacy and creating "success expectations" with students and practices relative to teachers. She suggested that because research indicates that students must:

achieve success with tasks consistently; learn to set realistic, near and specific goals; be taught to identify the relationship between effort and outcome; and be taught to see themselves as successful learners... (p. 34)

teachers should be subject to the same instructional strategies. Miller maintained that teachers need consistently successful experiences with low achieving students to establish and strengthen their belief that their competence made the difference. They need evidence that links their efforts to positive student outcomes. They must be encouraged to set near, realistic and specific goals related to the development of new teaching behaviors based on the literature regarding effective practices with low achieving students. Finally, teachers need continuous support and feedback--coaching, modeling, problem solving with case studies, videos of experts, role playing with colleagues, and collaboration with special 
support personnel in order to expand their sense of efficacy.

Designing staff development focused on success strategies for teachers, regardless of level of experience, is an important lesson. Just as "one size fits all" is an instructional approach no longer effective in all classrooms for all students, neither is staff development effective when it fails to recognize the differences in adult learners. Those differences may be related to experience, stage of career, or general motivation, but they are often ignored in favor of a single presentation by an outside expert with no follow-up or opportunity to practice.

A related concern, one that must be addressed by any administrator committed to increasing teacher perceptions of efficacy, is that efficacy is highly individualistic. General teaching efficacy, or attitude about the potential of teachers to effect change, is also independent of one's belief and confidence in one's own skills. Thus, a teacher can lack confidence in the profession, in him/herself or both. What this means to the practicing administrator is clear: There is no substitute for personal knowledge based on time spent with each individual teacher in the school.

There is no way that a principal can personally influence a teacher's sense of efficacy without devoting 
time to conversation, observation and feedback. Staff development becomes support for a thousand "I think I'll try this" efforts. Support may mean materials or supplies or time. To the Bridgeport teachers support was sharing ideas with colleagues. They also needed support from the principal: empathy, patience and a willingness to "fend off" the central office expectations in favor of teachergenerated innovation.

How does one find the time to engage in such a collaborative effort? It may not be politically feasible to fail to produce the reports, the end-of-year evaluations, or the obligatory statements of school goals and related activities. First of all, the administrator must first realize that he/she can provide valuable support, but that he/she is not the only resource in the school and should not be. The ultimate goal is dialogue around instructional risk taking and the more who participate, the more "critical mass" is created to move the school forward. The effective principal must find ways to create time, for him/herself and for staff in order to engage in professional inquiry. Ideas include the following:

- seek early release or late start days to engage in staff development/conversation;

- Allow teachers to discontinue paperwork that is not critical after an assessment is made; 
- Request dispensation from the school board/central office from state or district mandates while in a "pilot" phase of school improvement;

- Work with the employee associations to allow staff to design their own "rotating substitute" plan in which they devote plan periods to helping colleagues observe one another teach;

- Agree to take classes for teachers to free them up to share ideas;

- Use parent volunteers to organize and help chaperon all school/all class events (i.e., field trips, job shadowing in a local company, field research, guest speakers) that allow some teachers to stay behind and plan together.

Above all, the principal must work with teachers as individuals rather than as a total group and promote professional dialogue. Whether it is rotating the faculty meetings from room to room and beginning each meeting with an opportunity for the host teacher to share a new idea or highlighting new ideas in the weekly bulletin and letters home, the effective principal supports change and sends the consistent message to teachers that they have the skills to make the difference and that those skills are valued. In summary, school administrators should focus on the following strategies to increase perceptions of efficacy among staff: 
- Give up control and allow others to make decisions;

- Help teachers learn to identify and use effective strategies in the classroom;

- Establish a collegial approach to problem solving;

- Reduce role overload and help teachers set high but realistic expectations for themselves;

- Encourage collaboration in all aspects of schooling;

- Engage in staff development that is based on sound instructional |practices and focuses on success strategies for teachers;

- work with teachers on an individual basis rather than in groups;

- Devote considerable time to conversation, observation and feedback with each staff member regardless of other demands; and

- create time for teachers to engage in dialogue by whatever means possible.

\section{Recommendations for Teachers}

It is clear that teachers hold the key to school reform and that without them no real change will occur. The comments of Bridgeport teachers about their efforts to "look good" in the past are representative of teacher attitudes everywhere: Superficial and recurring change has forced the teacher, bent on survival, to adopt 
behaviors designed to fool the eye while maintaining the status quo. One can enter any faculty room and hear predictable comments about the latest school restructuring legislation, comments that range from critical to hopeful but always in relationship to decisions made by others outside the syster. At what point will teachers simply refuse to be "done to" anymore?

This author recalls a poster from the early $1970 \mathrm{~s}$ that depicted a large mushroom cloud from an atomic blast and the caption, "What If They Had a War and Nobody Came?" The parallel seems obvious. It is not "What If They Told You to Do $X$, and You Refused?" because that reaction happens now. Teachers faced with a new set of expectations, the latest reading program, a new curriculum in global education, or earthquake drills know well how to go through the motions while continuing to teach with the old materials or methods that are tried and true in the belief that they may be more effective or just as effective as the "new." They simply refuse, mostly by passive resistance, to implement the changes that are mandated by others.

The parallel message to the anti-war poster is instead "What If They Told You to Do $X$, and You Refused Because $Y$ Better Reflects what we know About Teaching and Learning?" To stop doing what no longer makes sense would be a testament to courage and to professionalism. There 
are several key assumptions implicit in such an act, however, assumptions that may are may not be well-founded.

1. It is assumed that teachers know enough about effective teaching and learning to be able to discriminate as experts on the relative merit of Practice $x$ versus Practice $Y$. They read professional journals, go to conferences and share instructional problems with colleagues to come up with new ideas and strategies to meet the needs of their students. They also recognize that their subjective, intuitive knowledge base as to what works and what does not has validity, but such data is insufficient in and by itself. As such, they need to collect, monitor and use data to drive instructional decisions, a process that is time-consuming and threatening to many.

2. Implicit in the first assumption is another one: Teachers would prefer to take control of the agenda rather than blame others for the continued failure of American schools to meet the needs of a diverse clientele. Teachers must want to emulate those at Bridgeport who are clearly in control as professionals despite the fact that they are experiencing fatigue at the long hours, the continual meetings, and the personal costs associated with the spirit of inquiry that pervades the school. They must be willing to commit themselves to taking responsibility and action. 
3. Collective action around supporting Practice $Y$, or even Practice $\mathrm{x}$ for that matter, would focus attention on teachers as a political force beyond any site council or teachers' union. It would also elevate the profession in terms of status, for a profession without a clearly articulated knowledge base does not garner respect nor confidence. Bridgeport teachers exhibit the confidence of professionals. They are efficacious and empowered by collective action. No "top down" administrator is likely to be successful there because the school belongs to the students and the staff. To be a political force for change, however, requires passion and a great deal of work to gather and sustain support. It is easier to do what is comfortable even if it does not make sense; it is hard work to change. Teachers must, however, become professionals and stop focusing on collective bargaining and inflexible contracts as a poor substitute.

4. Taking control of the educational agenda implies a consensus in terms of a professional mission and a set of expectations for teachers that exceed the current focus on accountability as voiced by members of the public and the legislature. Implicit in the notion of professional standards is procedures for dealing with those who do not achieve them and a belief in a rigorous review of performance not now possible with the Fair Dismissal or collective bargaining law. The teachers at Bridgeport 
were aware that some were more "bought in" than others, that there was a need to confront one another rather than rely on the principal. It was difficult to hold up a red card, to stand alone in a public way, but teachers must see the need to police themselves and be willing to do so.

5. Finally, it is assumed that the countless efforts to pass legislation that makes schools more accountable will continue to fail and we are willing to take considerable personal and professional risks in order to prevent that from happening. It is teachers themselves who must agree to be accountable to themselves and to one another. They must break the cycle of more and more tests and less and less time to teach. They must, like Theresa, stop documenting for failure and begin to define and pursue success. There is no external answer, no state plan, no recipe. Like the Accelerated School model, there is only a process which must begin at some point and continue on. School improvement is not a destination but a journey.

These are some of the implications of the Bridgeport research for classroom teachers. The decision is really up to each individual behind the classroom door. It is true that our classrooms are built to divide and separate, but the isolation of teaching also brings its rewards: Teaching is a highly autonomous profession, for once the door closes, the decisions that are made are the teacher's 
alone. Whether one chooses $X$ over $Y$, uses the same lesson plans period after period, year after year, or assigns the chapter questions even though they miss the point is really up to the teacher. No district office or state mandate can really influence what goes on there. Just as reforms have failed because they have not engaged the teacher, so is the teacher vulnerable to the charge that he/she could make significant changes in their own classrooms if motivated to do so.

One could suggest many reasons why a teacher might elect to continue practices that he or she knows to be ineffective. It is easier, it keeps the kids busy, students like the dittos better than having to think and they are certainly easier to correct. Or teachers are tired, they have to coach, there is no support at home anyway. How much longer will the circular arguments persist?

Bridgeport teachers have stepped up to the task of taking control of the agenda. Others have only to follow suit. There is no "magic bullet." Efficacy may be influenced by many factors, but the most important lesson of Bridgeport is that teachers must come forward and begin the conversation. Only then will they develop confidence in their own abilities rather than relying on others to decide for them. What would happen if they had a war, and nobody came? 


\section{Implications for Further} Research

Bronfenbrenner (1976) promoted the idea of the "transforming experiment," a powerful. scientific approach because it is an effective means of illuminating causal relationships. Ashton (1984) recommended a conscious design of such experiments if the goal is to restructure education and to increase teachers' perceptions of efficacy. She specifically advocated for changes in teacher education and in the organizational structure of schools.

Because it is clear that teacher efficacy is highly dependent on specific teaching situations, Ashton (1984) believed that emphasis in preservice training must be on developing analytical and evaluative skills in teachers. In addition, a wide range of teaching experiences should be required for both beginning and experienced teachers so that skills are developed in many contexts. A systematic analysis of the tasks and responsibilities of teaching is also recommended with a hierarchy of skills and "gradual immersion" into the full range of teaching duties. Because teachers judge their own effectiveness in comparison to others, and their isolation fosters lack of knowledge about other strategies and styles, teachers should have frequent opportunity to observe and compare themselves and other professionals. Above all, teachers 
must be taught to take the time to be reflective rather than respond to the day-to-day demands of the job without benefit of analysis. Further research as to the benefits of such changes in teacher training and in staff development practices in general is necessary, particularly as such changes in practice relate to teachers' perceptions of their ability to effect change in their classrooms and in the lives of their students.

Ashton (1984) also believed that if one focused only on the teacher and ignored the organization and structure that form the context for teaching, efforts to effect change would fail. Lortie (1975), Little (1982), Lieberman (1986, 1988a, 1988b) and others have described the socialization of teachers. Hargreaves (1972) identified five teacher norms that exert pressure on new teachers to lower their expectations of self and students: autonomy, loyalty to staff group, mediocrity, cynicism, and a certain degree of anti-intellectualism that pervades most schools. Ashton, Webb, and Doda (1983) suggested that the negative socialization of teachers be addressed by:

reducing the responsibilities of beginning teachers to allow them to assume responsibilities gradually; fostering analysis of classroom teaching experiences; creating professional and collegial relationships between new and experienced teachers that are supportive in nature; designing systems of evaluating that bolster rather than threaten efficacy; sensitizing teachers to the social and cultural forces that affect the school. (p. 26) 
Bridgeport Elementary is in the process of creating a new culture, one that reflects norms of collegiality and support. Further research into the specific practices that ameliorate the power of "old norms," many of them negative, and those that foster the creation and institutionalizing of new norms, more conducive to change, is needed.

Ashton, Webb, and Doda (1983) also advocated for other organizational changes in schools to foster teachers' perceptions of efficacy. These included participatory decision making to transform an impersonal bureaucracy into a living community with increased involvement from parents. They also suggested that:

Collaborative efforts of schools of education, teacher organizations, and school districts could result in transforming experiments designed to introduce a sense of community within schools. (p. 27)

Certainly the consortium of Accelerated schools working in conjunction with Portland state university is one such effort, one that at least from the perspective of Bridgeport teachers appears to be working. Additional efforts to connect the teacher training institutions with the reality of the school experience are not only desirable but essential if teacher preparation programs are to have relevancy and purpose in the increasingly complex and stressful world of the classroom. 
Studies that investigate the applicability of theory to classroom practice, particularly the relationship of effective teaching strategies to the development of teacher efficacy, are essential.

Finally,

rather than focus on the identification of efficacy as a characteristic internal to the teacher, future research should explore the processes by which teacher education and socializing practices, organizational structures, instructional techniques, administrative strategies and home-school relationships can reduce the threats and increase support of teachers' sense of efficacy. (Ashton, Webb, \& Doda, 1983, p. 28)

Because teachers' sense of efficacy is:

negotiated daily in their myriad transactions with students, parents, peers, and administrators, efficacy is not a character trait with the potential for screening and placement based on a basic belief in the stability of human traits. (p. 28)

Further research that investigates the complex

interrelationships among these variables and the construct of efficacy is warranted if those committed to school restructuring wish current efforts to succeed.

The teacher is ever-vulnerable to self doubt induced by the unpredictability and uncontrollability of human interaction. Given this uncertainty, teachers' sense of efficacy is in continual jeopardy, in danger of attack by resistant or hostile students, angry parents, demanding administrators and dissatisfied colleagues. (p. 28)

Teachers need our help. Without them, educational reform is going nowhere. Teachers also need to stand up and be 
counted or they will never experience a Bridgeport of their own. 
REFERENCES

Alfonso, R. J., \& Goldsberry, L. (1982) . Colleagueship in supervision. In T. Sergiovanni (Ed.), Supervision of teaching (pp. 90-107). Alexandria, VA: ASCD.

Armor, D. J., Conry-Oseguera, P., Cox, M. A., King, N., McDonnell, L. M., Pascal, A., Pauley, E., Zellman, G., Sumner, G. C., \& Thompson, V. M. (1976). Analysis of the school preferred reading program in selected Los Angeles minority schools (Report No. R2007-LLAUSD). Santa Monica, CA: Rand.

Ashton, P. T. (1984, September/October). Teacher efficacy: A motivational paradigm for effective teacher education. Journal of Teacher Education, $\underline{35}(5), 28-32$.

Ashton, P. T., \& Webb, R. B. (1986). Making a difference: Teachers' sense of efficacy and student achievement. New York: Longman.

Ashton, P. T., Webb, R. B., \& Doda, N. (1983). A study of teachers' sense of efficacy (Final Report, Contract No. 400-79-0075) . Gainesville: University of Florida, National Institute of Education.

Bacharach, S. B., Bauer, S. C., \& Shedd, J. (1986, April). The learning workplace: The conditions and resources of teaching. Ithaca, NY: OAP, Inc.

Bandura, A. (1977). Self-efficacy: Toward a unifying theory of behavior change. Psychological Review, 84 (2), 191-215.

Bandura, A. (1982, February). Self-efficacy mechanism in human agency. American Psychologist, 37(2), 122-147.

Bandura, A. (1986). Social foundations of thought and action. Englewood cliffs, NJ: Prentice-Hall.

Barfield, V., \& Burlingame, M. (1974). The pupil control ideology of teachers in selected schools. The Journal of Experimental Education, 42(4), 6-11. 
Bein, J., Anderson, D. E., \& Maes, W. R. (1990). Teacher locus of control and job satisfaction. Educational Research Quarterly, 14(3), 7-10.

Bentley, R. R., \& Rempel, A. V. (1964). The measurement of teacher morale: $\AA$ factor analysis approach. Educational and Psychological Measurement, 24, 631642 .

Berman, P., \& McLaughlin, M. (1978). Federal programs supporting educational change: Vol.. 8. Implementing and sustaining innovations. Santa Monica, CA: Rand Corporation.

Berman, P., \& Mclaughlin, M. (1979). An exploratory study of school district adaptation. Santa Monica, CA: Rand Corporation.

Berman, P., Mclaughlin, M., Bass, G., Pauly, E. \& Zellman, G. (1977). Federal programs supporting educational change: Vol. 7. Factors affecting implementation and continuation. Santa Monica, $\mathrm{CA}$ : Rand Corporation. (ERIC Document Reproduction Service No. ED 140 432)

Bird, T., \& Little, J. W. (1986, March). How schools organize the teaching occupation. The Elementary School Journal, 86(4), 493-511.

Blackbourne, J. M. \& Wilkes, S. T. (1985, November 6-8). The relationship of teacher morale and zones of indifference. Paper presented at the annual meeting of the Mid-South Educational Research Association, Biloxi, Mississippi.

Bolman, L. G., \& Deal, T. E. (1984). Modern approaches to understanding and managing organizations. San Francisco: Jossey-Bass.

Boyer, E. (1983). High school. New York: Harper and Row Publishers.

Brogdon, R. (1973). The effects of placing student teachers in centers as determined by selected cxiteria. Unpublished doctoral dissertation, Florida State University, Tallahassee, Florida.

Bronfenbrenner, U. (1976). The experimental ecology of education. Educational Researcher, 5(9), 5-15.

Brookover, W. (1977). Schools can make a difference. East Lansing: Michigan State University. 
Brookover, W., Beady, C., Flood, P., Schweitzer, J., \& Wisenbacker, J. (1979). School social systems and school achievement: Schools can make a difference. New York: Praeger.

Brookover, W. B., \& Lezotte, L. W. (1979). Changes in school characteristics coincident with changes in student achievement. East Lansing, MI: Institute for Research on Teaching.

Brunson, Q. (1976). Morale and professional activities in selected small North Dakota schools. Grand Forks: North Dakota University, Bureau of Educational Research and Services.

Campbell, A., Gurin, G., \& Miller, W. E. (1954). The voter decides. Evanston, IL: Row Peterson.

Campbell, D. T. (1975, July). Degrees of freedom and the case study. Comparative Political studies, $\underline{8}, 178-$ 193.

Center for Educational Research at Stanford. (1992, Fall). Collaborative change in accelerated schools: Big wheels and little wheels interacting. Stanford, $\mathrm{CA}$ : Stanford University, Center for Educational Research at stanford.

Chenoweth, T. (1992). Emerging national models of schooling for at-risk students. International Journal of Educational Reform, 1(3), 255-269.

Chenoweth, T., \& Everhart, R. (1983). The Restructured School: How do you know if something is happening? Planning and Changing, 22(3-4), 178-190.

Chenoweth, T., \& Kushman, J. (1992, May). Accelerated school documentation study: Research design. Portland, OR: Portland State University, School of Education, Center for Urban Research in Education.

Chenoweth, T., \& Kushman, J. (1993, April 12-16) . Courtship and school restructuring: Building early commitinent to school change for at-risk students, preliminary findings of a research study. Paper presented at the annual meeting of the American Educational Research Association, Atlanta, Georgia. 
Chenoweth, T., \& Kushman, J. (1994, April 5-7). Organizational learning and cultural change in an accelerated school. Paper presented at the annual meeting of the American Research Association, New Orleans, Louisiana.

Chester, M. D. (1991, April 2-6). Changes in attitudes within first year teachers in urban schools. Paper presented at the annual meeting of the American Educational Research Association, Chicago, Illinois.

Coleman, J., Campbell, E., Hobson, C., McPartland, J., Mood, A., Wenfeld, F., \& York, R. (1966). Equality of educational opportunity. Washington, DC: United States Department of Health, Education and Welfare.

Crisci, P. E., Giancola, J. M. \& Miller, C. A. (1987, Winter). Win/win, effective schools and reform: An agenda for the 1990s. Government Union Review, $\underline{8}(1)$ $1-24$.

Cuban, L. (1985, September). Conflict and leadership in the superintendency. phi Delta Kappan, 67(1), 28-30.

Cuban, L. (1986, september). Persistent instruction: Another look at constancy in the classroom. Phi Delta Kappan, 68(1), 7-11.

Cuban, I. (1988, August). Why do some reforms persist? Educational Administration Quarterly, 24(3), 329-335.

Cuban, L. (1990, January/February). Reforming again, again, and again. Educational Researcher, 19(1), 313 .

David, J. L. (1989, May). Synthesis of research on school-based management. Educational Leadership, $\underline{46}(8), 45-53$.

Deal, T., Meyer, J., Scott, R., \& Rowan, B. (1985). organizational environments: Ritual and rationality. Newbury Park, CA: Sage.

Decharms, R., Carpenter, V. \& \& Kuperman, A. (1965, September). The "Origin Pawn" variable in person perception. Sociometry, 28(3), 241-258.

Deci, E. (1975). Intrinsic and extrinsic motivation. New York: Plenum. 
Dembo, M. H., \& Gibson, S. (1985). Teachers' sense of efficacy: An important factor in school improvement. Elementary School Journal, 86(2), 173-184.

Denham, C., \& Michael, J. (1981). Teacher sense of efficacy: A definition of the construct and a model for further research. Educational Research Quarterly, 6 $(1), 39-61$.

Dewey, J. (1903). Ethical principles underlying education. Chicago: University of Chicago Press.

Dewey, J. (1916). Democracy and education. New York: MacMillan.

Dewey, J. (1938). Experience and education. New York: MacMillan.

Drucker, P. (1988, January/February). The coming of the new organization. Harvard Business Review, 66 (66), 45-53.

Drucker, P. F. (1991, November/December). The new productivity challenge. Harvard Business Review, 69(69), 69-79.

Drucker, P. F. (1993, May/June). The post capitalist executive: An interview with Peter $F$. Drucker. Harvard Business Review, 71 (71), 114-122.

Duke, D. L., Showers, B., \& Imber, M. (1980, winter). Teachers and shared decision making: The costs and benefits of involvement. Educational Administration Quarterly, 16(1), 93-106.

Dunkin, M. J., \& Biddle, B. J. (1974). The study of teaching. New York: Holt, Rinehart and Winston.

Dunnette, M., Arvey, R., \& Banas, P. (1973). Why do they leave? Personnel, $\underline{50}(3), 25-38$.

Dutton, M. (1990). Investigation of the relationship between training in cooperative learning and job satisfaction. Unpublished doctoral dissertation, Portland State University, Portland, Oregon.

Easton, D. (1965). A framework for political analysis. Englewood cliffs, NJ: Prentice Hall.

Edmonds, R. (1979, March/April). Some schools work and more can. Social Policy, $9(6), 28-32$. 
Eisner, E. (1988, February). The ecology of school improvement. Educational Leadership, 45(5), 24-29.

Elementary and Secondary Educational Act (1965).

Elmore, R. F. (1990). Restructuring schools. San Francisco, CA: Jossey-Bass.

Elmore, R. F., \& McLaughlin, M. W. (1988) . Steady work: Policy, practice and the reform of education. Santa Monica, CA: Rand Corporation.

Emmer, E. T. (1990, April 16-20). A scale for measuring teacher efficacy in classroom management and discipline. Paper presented at the annual meeting of the American Educational Research Association, Boston, MA.

Epstein, S. (1973). The self concept revisited or a theory of a theory. American Psychologist, 28, 405416.

Etzioni, A. (1975). Comparative analysis of complex organizations. New York: Friend Press.

Evans, E. D., \& Tribble, M. (1986, November/December). Perceived teaching problems, self-efficacy, and commitment to teaching. Journal of Educational Research, $80(2), 81-85$.

Feiman-Nemser, S., \& Floden, R. E. (1986). The cultures of teaching. In M. C. Wittrock's (Ed.), Handbook of research on teaching (pp. 505-526). New York: Mackillan.

Finnan, C. R. (1994). Making change our friend in accelerated schools. Unpublished manuscript, Charleston, SC: University of Charleston.

Fiske, E. B. (1991). Smart schools, smart kids: Why do some schools work? New York: Simon \& Schuster.

Freedberg, L. (1989). Don't remediate, accelerate: Can disadvantaged students benefit from fast-forward instruction? California Tomorrow, $4(1), 30-31$.

French, J. R. P., Jr., \& Raven, B. H. (1959). The bases of social power. In $D$. Cartwright (Ed.), studies in social power (pp. 150-167). Ann Arbor, MI: Institute for Social Research. 
Frieze, I., Fisher, J., Hanusa, B., McHugh, M., \& Valle, v. (1979). Attributions of the causes of success and failure as internal and external barriers to achievement in women. In J. Sherman \& F. Denmark (Eds.), Psychology of women: Future directions of research (pp. 124-162). New York: Psychological Dimensions.

Fullan, M. (1982). The meaning of educational change. New York: Columbia University, Teachers College.

Fuller, B., Wood, K., Rapoport, T. \& Dornbusch, S. (1982, Spring). The organizational context of individual efficacy. Review of Educational Research, $\underline{52}(1), 7-30$.

Gibson, S., \& Dembo, M. (1984). Teacher efficacy: A construct validation. Journal of Education Psychology, 76 (4), 569-582.

Gomez, J. J. (1989, October). The path to site-based management isn't smooth, but we're scaling the obstacles one by one. The American School Board Journal, 176(10), 20-22.

Goodlad, J. I. (1984). A place called school: Prospects for the future. New York: McGraw-Hill.

Goodson, I. (1991). Sponsoring the teacher's voice. In A. Hargreaves \& M. Fullan (Eds.), Understanding teacher development. London: Cassell and New York: Teachers College Press.

Gorrell, J. (1990). Some contributions of self-efficacy research to self-concept theory. Journal of Research and Development in Education, 23 (2), 73-81.

Greenwood, G. E., Olejnik, S. F., \& Parkay, F. W. (1990, Winter). Relationships between four teacher efficacy belief patterns and selected teacher characteristics. Journal of Research and Development in Education, $23(2), 102-106$.

Gurin, G. (1968). Inner-city negro youth in a job training project: A study of factors related to attrition and job success. Ann Arbor: Survey Research Center.

Guskey, T. R. (1987, September/October). Context variables that affect measures of teacher efficacy. Journal of Educational Research, 81(1), 41-47. 
Guthrie, J. W., \& Wynne, E. (1971). New models for American education. Englewood cliffs, NJ: PrenticeHall.

Hackman, J., \& Oldham, G. (1975, summer). A new strategy for job enrichment. California Management Review, 17(4), 57-71.

Hargreaves, A. (1972). Staffroom relationships. New Society, pp. 434-437.

Hargreaves, A. (1991) . Restructuring restructuring: Postmodernity and the prospects for educational change. Viewpoint, 120, 1-35.

Harrison, C. R. (1989, May). Site-based management: The realities of implementation. Educational Leadership, $\underline{46}(8), 55-58$.

Heller, R. W. (1989, November). You like school-based power, but you wonder if others do. The Executive Educator, 11(11), 15-18.

Herzberg, F. (1966). Work and the nature of man. Cleveland: World.

Herzberg, F. (1968, January-February). One more time: How do you motivate employees? Harvard Business Review, $46(1), 53-59$.

Herzberg, F., Mausner, B., \& Snyderman, B. B. (1959). The motivation to work. New York: John Wiley \& Sons, Inc.

Hoover-Dempsey, K. V., Bassler, O. C., \& Brissie, J. S. (1987). Parent involvement: Contribution of teacher efficacy, school socioeconomic status and other school characteristics. American Educational Research Journal, 24 (3), 417-430.

Hopfenberg, w. S., Levin, H. M., Meister, G., \& Rogers, J. (1990). Toward accelerated middle schools. Report prepared for the Project to Develop Accelerated Middle Schools for At-Risk Youth. Stanford, CA: Center for Educational Research, Stanford University. (ERIC Document Reproduction Service No. ED 326 933)

Hord, S. M. (1981, April). Working together, cooperation or collaboration? Research and development report prepared for the Research and Development Center for Teacher Education, University of Texas, Austin, Texas. 
Hord, S. M. (1986, February). A synthesis of research on organizational collaboration. Educational Leadership, 43(5), 22-25.

Hoy, W. K., \& Woolfolk, A. E. (1990). Socialization of student teachers. American Educational Research Journal, 27(2), 279-300.

Huberman, A. M., \& Miles, M. B. (1984). Rethinking the quest for school improvement: Some findings from the DESSI study. Teachers College Record, 86, 34-54.

Imber, M. \& Duke, D. L. (1984). Teacher participation in school decision making: A framework for research. The Journal of Educational Administration, 22 (1), 2434 .

Jenkins, K., \& Houlihan, G. T. (1990, February). We're cutting through the red tape to real school reform. The Executive Educator, 12(2), 18-19, 27.

Johnson, D. W. , \& Johnson, R. T. (1987, November). Research shows the benefits of adult cooperation. Educational Leadership, 45(3), 27-30.

Johnson, D. W., \& Johnson, R. T. (1989). Leading the cooperative school. Edina, MN: Interaction Book Company.

Johnson, S. M. (1984, May). Merit pay for teachers: A poor prescription for reform. Harvard Educational Review, 54(2), 27-30.

Kahn, R., Wolfe, D. , \& Rosenthal, R. (1964). organizational stress: Studies in role conflict and ambiguity. New York: Wiley.

Kanter, R. M. (1977). Men and women of the corporation. New York: Basic Books.

Kanter, R. M. (1979, July-August). Power failure in management circuits. Harvard Business Review, $\underline{57}(4)$, 65-75.

Kanter, R. M. (1983). The change masters. New York: Simon and Schuster.

Kelly, G. A. (1955) . The psychology of personal constructs. New York: Norton.

Knowles, M. S. (1970). The modern practice of adult education. New York: Association Press. 
Knowles, M. S. (1978). The adult learner: A neglected species. Houston: Gulf.

Kotthamp, R. B., Provenzo, E. F., \& Cohn, M. M. (1986, April). Stability and change in a profession: Two decades of teacher attitudes. Phi Delta Kappan, $\underline{67}(8), 559-568$.

Lane, J. J., \& Wallberg, H. J. (1989, November). Sitemanaged schools: The Chicago plan. Education Digest, 55, 27-31.

Lecky, P. (1945). Self consistency: A theory of personality. New York: Island Press.

Lefcourt, H. (1976). Locus of control: current trends in theory and research. Hillsdale, NJ: Lawrence Erlbaum.

Levin, H. M. (1988). Don't remediate: Accelerate. Paper presented at Accelerating the Education of At-Risk Students, an invitational conference sponsored by the Stanford University School of Education with support from the Rockefeller Foundation, stanford, California.

Levin, H. M. (1989a, May). Accelerated schools: A new strategy for at-risk students (Policy Bulletin No. 6). Bloomington, IN: Indiana University, School of Education, Consortium on Educational Policy Studies.

Levin, H. M. (1989b). Financing the education of at-risk students. Educational Evaluat:ion and Policy Analysis, 11(1), 47-60.

Levin, H. M. (1989c, November). Interview conducted with author at Stanford University (transcribed audio cassette recording). Portland, OR: Portland state University, School of Education, Center for Urban Research in Education.

Levin, H. M. (1990, June). Leadership and organizational reform: Improving schools for at-risk students. Portland, OR: Portland State University, Center for Urban Research in Education.

Levin, H. M. (1991). Building school capacity for effective teacher empowerment: Applications to elementary schools with at-risk students. New Brunswick, NJ: Consortium for Policy Research in Education. 
Levine, S. (1989). Promoting adult growth in schools: The promise of professional development. Needham, MA: Allyn and Bacon.

Lieberman, A. (1986, February). Collaborative work. Educational Leadership, $\underline{43}(5), 4-8$.

Lieberman, A. (1988a). Building a professional culture in schools. New York: Teachers College Press.

Lieberman, A. (1988b, May). Teachers and principals: Turf, tension, and new tasks. Phi Delta Kappan, $\underline{68}(9), 648-653$.

Lieberman, A., \& Miller, L. (1984). Teachers, their world, their work: Implications for school improvement. Alexandria, VA: ASCD.

Lightfoot, S. L. (1983a). The good high school: Portraits of character and culture. New York: Basic Books.

Lightfoot, S. L. (1983b). The lives of teachers. In L. S. Schulman \& G. Sykes (Eds.), Handbook of teaching and policy (pp. 241-260). New York: Longman.

Likert, R. (1971). The principle of supportive relationships. In D. Pugh (Ed.), organizational theory (pp. 279-304). New York: Penguin.

Little, J. W. (1982). Norms of collegiality and experimentation: Workplace conditions of school success. American Educational Research Journal, 19 (3) $325-340$.

Little, J. W. (1986). Seductive images and organizational realities in professional development. In A. Lieberman (Ed.), Rethinking school improvement: Research, craft and concept (pp.26-44). New York: Teachers College Press.

Locke, E. (1976). The nature and causes of job satisfaction. In M. Dunnette (Ed.), Handbook of industrial and organizational psychology (pp. 12971350). Chicago: Rand McNalley.

Lortie, D. C. (1975). Schoolteacher: A sociological study. Chicago: University of Chicago Press.

Maccoby, E. E., \& Jacklin, C. N. (1974). The psychology of sex differences. Stanford, CA: Stanford University Press. 
Mann, D. (1990, January). It's time to trade red tape for accountability in education. The Executive Educator, 12(1), 26-28.

Maslow, A. H. (1954). Motivation and personality. New York: Harper \& Row.

Maslow, A. H. (1968). Toward a psychology of being. New York: D. Van Nostrand Company.

McCarthy, J. (1991, April 3-7). Accelerated schools: The satellite center project. Paper presented at the annual meeting of the American Educational Research Association, Chicago, Illinois. (ERIC Document Reproduction Service No. ED 336 849)

McCarthy, J. (1992, April 20-24). The effect of the accelerated schools process on individual teachers' decision-making and instructional strategies. Paper presented at the annual meeting of the American Educational Research Association, San Francisco, California. (ERIC Document Reproduction Service No. ED 347 690)

McCarthy, J., \& Levin, H. M. (1991, April 3-7). Accelerated schools: Evolving thoughts on the evaluation of an innovative model. Paper presented at the annual meeting of the American Educational Research Association, Chicago, Illinois. (ERIC Document Reproduction Service No. ED 336 848)

McDaniel, E. A., \& Dibella-McCarthy, H. (1989, Summer). Enhancing teacher efficacy in special education. Teaching Exceptional Children, 21(4), 34-38.

McGowan, M. L. (1986). Self efficacy: Operationalizing challenge education. Bradford Paper Annuals, $1(86)$, 65-69.

McNeil, L. M. (1986). Contradictions of control: School structure and school knowledge. New York: Methuen/ Routledge and Kegan Paul.

McNeil, I. M. (1988, January). Contradictions of control, part 1: Administrators and teachers. Phi Delta Kappan, 69(5), 333-339.

Midgely, C., Feldlaufer, H., \& Eccles, J. (1990). Change in teacher efficacy and student self and task-related beliefs in mathematics during the transition to junior high school. Journal of Educational Psychology, 81(2), 247-258. 
Miles, M. B., \& Huberman, A. M. (1984). Qualitative data analysis. Beverly Hills: Sage.

Miller, P. S. (1991, Fall). Increasing teacher efficacy with at-risk students. Equity and Excellence, 25(1), 30-35.

Mitchell, T. (1974). Expectancy models of job satisfaction, occupational performance and effort. Psychological Bulletin, 81(12), 1053-1077.

National Commission on Excellence in Education. (1983). A nation at risk: The imperative for educational reform. Washington, DC: United States Department of Education.

oja, s. N., \& Pine, G. J. (1984). Collaborative action research: A 2 year study of teachers' stages of development and school contexts. Durham: New Hampshire University, Department of Education, National Institute of Education.

O'Neil, J. (1990, April). Piecing together the restructuring puzzle. Educational Leadership, 47(7), 4-10.

Oregon Ballot Measure \#5 (1990).

Owens, R. L. (1987). Organizational behavior in education. Englewood Cliffs, NJ: Prentice-Hall.

Palardy, M. J. (1988, May). Institutional structure: An impediment to professionalism. NASSP Bulletin, 72(508), 82-84.

Parkay, F. W. , Greenwood, G., olejnik, S., \& Proller, N. (1988). A study of the relationships among teacher efficacy, locus of control, and stress. Journal of Research and Development in Education, 21 (4),13-22.

Patton, M. Q. (1982). Practical evaluation. Beverly Hills: Sage.

Patton, M. Q. (1987). How to use qualitative methods in evaluation. Newbury Park, CA: Sage.

Perko, L. (1985). Job satisfaction of teachers in the Portland metropolitan area. Unpublished doctoral dissertation, Portland State University, Portland, OR.

Peters, T. (1988). Thriving on chaos. New York: Alfred A. Knopf . 
Peters, T., \& Austin, N. (1985). A passion for excellence: The leadership difference. New York: Random House.

Peters, T., \& Waterman, R., Jr. (1982). In search of excellence: Lessons from America's best run companies. New York: Harper and Row.

Peterson, K., Hines, S., \& Yaakobi, D. (1980). Self concept and behavior perception changes of student teachers. Educational Research Quarterly, 5(4), 41-50.

Polkington, R., Jr., Bartels, D. M., \& Levin, H. M. (1990, April 16-20). Accelerated schools: The inquiry process and the prospects for school change. Paper presented at the annual meeting of the American Educational Research Association, Boston, MA.

Price, R. (1981). Influence among middle managers. Unpublished doctoral dissertation, Stanford University, Stanford, CA.

Purkey, S., \& Smith, M. (1982). Synthesis of research on effective schools. Educational Leadership, $40(3)$, 64-69.

Purkey, S. C., \& Smith, M. S. (1983). Effective schools: A review. Elementary School Journal, $83(4), 427-452$.

Rabinowitz, S., \& Hall, D. (1977). Organizational research on job involvement. Psychological Bulletin, $84(2), 265-288$.

Rist, M. C. (1989, August). Here's what empowerment will mean for your schools. The Executive Educator, $11(8), 16-19$.

Rogers, J. S., \& Polkinghorn, R., Jr. (1990, April 1620). The inquiry process in the accelerated school: A Deweyan approach to school renewal. Paper presented at the annual meeting of the American Educational Research Association, Boston, Massachusetts. (ERIC Document Reproduction Service No. ED 323636 )

Rose, J. S. \& \& Medway, F. J. (1981). Measurement of teachers' beliefs in their control over student outcome. Journal of Educational Research, 74(3), 185-190. 
Rosenblum, S., \& Louis, K. S. (1981). Stability and change: Innovation in an educational context. New York: Plenum Press.

Rosenholtz, S. J. (1985a). Effective schools: Interpreting the evidence. American Journal of Education, 23(3), 352-388.

Rosenholtz, S. J. (1985b, January). Political myths about education reform: Lessons from research on teaching. Phi Delta Kappan, 66(5), 349-355.

Rosenholtz, S. J. (1987, August). Educational reform strategies: will they increase teacher commitment? American Journal of Education, 95(4), 534-562.

Rosenholtz, S. J. (1989). Teachers' workplace: The social organization of schools. New York: Longman.

Rossman, G. B., Corbett, H. D., \& Firestone, W. A. (1988). Change and effectiveness in schools: A cultural perspective. Albany: State University of New York Press.

Rotter, J. B. (1966). Generalized expectations for internal versus external control of reinforcement. Psychological Monographs, 80, 1-28.

Ruscoe, G. C., \& Whitford, B. (1991, April 3-7). Quantitative and qualitative perspectives on teacher attitudes: The third year. Paper presented at the annual meeting of the American Educational Research Association, Chicago, Illinois.

Rutherford, W. L. (1986, April 16-20). Teachers' contributions to school improvement: Reflections on fifteen years of research ( $R \& D$ Report 3219). Paper presented at the annual meeting of the American Educational Research Association, San Francisco, California.

Rutter, M., Maughan, B., Mortimore, P., Ouston, J., \& Smith, A. (1979). Fifteen thousand hours: Secondary schools and their effects on children. Cambridge: Harvard University Press.

Sarason, S. (1971). The culture of school and the problem of change. Boston: Allyn \& Bacon.

Sarason, S. B. (1982). The culture of the school and the problem of change. Boston: Allyn and Bacon. 
Sarason, S. B. (1990). The predictable failure of school reform. San Francisco: Jossey-Bass.

Schaefer, R. J. (1967). The school as a center of inquiry. New York: Harper \& Row.

Schatzman, L., \& Strauss, A. (1970). Field research: Strategies for a natural ecology. Englewood cliffs, NJ: Prentice-Hall.

Schein, E. (1985). Organizational culture and leadership: A dynamic view. San Francisco: JosseyBass.

Schein, E. (1991). Organizational culture and leadership: A dynamic view (2nd ed.). San Francisco: Jossey-Bass.

Schlechty, P. (1990). Schools for the twenty-first century. San Francisco: Jossey-Bass.

Schmuck, R. A. \& Runkel, P. J. (1985). The handbook of organization development in schools. Palo Alto: Mayfield.

Sergiovanni, T. J. (1987) . The principalship: A reflective practice perspective. Newton, MA: Allyn and Bacon.

Sergiovanni, T. (1990). Value-added leadership. Orlando: Harcourt Brace Jovanovich, Inc.

Sergiovanni, T., \& Corbally, J. (Eds.) . (1984). Leadership and organizational culture: New perspectives on administrative theory and practice. Chicago: University of Illinois Press.

Sirotnik, K. A., \& Clark, R. W. (1988, May). Schoolcentered decision making and renewal. Phi Delta Kappan, 69(9), 660-664.

Sizer, T. R. (1984). Horace's compromise. Boston: Houghton Mifflin Company.

Slavin, R. E. (1987, November). Cooperative learning and the cooperative school. Educational Leadership, 45 (3), 7-13.

Smith, S. C. (1987, November). The collaborative school takes shape. Educational Leadership, 45(3) 4-7. 
Snygg, D., \& Combs, A. W. (1949). Individual behavior: A new frame of reference for psychology. New York: Harper.

Sparks, D. C. (1979). A biased look at teacher job satisfaction. Clearinghouse, $\underline{52}(9), 447-449$.

Sparks, D. C. (1988a, Fall). Leadership for school improvement: An interview with Richard Wallace. Journal of Staff Development, $9(4), 46-48,50$.

Sparks, G. (1988b). Teachers' attitude towards change and subsequent improvements in classroom teaching. Journal of Educational Psychology, Bo(1), 111-117.

Starko, A. J., \& Schack, G. D. (1989, Summer). Perceived need, teacher efficacy, and teaching strategies for the. Gifted child Quarterly, 33(3), 118-122.

Stewart, R. (1976). Contrasts in management. London: McGraw-Hill.

Stipek, D., \& Weisz, J. (1981, Spring). Perceived personal control and academic achievement. Review of Educational Research, 51(1), 101-137.

Strother-Burnett, D. (1990, February). What I learned from what I had forgotten about teaching: Notes from a professor: An interview with Larry Cuban. Phi Delta Kappan, 71(6), 479-482.

Trentham, L., Silvern, S., \& Brogdon, R. (1985). Teacher efficacy and teacher competency ratings. Psychology in the Schools, 22, 343-352.

Tye, B. B. (1987, December). The deep structure of schooling. Phi Delta Kappan, 69(4), 281-284.

Vroom, V. H. (1964). Work and motivation. New York: John wiley.

Waller, w. (1967). The sociology of teaching. New York: John Wiley \& Sons.

Webb, R. (1982, March 19-23). Teaching and the domains of efficacy. Paper presented at the annual meeting of the American Research Association, New York.

Weber, G. (1971). Inner city children can be taught to read: Four successful schools (Occasional Paper, No. 18). Washington, DC: Council for Basic Education. 
Weick, K. E. (1982, June). Administering education in loosely coupled schools. Phi Delta Kappan, 63(10), 673-676.

Weiler, H. N. (1983, June). Legalization, expertise, and participation: strategies of compensatory legitimation in educational policy. Comparative Education Review, 27(2), 259-277.

Weiner, B. (1976). Social learning (locus of control) versus attributional (causal stability) interpretations of expectancy of success. Journal of Personality, 44(1), 52-68.

White, R. (1959). Motivation reconsidered: The concept of competence. Psychological Review, 66 (5), 297-333.

Willower, D. J., Eidell, T. L., \& Hoy, W. K. (1967). The school and pupil control ideology (Pennsylvania state Studies Monograph No. 24). University Park: Pennsylvania state University.

Wise, A. E. (1988, January). Legislated learning revisited. Phi Delta Kappan, 69(5), 328-332.

Wolcott, H. L. (1988). Ethnographic research in education. In R. M. Jaeger (Ed.), Complementary methods for research in education (pp. 187-210). Washington, DC: American Educational Research Association.

Woolfolk, A. E., \& Hoy, W. K. (1990, March). Prospective teachers' sense of efficacy and beliefs about control. Journal of Educational Psychology, 82(1), 81-91.

Woolfolk, A. E., Rosoff, B., \& HoY, W. K. (1990). Teacher's sense of efficacy and their beliefs about managing students. Teaching and Teacher Education, 6(2), 137-148.

Yin, R. K. (1984). Case study research: Design and methods (Applied Social Research Methods Series Volume 5). Beverly Hills: Sage. 
APPENDIX A

INTERVIEW PROTOCOL USED IN BRIDGEPORT INTERVIEWS WINTER 1993 
INTERVIEW PROTOCOL

Principal Interview (spring 1993)

I. Courtship

How yould you assess the staff's overall level of commitment at this time.

How vould you characterlze the staff's level of understanding of the accelerated school process?

II. Trainlng and Development

Descrlbe the extent and quality of trainlng and development so far:

* Teaming with Excellence - Group process, meeting management, and Interpersonal relationship skills.

* Taking stock.

* Developlng a school vision.

* Using the Inquiry process to ldentify and solve school problems.

* Knowledge of instructional and curricular practices that accelerate learning.

The best learning and professlonal development came when?

What have you done to promote training and development?

Has your role changed? Do you see future role changes?

Have classrooms changed? How will they look in the future?

III. Lesgons Learned

What's different? What's changed?

What are some lessons learned?

What is the good news? Bad news? 


\section{Title: Sample Questions for Consideration for Inclusion in Interview Protocol}

Instructions: I'd like to ask you a number of questions regarding the problems and rewards of teaching. Of course, your comments are confidential and will not be identified by your name, your school, or even the grade level you teach.

1. Teachers are asked to pursue many goals and to accomplish many things. Of all the things that you do as a teacher, identify the one you think is most important. (Probe until you have a clear sense of what the teacher identifies as his or her primary objective.)

2. How can you tell if you are achieving the objective you have just identified? (Probe here until you get some specific indicators the teacher uses to define success.)

3. What kinds of things make it most difficult to achieve the objectives you have identified? (Probe here until the teacher identifies specific problems that impede progress.)

4. What kinds of students are most difficult to reach? That is, what type of students are least likely to meet your identified objective? (We are interested in student types, e.g., poverty kids, black kids, bright kids, rich kids, and so on. However, the teacher may find it easier to talk about specific students. That's fine, but stay with the questioning long enough so that you can go beyond specific personalities and get a sense of the "kinds of students" the teacher is talking about.)

5. Most teachers would say there are students that they never reach. Are there students you have failed to reach this year? Who are they and what are they like? (Probe here until you know when the teacher will give up on a student. Try also to determine how many students fell into this category this year.)

6. What do you think the students you have just identified will be doing 5 years from now? Ten years from now? Twenty years from now?

7. What are your strong points as a teacher?

8. Where do you think you need to improve as a teacher?

9. Are there constraints on you that limit your effectiveness? If so, what are they? (Probe here to find out what the teacher would like to be doing but cannot do.)

10. Compare this school with other schools with which you are familiar. Is it better or worse? Why? (Probe here until the teacher has identified what she or he takes to be the strong points and the weak points of the school.)

11. When you are having difficulty as a teacher, to whom do you go for help? (Probe for specific names.) What kinds of help do you get from that person? (Probe here until you understand whether the teacher gets specific suggestions or whether the relationship is more "therapeutic." That is, does the teacher commiserate with his or her helper, or analyze problems and try to solve them?) 
12. What do you find rewarding as a teacher? That is, what do you get from your students, peers, remuneration, and so on, that makes teaching worth while? Have you ever thought of leaving teaching? What kinds of things make you consider leaving the profession? If you had it to do over again, do you think you would choose teaching? Why?

13. If you could pursue only one objective as a teacher, what would that objective be? (Probe here until you get a sense of whether the teacher tends toward valuing basic skills or interpersonal relationships.)

14. We hear a good deal about teacher stress these days. What kinds of things have caused you stress this year?

15. Teachers sometimes claim that they change with experience. Think back to when you began the accelerated schools process and consider how you have changed. Have your objectives changed? Have your teaching strategies changed? Have your relationships with students changed? How so?

16. How do you approach teaching low achieving students?

17. What do you need from principals, colleagues, parents, students to be successful?

18. How has the accelerated schools process helped/hindered your ability to make a difference in the classroom?

(Adapted from Ashton and Webb, 1986 and Armer, et al., 1976.) 
APPENDIX B

EFFICACY SURVEY CONSENT FORM 


\section{Efficacy Survey \\ Informed Consent Form}

I, agree to take part in this research project involving selected participants in the Accelerated Schools Project in the Roosevelt Cluster in Portland Public Schools. I understand this study involves a brief survey designed to give the researchers information about my opinions as a teacher.

I understand that in order to complete the 20-item survey, I will be asked to give approximately ten minutes of my time. Deborah Sommer has told me that the purpose of the study is to gather information about my beliefs and attitudes about my ability as a teacher to make a difference in the classroom for students at School.

I may not receive any direct benefit from taking part in this study. But the study may help to increase knowledge that may help others in the future.

Deborah Sommer has offered to answer any questions I have about the study and what I am expected to do. She has promised that all information I give will be kept confidential to the extent permitted by law, and that the names of all people in the study will be kept confidential.

I understand that I do not have to take part in this study and that I may withdraw from this study without affecting my relationship with Portland State University or the Portland Public School District.

I have read and understand the above information and agree to take part in this study.

Date: Signature:

If you have concerns or questions about this study, please contact the Chair of the Human Subjects Research Review Committee, Office of Rescarch and Sponsored Projects, 105 Neuberger Hall, Purtland State University, (503) 725-341\%. 


\section{APPENDIX C}

DEMOGRAPHIC SURVEY/EFFICACY SCALE BASED ON INSTRUMENT DEVELOPED BY GIBSON AND DEMBO (1984) 


\section{ACCELFRATED SCHOOLS PROJECT}

Directions: The purpose of the following questions and the attached survey is to gather information from

teachers participating in the Accelerated Schools Project during 1993-94. If you would take just a few

moments to respond, it would be greatly appreciated. Please be assured that all responses will be kept

confidential.

Dote

Name

Elementary School

I. Basic Demographic Information

Gender $\quad M \quad F \quad$ (circle)

Current grade level assignment

What additional characteristics pertain to your present teaching assignment?

(i.e., team teaching, multi-age primary, special needs classroom, job share, etc.)

Total number of years of teaching experience

Total number of years teaching in present school

Highest degree held 
10. If a student in my class becomes disruptive and noisy, I feel assured that I know some techniques to redirect him quickly.

11. The amount that a student can learn is primarily related to family background.

12. Teachers are not a very powerful influence on student achievement when all factors are considered.

13. When the grades of my students improve, it is usually because I found more effective teaching approaches.

14. If a student masters a new math concept quickly, this might be because I knew the necessary steps in teaching that concept.

15. When it comes right down to it, a teacher really can't do much because most of a student's motivation and performance depends on his/her home environment.

16. When a student gets a better grade than he usually gets, it is usually because I found better ways of teaching that student.

17. If a student did not remember information I gave in a previous lesson, I would know how to increase his/her retention in the next lesson.

18. When I really try, I can get through to most difficult students.

19. School rules and policies hinder my doing the job I was hired to do.

20. If one of my students couldn't do a class assignment, I would be able to accurately assess whether the assignment was at the correct level of difficulty.

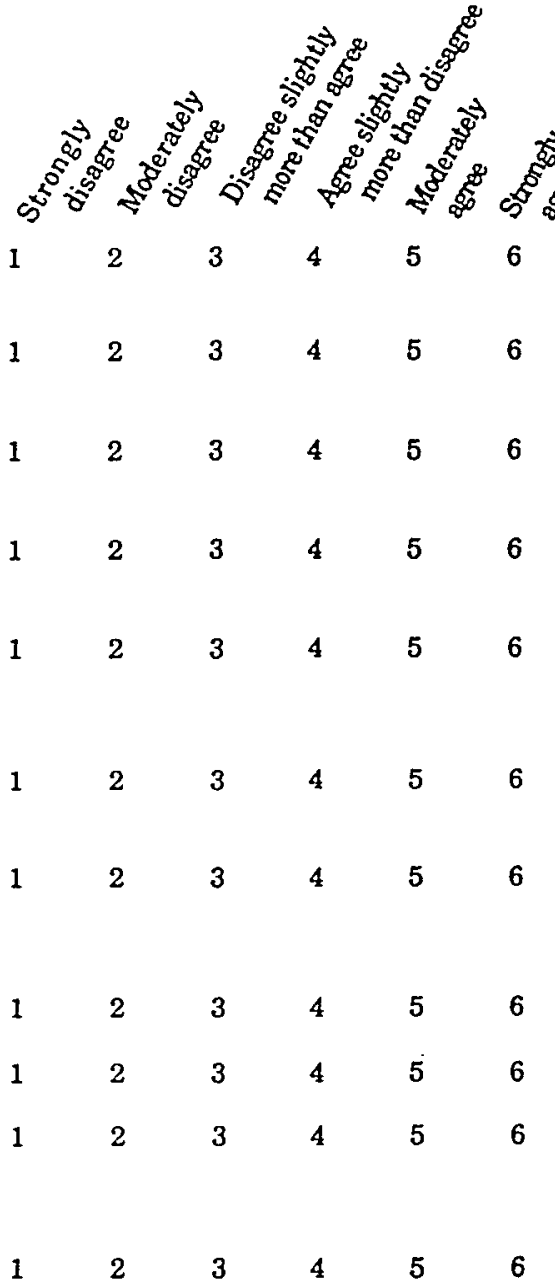

Adapted from Gibson and Dembo (1983) 
11. Please indicate the degree to which you agree with each statement below by circling the appropriate numeral to the right of each statement.

1. When a student does better than usual, many times it is because I exerted a little extra effort.

2. The hours in my class have little influence on students compared to the influence of their home environment.

3. A teacher is very limited in what he/she can achieve because a student's home environment is a large influence on his/her achievement.

4. If students aren't disciplined at home, they aren't likely to accept any discipline.

5. I have enough training to deal with almost any learning situation.

6. My teacher training program and/or experience has given me the necessary skills to be an effective teacher.

7. If I try really hard, I can get through to even the most difficult or unmotivated students.

8. When a student is having difficulty with an assignment, I am usually able to adjust it to his/her level.

9. If parents would do more with their children, I could do more.

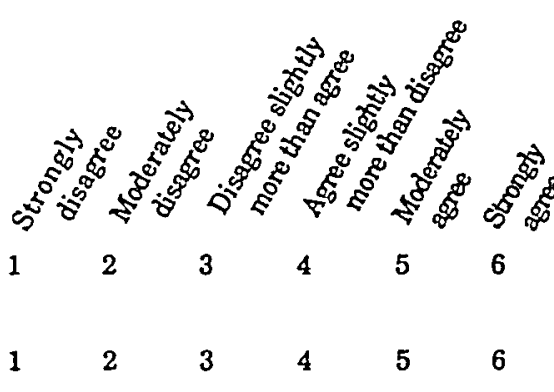

$\begin{array}{llllll}1 & 2 & 3 & 4 & 5 & 6 \\ 1 & 2 & 3 & 4 & 5 & 6 \\ 1 & 2 & 3 & 4 & 5 & 6 \\ 1 . & 2 & 3 & 4 & 5 & 6 \\ 1 & 2 & 3 & 4 & 5 & 6 \\ 1 & 2 & 3 & 4 & 5 & 6 \\ 1 & 2 & 3 & 4 & 5 & 6\end{array}$ 
APPENDIX D

FOCUS GROUP INTERVIEW QUESTIONS 
Focus Groups

Interview Questions

1. There is a concern expressed by many teachers that the hours they spend with students in the classroom have little influence compared to the influence of their home environment. Share a bit about your perceptions of how much you can influence young people. (Gibson \& Dembo \#2)

2. Do you believe that if a teacher has adequate skills and motivation, he/she can get through to even the most difficult students? (Gibson \& Dembo \#5)

(Probe: What is it about the accelerated schools model that you think makes you more effective with "at risk" students?)

3. As educators we have been trained to recognize and address individual differences among students. Think about individual differences among teachers (Gibson \& Dembo \#11). How much of a factor do you believe those differences are when it comes to student achievement? Can the same student do markedly different with different teachers?

(Probe: Are accelerated school teachers as a group more effective as a group than those in a non-accelerated school?)

4. One of the basic premises of the accelerated school model is that the community, the staff and the administration working together can exert a powerful influence on students. What is it about the model that makes this possible?

5. Many teachers and outside visitors of schools today believe that school rules and policies hinder the job they were hired to do (Gibson \& Dembo \#26). How is an accelerated school different or the same in this regard? 
APPENDIX E

OPEN-ENDED EFFICACY QUESTIONNAIRE 
Efficacy Questionnaire

Ball Elementary School

Name

Please complete each statement based on your initial response.

1. The trouble with most schools nowadays is.....

2. The best thing about accelerated schools is.....

3. One of the major ways in which teachers can make a difference is.....

4. Capable teachers who fail to "get through to students" are often.....

5. A teacher should always be willing to.....

6. No matter how hard teachers try, they always.....

7. When I make out my lesson plans, I am almost always certain that....

8. Getting people to do the right thing depends upon..... 
9. As far as schools go, most of us have to deal with the frustrations caused by.....

10. In the long run, accelerated schools make a difference because.....

11. Becoming a successful teacher is a matter of.....

12. It is hard to know whether or not a teacher.....

13. I feel that the accelerated school model is an improvement over what we did before because.....

14. Many times I feel I have little influence over.....

15. At one school, there is too much emphasis on.....

16. Most of the time I don't understand why teachers.... 
17. It is important that my relationship with my principal is.....

18. Schools would be more effective if.....

19. If I could change one thing at my school that I believe could help me do a better job, it would be.....

20. If teachers in another school are considering becoming members of an accelerated school, I would give them the following advice.

21. As an accelerated school teacher, the most important change I have noticed in myself over the last two years is.....

22. The most frustrating aspect of my job is....

23. Teachers could be more effective if.....

24. The best principal is one who.....

25. My proudest accomplishment this year is..... 


\section{APPENDIX F}

LETTER TO PRINCIPAL OF BRIDGEPORT ELEMENTARY SETTING UP PANEL DISCUSSION ON ACCELERATED SCHOOLS

WITH NEIGHBORING DISTRICT 


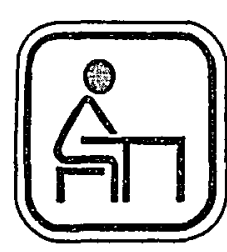

\section{Beaverton Schools}

District 48

P.O. Box 200 Beaverton, Oregon 97075-0200

May 4, 1994

Dear

Thanks again for following up on plans to have Ball Elementary teachers share their perceptions and experiences relative to accelerated schools with Beaverton teachers. I do appreciate their willingness to work with our teachers as they go through the "courtship" phase and consider becoming an accelerated school. Based on our conversation on May 2, the following schedule is offered for your information:

$\begin{array}{ll}\text { May 5 } & \begin{array}{l}\text { Presentation by Deborah Sommer and Tom Chenoweth to Barnes } \\ \text { Elementary (3:10 p.m.) }\end{array} \\ \text { May 13 } & \begin{array}{l}\text { Three teachers from Ball (from the ten listed on the attached memo) to } \\ \text { visit Beaverton 9:00 a.m. - 3:00 p.m. }\end{array} \\ \text { May 18 } & \begin{array}{l}\text { Presentation by Deborah Sommer and Tom Chenoweth to Aloha Park } \\ \text { Elementary (3:10 p.m.) }\end{array} \\ \text { May 20 } & \begin{array}{l}\text { Three teachers from Ball to visit Beaverton 9:00 a.m. - 3:00 p.m. } \\ \text { May 24/28 }\end{array} \\ \begin{array}{l}\text { Deborah Sommer to visit Ball Elementary to interview two teachers } \\ \text { each day: 3:00-3:30/3:30-4:00 for a total of four interviews }\end{array}\end{array}$

Substitute costs will be borne by Beaverton School District. Mary McDonald, from your payroll office, has indicated Portland Public Schools will bill us for three sub days on May 13 and three sub days on May 20.

I have contacted the principals at both elementary schools to let them know of the visitation and have tentatively planned the following for May 13/20:

9:00-11:00 Beaverton Administration Center with Deborah Sommer (16550 SW Merlo Road, Beaverton - map attached) (discussion of accelerated schools/school organization for PSU research project)

11:00-12:00 Lunch at the school with principalleadership team

12:00-3:00 Informal discussion between Ball teachers and Beaverton teachers related to accelerated schools implementation 